\title{
Identification and Development of 1,4-Diaryl-1,2,3-triazolo-based Ureas as Novel FLT3 Inhibitors
}

Jisheng Liu, ${ }^{+, \xi}$ Yuting Wang, ${ }^{\dagger, \xi}$ Chen Chen, ${ }^{\dagger, \xi}$ Zhengchao Tu, ${ }^{+}{ }^{+}$Sihua Zhu, ${ }^{\dagger}$ Fengtao Zhou, ${ }^{\dagger}$ Hongfei Si, ${ }^{\dagger}$ Canhui Zheng*, Zhang Zhang*, ${ }^{\dagger}$ Qian Cai* ${ }^{*}$

${ }^{\dagger}$ International Cooperative Laboratory of Traditional Chinese Medicine Modernization and Innovative Drug Discovery of Chinese Ministry of Education (MOE), College of Pharmacy, Jinan University, No. 601 Huangpu Avenue West, Guangzhou 510632, China

${ }^{\ddagger}$ Guangzhou Institutes of Biomedicine and Health, Chinese Academy of Science, No. 190 Kaiyuan Avenue, Guangzhou, 510530, China

SSchool of Pharmacy, Second Military Medical University, 325 Guohe Road, Shanghai 200433, China. Canhuizheng@smmu.edu.cn; zzmoxue@163.com; caiqian@jnu.edu.cn

$\xi$ J. Liu, Y. Wang, Y. Wang and C. Chen contributed equally.

\section{Supporting Information}

\section{Table of Contents}

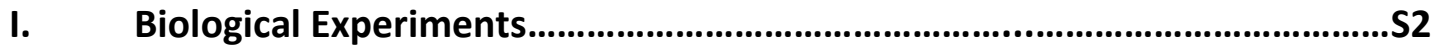

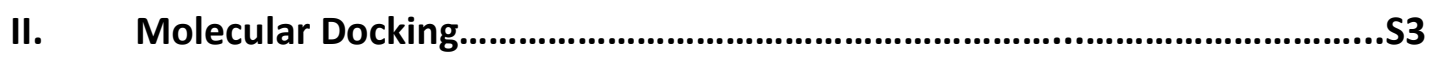

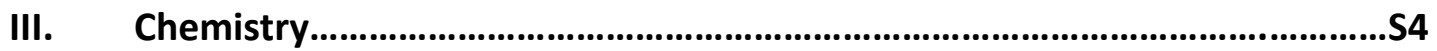

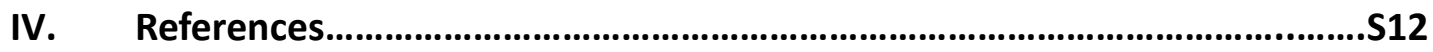

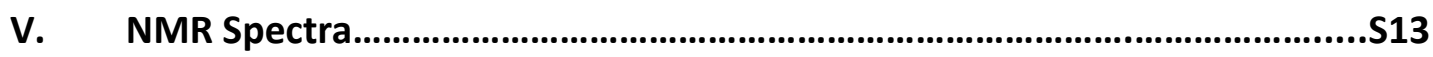




\section{Biological Experiments}

\subsection{Cell cultures}

The AML cell lines MV4-11, MOLM-13,KG1, U937 and other leukemia cell lines HL60, and NB4, were purchased from the American type culture collection (ATCC) or Shanghai Cell Bank (Type Culture Collection, Chinese Academy of Sciences). The base medium for MV4-11 cell line is gibco-formulated Iscove's Modified Dulbecco's Medium. All other cell line were maintained in RPMI-1640 supplemented with $10 \%$ FBS, $100 \mathrm{U} / \mathrm{mL}$ penicillin, $50 \mathrm{mg} / \mathrm{mL}$ streptomycin, and 2 $\mathrm{mmol} / \mathrm{L}$ glutamine in a humidified $\mathrm{CO} 2$ incubator at $37{ }^{\circ} \mathrm{C}$. All cells were passaged for less than 3 months before renewal from frozen, early-passage stocks obtained from the indicated sources.

\subsection{Construction of Ba/F3-FLT3 stable cells}

The Ba/F3 cell lines stably expressing FLT3-ITD were self-established. Ba/F3 cells transfected the pCDNA3.1 plasmids using Amaxa Cell Line Nucleofector Kit V (Lonza, Cologne, Germany) by electroporation. Stable lines were selected by G418 (Merck, Whitehouse Station, NJ, USA) and withdrawal of Interleukin-3 (IL-3, R\&D). All Ba/F3 stable cell lines were verified by monitoring both DNA sequences through DNA sequencing and protein expression levels of the corresponding FLT3 mutants through western blotting analysis. Parental Ba/F3 cells were cultured in RPMI 1640 supplemented with $10 \%$ Fetal Bovine Serum (FBS) and (Il-3, $10 \mathrm{ng} / \mathrm{ml}$ ), while all FLT3transformed $\mathrm{Ba} / \mathrm{F} 3$ stable cell lines were cultured in in RPMI 1640 supplemented with $10 \%$ Fetal Bovine Serum (FBS) without Il-3.

\subsection{Proliferation assay}

Cells were placed in 96-well plates (1500 3000/well) in complete medium. After incubation overnight, the cells were exposed to various concentrations $(0.0015 \sim 30 \mu \mathrm{M})$ of compounds for a further $72 \mathrm{~h}$. Cell proliferation was evaluated by Cell Counting Kit 8 (CCK8, CK04, Dojindo Laboratories, Kumamoto, Japan). IC50 values were calculated by concentration-response curve fitting using GraphPad Prism 5.0 software. Each IC50 value is expressed as mean \pm SD.

\subsection{Cell cycle analysis}

After 48-hrs treatment with compound $\mathbf{2 8}$ or DMSO, cells were harvested and washed twice with PBS. Approximately $6 \times 10^{5}$ cells were re-suspended in $150 \mu \mathrm{L}$ BD Cytofix/Cytoperm buffer solution (\#554722, BD). After 20 minutes at $4{ }^{\circ} \mathrm{C}$, the cells were washed twice with BD Perm/Wash buffer (\#554723, BD) and incubated with $200 \mu \mathrm{l}$ of dyeing buffer (containing $0.1 \mathrm{mg} / \mathrm{ml}$ propidium iodide, $2 \mathrm{mg} / \mathrm{ml}$ RNaseA) in the dark for 20 minutes at $4{ }^{\circ} \mathrm{C}$. The cells were then analyzed on a Guava easyCyte flow cytometer (Merck, Whitehouse Station, NJ, USA).

\subsection{Cell apoptosis analysis}

After 48-hr treatment with compound $\mathbf{2 8}$ or DMSO, cells were harvested and washed twice with ice-cold PBS. Approximately $6 \times 10^{5}$ cells were re-suspended in $100 \mu \mathrm{L} 1 \times \mathrm{BD}$ Binding buffer solution (\#556454, BD), and then incubated with Annexin V-PE(\#556422, BD) and 7$\mathrm{ADD}(\# 559925, \mathrm{BD})$ in the dark for 15 minutes. Finally,400 $\mu \mathrm{L} 1 \times \mathrm{BD}$ Binding buffer solution were replenished. The cells were then analyzed on a Guava easyCyte flow cytometer (Merck, Whitehouse Station, NJ, USA).

\subsection{Western blot analysis}

Cells were treated with various concentrations of each tested compound for a designated time. Then cells were lysed in using $1 \times$ SDS sample lysis buffer (CST recommended) with protease and phosphatase inhibitors. Cell lysates were loaded and electrophoresed onto 8-12\% SDS-PAGE gel, then the separated proteins were transferred to a PVDF film. The film were blocked with 5\% fatfree milk in TBS solution containing $0.5 \%$ Tween- 20 for $4 \mathrm{~h}$ at room temperature, then incubated with the corresponding primary antibody $(1: 1000-1: 200)$ overnight at $4{ }^{\circ} \mathrm{C}$. After washing with TBST, HRP-conjugated secondary antibody was incubated for $2 \mathrm{~h}$. The protein signals were visualized by ECL Western Blotting Detection Kit (Thermo Scientific, Waltham. MA, USA), and detected with Amersham Imager 600 system (GE, Boston, MA, USA). 


\subsection{In Vitro Kinase Assay.}

All the binding affinities (Kd) and kinome selectivity profiles (KINOMEscan profiling) were conducted Eurofins DiscoveryX Corporation (San Diego, CA, USA) by following the previous described protocols (J. Med. Chem. 61(2018):7977-7990). The data are mean values from two independent experiments with variation less than $15 \%$. Briefly, kinases were tagged with DNA for qPCR detection, while the biotinylated small molecule ligands were immobilized to streptavidincoated magnetic beads. Compounds that bind to the kinase active prevent kinase binding to the immobilized ligand. Thus, "hits" of KINOMEscan profiling could be identified by measuring the amount of kinase captured in test versus control samples by using a quantitative, precise and ultrasensitive qPCR method that detects the associated DNA label. In a similar manner, Kd values for test compound-kinase interaction are calculated by measuring the amount of kinase captured on the solid support as a function of the test compound concentration. The enzyme potency test (IC50) was conducted by Eurofins Cerep SA (France).

For kinase inhibitory assay, FLT3 and the $Z^{\prime}$-Lyte Kinase Assay Kit were purchased from Invitrogen (Waltham, MA, USA), and the assays were performed according to the manufacturer's instructions. The concentrations of kinases were determined by optimization experiments. First, the solutions of the compounds were diluted to $10 \mathrm{mM}$ in DMSO, and then were further diluted to 10 different concentrations by three times gradient dilution. Second, FLT3 kinase/peptide mixture containing $1 \times$ kinase and $2 \mu \mathrm{M}$ Tyr2 peptide (PV3191; Invitrogen) was prepared immediately before use. A kinase/peptide mixture was prepared by diluting peptide and kinase in 1×kinase buffer, and $2 \mu \mathrm{M}$ of the corresponding peptide-phosphopeptide solutions were made by adding peptidephosphopeptide to $1 \times$ kinase Buffer. The final $5 \mu \mathrm{L}$ reaction solution consists of the appropriate concentration of FLT3, $2 \mu \mathrm{M}$ Tyr peptide in $1 \times$ kinase buffer. Third, $5 \mathrm{~nL}$ of diluted compounds and ATP solution were added to $5 \mu \mathrm{L}$ of kinase/peptide mixture by an Echo instrument. ATP final concentrations were $500 \mu \mathrm{M}, 10 \mu \mathrm{M}$ and $25 \mu \mathrm{M}$ in FLT3 kinase/peptide mixture. The plate wells were mixed thoroughly and incubated for $1.5 \mathrm{~h}$ at room temperature (rt). Then $2.5 \mu \mathrm{L}$ development solution was added to each well and the plate was incubated for $1 \mathrm{~h}$ at $\mathrm{rt}$; the phosphopeptides were cleaved at this time. Finally, $2.5 \mu \mathrm{L}$ of stop reagent was added to terminate the reaction. For the control setting, $5 \mu \mathrm{L}$ phosphopeptide solution instead of the kinase/peptide mixture was used as a $100 \%$ phosphorylation control. The kinase/peptide mixture containing no ATP solution was used as a 100\% inhibition control, and DMSO instead of compound solution was used as the $0 \%$ inhibitor control. The plate was measured on an EnVision Multilabel Reader (Perkin-Elmer). Curve fitting and data presentation was performed using GraphPad Prism, version 5.0. Every experiment was repeated at least 2 twice.

\subsection{Mice xenograft tumor models.}

Male CB17-SCID mice were purchased from Vital River Laboratory Animal Technology Inc. (Beijing, China). All animal experiments were carried out under protocols approved by the Institutional Animal Care and Use Committee of the Medical College of Jinan University. $5 \times 10^{6}$ MV4-11 cells combined with matrigel (v/v, 1:1) were injected subcutaneously in the right flank of SCID mice. Mice were randomly grouped when the mean tumor volume reached $100-200 \mathrm{~mm}^{3}$. The animals were treated for 16 consecutive days once every two days by oral gavage with compound $\mathbf{2 8}(10,20 \mathrm{or} 40 \mathrm{mg} / \mathrm{kg})$ or vehicle. Tumor volume and body weight were monitored once every day. Tumor volume was calculated as $\mathrm{L} \times \mathrm{W}^{2} / 2$, where $\mathrm{L}$ and $\mathrm{W}$ are the length and width of the tumor, respectively.

\section{Molecular docking.}

A reported structure of FLT3 kinase complex with Quizartinib (PDB code 4RT7) was used as the protein template. Docking was carried out with GOLD 5.0 program (The Cambridge Crystallographic Data Centre: Cambridge, United Kingdom). GoldScore was used as the scoring function, and most accurate genetic algorithm search options were set. The figure of the binding mode was produced by Discovery Studio 3.0 (Accelrys, Inc.: San Diego, California). 


\section{Chemistry}

\subsection{General}

All reagents were purchased from chemical and biological company. ${ }^{1} \mathrm{H}$ NMR and ${ }^{13} \mathrm{C}$ NMR spectra were recorded on a Bruker AV-400 or $500 \mathrm{MHz}$ spectrometer. High resolution mass spectra (HRMS) were obtained on a Q-STAR Elite ESI-LC-MS/MS Spectrometer.

\subsection{Typical procedures for the synthesis of compounds 13 .}

\section{Route 1:}

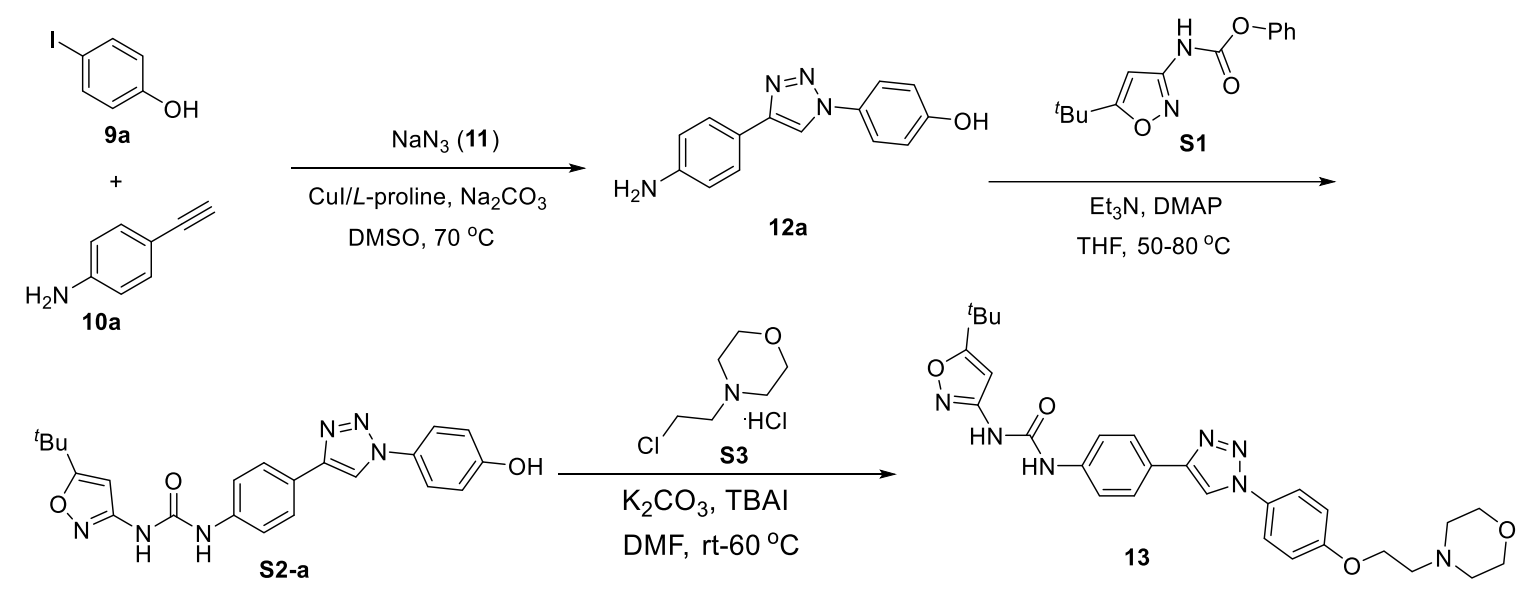

Compound 12a was synthesized according to literature ${ }^{2}$ reported procedure: Compound $9 \mathbf{a}$, , (4iodophenol, $2.2 \mathrm{~g}, 10 \mathrm{mmol}, 1$ equiv) and compound 10a (4-ethynylaniline, $1.17 \mathrm{~g}, 10 \mathrm{mmol}, 1$ equiv) in a $200 \mathrm{~mL}$ flask were added $L$-proline ( $240 \mathrm{mg}, 2 \mathrm{mmol}, 0.2$ equiv), $\mathrm{Na}_{2} \mathrm{CO}_{3}$ (1.06 g, 10 mmol, 1.0 equiv), $\mathrm{NaN}_{3}$ ( $780 \mathrm{mg}, 12 \mathrm{mmol}, 1.2$ equiv), DMSO ( $10 \mathrm{~mL}$ ), and $\mathrm{CuI}(95 \mathrm{mg}, 0.5 \mathrm{mmol}$, 0.05 equiv). The mixture was stirred overnight at $70{ }^{\circ} \mathrm{C}$. Upon completion (monitored by TLC), the crude mixture was quenched with $\mathrm{NH}_{4} \mathrm{OH}(10 \mathrm{~mL})$ and added water $(50 \mathrm{~mL})$, extracted with ethyl acetate for three time $(50 \mathrm{~mL} * 3)$, the combined organic phase was dried over $\mathrm{Na}_{2} \mathrm{SO}_{4}$, concentrated by vacuum. The residue was washed with cold $\mathrm{CH}_{2} \mathrm{Cl}_{2}$ to afford intermediate 12a as a brown solid $(2.04 \mathrm{~g}, 81 \%) .{ }^{1} \mathrm{H}$ NMR $\left(400 \mathrm{MHz}, d^{6}\right.$-DMSO) $\delta 9.92(\mathrm{~s}, 1 \mathrm{H}), 8.91(\mathrm{~s}, 1 \mathrm{H}), 7.68(\mathrm{~d}, J=8.8 \mathrm{~Hz}, 2 \mathrm{H})$, $7.57(\mathrm{~d}, J=8.8 \mathrm{~Hz}, 2 \mathrm{H}), 6.94(\mathrm{~d}, J=8.8 \mathrm{~Hz}, 2 \mathrm{H}), 6.64(\mathrm{~d}, J=6.8 \mathrm{~Hz}, 2 \mathrm{H}), 5.27$ (brs, 2H). ESI-MS $\mathrm{m} / \mathrm{z} 253.1(\mathrm{M}+\mathrm{H})^{+}$.

Compound 13 was synthesized according to literature reported procedures: 1,4-Diaryl-1,2,3triazole compound 12a (5 mmol, 1.0 equiv) and compound $\mathbf{S 1}$ (phenyl (5-(tert-butyl)isoxazol-3yl)carbamate, $6 \mathrm{mmol}, 1.2$ equiv), $\mathrm{Et}_{3} \mathrm{~N}$ ( $15 \mathrm{~mol}, 3.0$ equiv) and DMAP ( $0.5 \mathrm{mmol}, 0.1$ equiv) were stirred in THF $(25 \mathrm{~mL})$ at $50-80{ }^{\circ} \mathrm{C}$ overnight. The solvent was removed and the mixture was extracted with ethyl acetate, washed with water, and dried over anhydrous $\mathrm{Na}_{2} \mathrm{SO}_{4}$, and concentrated. The residue was washed with cold $\mathrm{CH}_{2} \mathrm{Cl}_{2}$ to afford intermediate $\mathbf{S 2 - a}$ as a white solid (1.88 g, 90\%). ${ }^{1} \mathrm{H}$ NMR $\left(400 \mathrm{MHz}, d^{6}\right.$-DMSO) $\delta 9.78(\mathrm{~s}, 1 \mathrm{H}), 9.44(\mathrm{~s}, 1 \mathrm{H}), 9.05(\mathrm{~s}, 1 \mathrm{H}), 7.86(\mathrm{~d}, J=8.8 \mathrm{~Hz}, 2 \mathrm{H})$, $7.71(\mathrm{dd}, J=6.8 \mathrm{~Hz}, 2.0 \mathrm{~Hz}, 2 \mathrm{H}), 7.59(\mathrm{~d}, J=8.8 \mathrm{~Hz}, 2 \mathrm{H}), 6.97(\mathrm{dd}, J=6.8 \mathrm{~Hz}, 2.0 \mathrm{~Hz}, 2 \mathrm{H}), 6.54$ (s, 1H), $1.31(\mathrm{~s}, 9 \mathrm{H}) .{ }^{13} \mathrm{C}$ NMR (101 MHz, $d^{6}$-DMSO) $\delta 180.6,158.8,158.4,151.9,147.3,139.5$, 129.2, 126.4, 125.1, 122.2, 119.2, 119.1, 116.6, 93.0, 32.9, 28.8. ESI-MS $m / z$ 419.1 $(\mathrm{M}+\mathrm{H})^{+}$; HRMS calcd for $\mathrm{C}_{22} \mathrm{H}_{23} \mathrm{~N}_{6} \mathrm{O}_{3}{ }^{+}(\mathrm{M}+\mathrm{H})^{+} 419.1826$, found 419.1825 .

Compound S2-a (1 mmol, 1.0 equiv) and compound S3 (4-(2-chloroethyl)morpholine hydrochloride acid, $1.5 \mathrm{mmol}, 1.5$ equiv) in DMF $(20 \mathrm{ml})$ were added $\mathrm{K}_{2} \mathrm{CO}_{3}(3 \mathrm{mmol}, 3.0$ equiv) and TBAI $(0.1 \mathrm{mmol})$. The mixture were heated to $60^{\circ} \mathrm{C}$ overnight, and then diluted with water and extracted with EtOAc. The combined organic layers were washed with water and brine and dried over anhydrous $\mathrm{Na}_{2} \mathrm{SO}_{4}$. The solvent was removed and the residue was purified by flash column chromatography to afford product $\mathbf{1 3}$ as a white solid (371 $\mathrm{mg}, 70 \%)$. 
Route 2:

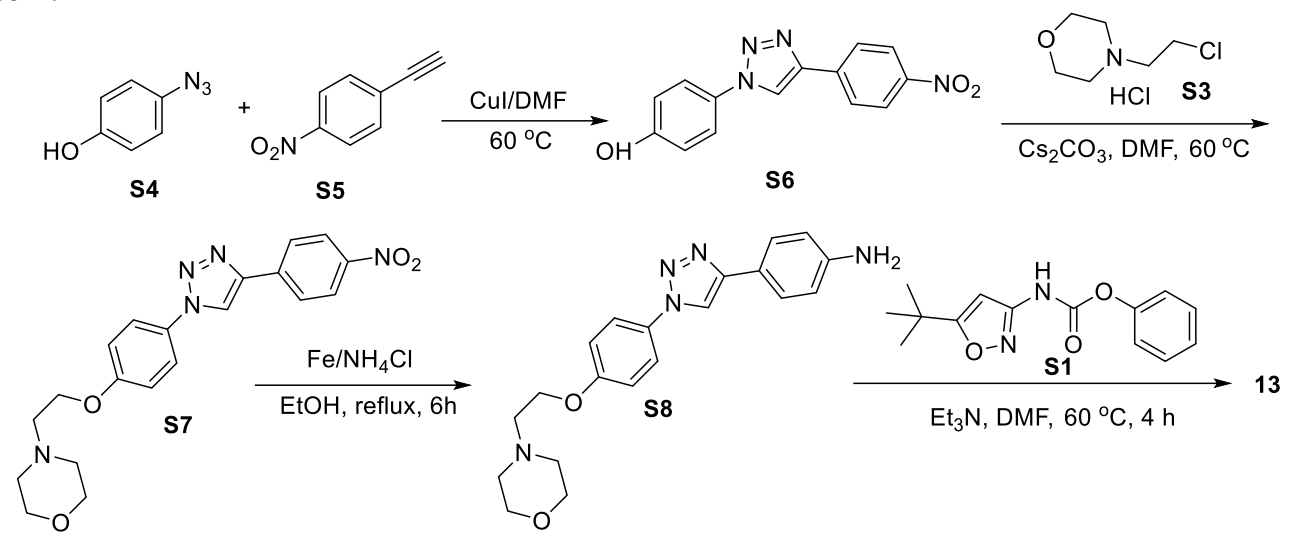

A mixture of 4-azidophenol (S4) (1.21 g, 9 mol), 1-ethynyl-4-nitrobenzene (S5) (1.33 g, 9 mmol) and $\mathrm{CuI}(172 \mathrm{mg}, 0.9 \mathrm{mmol})$ in DMF $(30 \mathrm{ml})$ were stirred for $4 \mathrm{~h}$ at $60{ }^{\circ} \mathrm{C}$. The reaction mixture was cooled to room temperature and diluted with water $(50 \mathrm{~mL})$ and extracted with EtOAc $(50 \mathrm{~mL}$ *3). The combined organic layers were washed with water and brine, dried over anhydrous $\mathrm{Na}_{2} \mathrm{SO}_{4}$. The solvent was evaporated in vacuum and the residue was purified by flash chromatography (eluting with PE : EtOAc $=2: 1)$ to afford $(\mathbf{S 6})$ as a yellow solid $(2.28 \mathrm{~g}, 90 \%) .{ }^{1} \mathrm{H}$ NMR $(400 \mathrm{MHz}$, $d^{6}$-DMSO) $\delta 10.02(\mathrm{~s}, 1 \mathrm{H}), 9.37(\mathrm{~s}, 1 \mathrm{H}), 8.35(\mathrm{~d}, J=8.5 \mathrm{~Hz}, 2 \mathrm{H}), 8.18(\mathrm{~d}, J=8.5 \mathrm{~Hz}, 2 \mathrm{H}), 7.72(\mathrm{~d}$, $J=8.5 \mathrm{~Hz}, 2 \mathrm{H}), 6.98(\mathrm{~d}, J=8.4 \mathrm{~Hz}, 2 \mathrm{H}) .{ }^{13} \mathrm{C}$ NMR $\left(101 \mathrm{MHz}, d^{6}\right.$-DMSO) $\delta 158.5,147.2,145.5$, $137.4,129.0,126.5,124.9,122.5,122.1,116.6$. ESI-MS $m / 2.283 .1(\mathrm{M}+\mathrm{H})^{+}$.

A mixture of (S6) (2.28 g, $8.1 \mathrm{mmol}$ ), (2-Chloroethyl) morpholine hydrochloride ( $\mathbf{S 3}, 2.26 \mathrm{~g}$, $12.1 \mathrm{mmol})$ and $\mathrm{Cs}_{2} \mathrm{CO}_{3}(7.90 \mathrm{~g}, 24.3 \mathrm{~mol})$ in DMF $(20 \mathrm{ml})$ were stirred at $60{ }^{\circ} \mathrm{C}$ for $4.5 \mathrm{~h}$, and then diluted with water $(50 \mathrm{~mL})$ and extracted with EtOAc $(50 \mathrm{~mL} * 3)$. The combined organic layers were washed with water and brine, dried over anhydrous $\mathrm{Na}_{2} \mathrm{SO}_{4}$. The solvent was evaporated in vacuum and the residue was purified by flash chromatography $\left(\mathrm{CH}_{2} \mathrm{Cl}_{2}: \mathrm{MeOH}=30: 1\right)$ to afford (S7) as a yellow solid $(2.78 \mathrm{~g}, 87 \%) . \quad{ }^{1} \mathrm{H}$ NMR $\left(400 \mathrm{MHz}, d^{6}\right.$-DMSO) $\delta 9.43(\mathrm{~s}, 1 \mathrm{H}), 8.35(\mathrm{~d}, J=$ $8.9 \mathrm{~Hz}, 2 \mathrm{H}), 8.18(\mathrm{~d}, J=8.9 \mathrm{~Hz}, 2 \mathrm{H}), 7.84(\mathrm{~d}, J=9.0 \mathrm{~Hz}, 2 \mathrm{H}), 7.19(\mathrm{~d}, J=9.0 \mathrm{~Hz}, 2 \mathrm{H}), 4.18(\mathrm{t}, J=$ $5.7 \mathrm{~Hz}, 2 \mathrm{H}), 3.64-3.56(\mathrm{~m}, 4 \mathrm{H}), 2.73(\mathrm{t}, J=5.7 \mathrm{~Hz}, 2 \mathrm{H}), 2.55-2.47(\mathrm{t}, \mathrm{J}=5.7 \mathrm{~Hz}, 4 \mathrm{H}) .{ }^{13} \mathrm{C} \mathrm{NMR}$ $\left(101 \mathrm{MHz}, d^{6}\right.$-DMSO) $\delta 159.2,147.2,145.6,137.2,130.2,126.5,124.9,122.1,122.0,116.0,66.7$, 66.3, 57.4, 54.1. ESI-MS $m / z 396.1(\mathrm{M}+\mathrm{H})^{+}$.

Compound $\mathbf{S 7}(2.78 \mathrm{~g}, 7 \mathrm{mmol})$ in $85 \% \mathrm{EtOH}(50 \mathrm{~mL})$ was added iron powder $(1.96 \mathrm{~g}, 35$ $\mathrm{mmol}$ ) and $\mathrm{NH}_{4} \mathrm{Cl}(1.52 \mathrm{~g}, 28 \mathrm{mmol})$. The mixture was refluxed at $75^{\circ} \mathrm{C}$ for $6 \mathrm{~h}$, and then filtrated. The filtrate was poured into saturated $\mathrm{NaHCO}_{3}$ solution and extracted with $\mathrm{CH}_{2} \mathrm{Cl}_{2}(100 \mathrm{~mL})$. The combined organic layers were washed with water and brine, and dried over anhydrous $\mathrm{Na}_{2} \mathrm{SO}_{4}$. The solvent was evaporated in vacuum and the residue was purified by flash chromatography $\left(\mathrm{CH}_{2} \mathrm{Cl}_{2}\right.$ : $\mathrm{MeOH}=30: 1)$ to afford (S8) as a light yellow solid $(2.43 \mathrm{~g}, 95 \%) .{ }^{1} \mathrm{H}$ NMR $\left(400 \mathrm{MHz}, d^{6}\right.$-DMSO $)$ $\delta 8.90(\mathrm{~s}, 1 \mathrm{H}), 7.83(\mathrm{~d}, J=8.7 \mathrm{~Hz}, 2 \mathrm{H}), 7.62(\mathrm{~d}, J=8.2 \mathrm{~Hz}, 2 \mathrm{H}), 7.17(\mathrm{~d}, J=8.8 \mathrm{~Hz}, 2 \mathrm{H}), 6.68(\mathrm{~d}$, $J=8.2 \mathrm{~Hz}, 2 \mathrm{H}), 5.32(\mathrm{~s}, 2 \mathrm{H}), 4.17(\mathrm{t}, J=5.4 \mathrm{~Hz}, 2 \mathrm{H}), 3.71-3.53(\mathrm{~m}, 4 \mathrm{H}), 2.73(\mathrm{t}, J=5.4 \mathrm{~Hz}, 2 \mathrm{H})$, $2.50(\mathrm{~s}, 4 \mathrm{H}) .{ }^{13} \mathrm{C}$ NMR $\left(101 \mathrm{MHz}, d^{6}\right.$-DMSO) $\delta 158.8,149.4,148.6,130.7,126.8,121.8,118.4$, 117.6, 115.9, 114.4, 66.7, 66.2, 57.4, 54.1. ESI-MS $m / z 366.2(\mathrm{M}+\mathrm{H})^{+}$.

A mixture of compound $\mathbf{S 8}(150 \mathrm{mg}, 0.41 \mathrm{mmol})$ and compound S1 (phenyl (5-(tertbutyl)isoxazol-3-yl)carbamate, $128 \mathrm{mg}, 0.48 \mathrm{mmol}), \mathrm{Et}_{3} \mathrm{~N}$ (123 mg, $\left.1.21 \mathrm{mmol}\right)$ in DMF (5 mL) was stirred at $60^{\circ} \mathrm{C}$ for 4 hours, and then diluted with water $(20 \mathrm{~mL})$. The mixture was extracted with EtOAc $(20 \mathrm{~mL} * 3)$. The combined organic layer was washed with water and brine, and dried over anhydrous $\mathrm{Na}_{2} \mathrm{SO}_{4}$. The solvent was evaporated in vacuum and the residue was purified by flash chromatography $\left(\mathrm{CH}_{2} \mathrm{Cl}_{2}: \mathrm{MeOH}=30: 1\right)$ to afford compound $\mathbf{1 3}$ as a white solid (170 $\mathrm{mg}$, $78 \%)$.

1-(5-(tert-butyl)isoxazol-3-yl)-3-(4-(1-(4-(2-morpholinoethoxy)phenyl)-1H-1,2,3-triazol-4yl)phenyl)urea (Compound 13): 


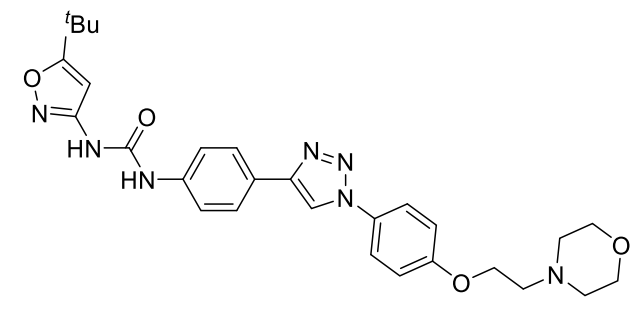

${ }^{1} \mathrm{H}$ NMR (400 MHz, $d^{6}$-DMSO) $\delta 9.58(\mathrm{~s}, 1 \mathrm{H}), 9.12(\mathrm{~s}, 1 \mathrm{H}), 8.98(\mathrm{~s}, 1 \mathrm{H}), 7.87(\mathrm{~d}, J=8.8 \mathrm{~Hz}, 2 \mathrm{H})$, $7.84(\mathrm{~d}, J=8.8 \mathrm{~Hz}, 2 \mathrm{H}), 7.58(\mathrm{~d}, J=8.8 \mathrm{~Hz}, 2 \mathrm{H}), 7.18(\mathrm{~d}, J=8.8 \mathrm{~Hz}, 2 \mathrm{H}), 6.53(\mathrm{~s}, 1 \mathrm{H}), 4.18(\mathrm{t}, J=$ $5.6 \mathrm{~Hz}, 2 \mathrm{H}), 3.59(\mathrm{t}, J=4.8 \mathrm{~Hz}, 4 \mathrm{H}), 2.72(\mathrm{t}, J=5.6 \mathrm{~Hz}, 2 \mathrm{H}), 2.50-2.52(\mathrm{~m}, 4 \mathrm{H}), 1.31(\mathrm{~s}, 9 \mathrm{H}) .{ }^{13} \mathrm{C}$ NMR (101 MHz, $d^{6}$-DMSO) $\delta 185.4,163.7,163.6,156.5,152.2,144.1,135.3,131.2,129.9,126.7$, 124.0, 123.9, 120.7, 97.9, 71.4, 71.0, 62.2, 58.8, 37.7, 33.6. ESI-MS $m / z$ 532.1 (M + H $)^{+} ; \mathrm{HRMS}$ calcd for $\mathrm{C}_{28} \mathrm{H}_{34} \mathrm{~N}_{7} \mathrm{O}_{4}{ }^{+}(\mathrm{M}+\mathrm{H})^{+}$required 532.2667, found 532.2659. HPLC analysis: $\mathrm{MeOH} / \mathrm{H}_{2} \mathrm{O}$ (72:28), RetTime: 6.64 min; purity: $98.9 \%$.

Compounds 14-32 were synthesized according to similar procedures (route 2) of compound 13. The corresponding intermediates were directly used without purification.

The purity of all final compounds 13-32 were analyzed by high performance liquid chromatography (HPLC) with a poroshell $120 \mathrm{C} 18$ reversed-phase column (EC-18 $\mu \mathrm{m}, 4.6 \mathrm{~mm} \times$ $150 \mathrm{~mm}$ ), with a flow rate of $1.0 \mathrm{~mL} / \mathrm{min}$, detector wavelength $=250 \mathrm{~nm}$. The eluent solvents were $\mathrm{MeOH}$ and $\mathrm{H}_{2} \mathrm{O}$

1-(5-(tert-butyl)isoxazol-3-yl)-3-(2-methyl-4-(1-(4-(2-morpholinoethoxy)phenyl)-1H-1,2,3triazol-4-yl)phenyl)urea (Compound 14):

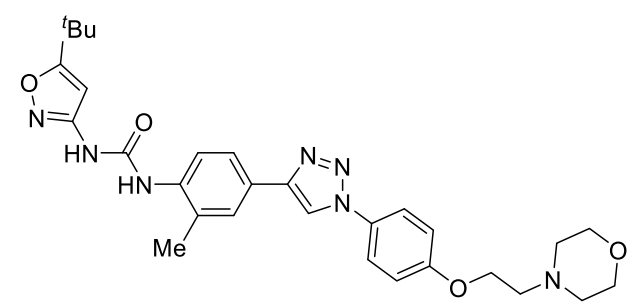

${ }^{1} \mathrm{H}$ NMR (400 MHz, $d^{6}$-DMSO) $\delta 9.94(\mathrm{~s}, 1 \mathrm{H}), 9.11(\mathrm{~s}, 1 \mathrm{H}), 8.35(\mathrm{~s}, 1 \mathrm{H}), 8.03(\mathrm{~d}, J=8.8 \mathrm{~Hz}, 2 \mathrm{H})$, $7.83(\mathrm{~d}, J=8.4 \mathrm{~Hz}, 1 \mathrm{H}), 7.78(\mathrm{~d}, J=2.0 \mathrm{~Hz}, 1 \mathrm{H}), 7.70(\mathrm{dd}, J=8.4 \mathrm{~Hz}, 2.0 \mathrm{~Hz}, 1 \mathrm{H}), 7.17(\mathrm{~d}, J=8.8$ $\mathrm{Hz}, 2 \mathrm{H}), 6.48(\mathrm{~s}, 1 \mathrm{H}), 4.17(\mathrm{t}, J=5.6 \mathrm{~Hz}, 2 \mathrm{H}), 3.59(\mathrm{t}, J=4.8 \mathrm{~Hz}, 4 \mathrm{H}), 2.72(\mathrm{t}, J=5.6 \mathrm{~Hz}, 2 \mathrm{H})$, 2.49-2.51 (m, 4H), 2.23 (s, 3H), 1.31 (s, 9H). ${ }^{13} \mathrm{C}$ NMR (101 MHz, $d^{6}$-DMSO) 8180.7, 159.0, 159.0, 151.9, 147.5, 137.3, 130.6, 128.2, 127.6, 125.6, 123.9, 122.0, 121.2, 119.4, 115.9, 92.8, 66.7, 66.2, 57.4, 54.1, 33.0, 28.8, 18.4. ESI-MS $m / z$ 546.2 $(\mathrm{M}+\mathrm{H})^{+}$. HRMS calcd for $\mathrm{C}_{29} \mathrm{H}_{36} \mathrm{~N}_{7} \mathrm{O}_{4}{ }^{+}(\mathrm{M}+\mathrm{H})^{+}$ required 546.2823, found 546.2822. HPLC analysis: $\mathrm{MeOH} / \mathrm{H}_{2} \mathrm{O}$ (72:28), RetTime: 7.4 min; purity: $99.4 \%$.

1-(5-(tert-butyl)isoxazol-3-yl)-3-(2-chloro-4-(1-(4-(2-morpholinoethoxy)phenyl)-1H-1,2,3triazol-4-yl)phenyl)urea (Compound 15):

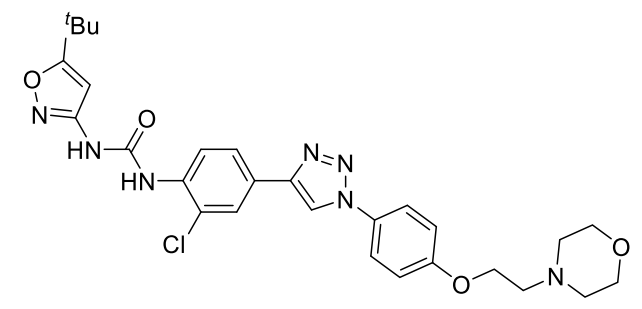

${ }^{1} \mathrm{H}$ NMR $\left(400 \mathrm{MHz}, d^{6}\right.$-DMSO) $\delta 10.31(\mathrm{~s}, 1 \mathrm{H}), 9.23(\mathrm{~s}, 1 \mathrm{H}), 8.80(\mathrm{~s}, 1 \mathrm{H}), 8.31(\mathrm{t}, J=8.8 \mathrm{~Hz}, 1 \mathrm{H})$, $8.02(\mathrm{~d}, J=2.0 \mathrm{~Hz}, 1 \mathrm{H}), 7.88(\mathrm{dd}, J=8.8 \mathrm{~Hz}, 2.0 \mathrm{~Hz}, 1 \mathrm{H}), 7.82(\mathrm{~d}, J=8.8 \mathrm{~Hz}, 2 \mathrm{H}), 7.18(\mathrm{~d}, J=8.8$ 
$\mathrm{Hz}, 2 \mathrm{H}), 6.50(\mathrm{~s}, 1 \mathrm{H}), 4.18(\mathrm{t}, J=5.6 \mathrm{~Hz}, 2 \mathrm{H}), 3.59(\mathrm{t}, J=4.8 \mathrm{~Hz}, 4 \mathrm{H}), 2.72(\mathrm{t}, J=5.6 \mathrm{~Hz}, 2 \mathrm{H})$, 2.49-2.51 (m, 4H), $1.31(\mathrm{~s}, 9 \mathrm{H}) .{ }^{13} \mathrm{C}$ NMR $\left(101 \mathrm{MHz}, d^{6}\right.$-DMSO) $\delta 180.9,159.0,158.7,151.6,146.1$, 135.6, 130.4, 126.6, 126.2, 124.9, 123.0, 122.0, 121.9, 120.1, 116.0, 92.9, 66.6, 66.2, 57.4, 54.1, 33.0, 28.9. ESI-MS $m / z$ 566.2 $(\mathrm{M}+\mathrm{H})^{+}$. HRMS calcd for $\mathrm{C}_{28} \mathrm{H}_{33} \mathrm{ClN}_{7} \mathrm{O}_{4}{ }^{+}(\mathrm{M}+\mathrm{H})^{+}$required 566.2277, found 566.2273. HPLC analysis: $\mathrm{MeOH} / \mathrm{H}_{2} \mathrm{O}$ (72:28), RetTime: $10.7 \mathrm{~min}$; purity: $96.9 \%$.

1-(5-(tert-butyl)isoxazol-3-yl)-3-(2-methoxy-4-(1-(4-(2-morpholinoethoxy)phenyl)-1H-1,2,3triazol-4-yl)phenyl)urea (Compound 16):

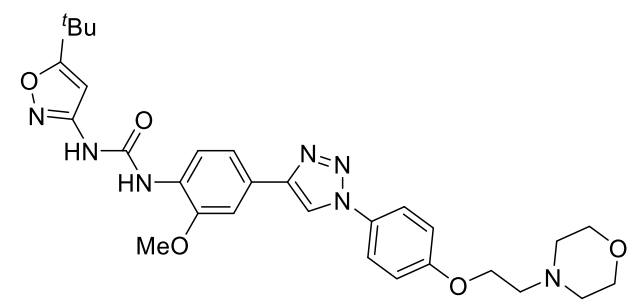

${ }^{1} \mathrm{H}$ NMR (400 MHz, $d^{6}$-DMSO) $\delta 10.12(\mathrm{~s}, 1 \mathrm{H}), 9.18(\mathrm{~s}, 1 \mathrm{H}), 8.77(\mathrm{~s}, 1 \mathrm{H}), 8.24(\mathrm{~d}, J=7.6 \mathrm{~Hz}, 1 \mathrm{H})$, $7.84(\mathrm{~d}, J=7.6 \mathrm{~Hz}, 2 \mathrm{H}), 7.59(\mathrm{~s}, 1 \mathrm{H}), 7.50(\mathrm{~d}, J=7.6 \mathrm{~Hz}, 1 \mathrm{H}), 7.18(\mathrm{~d}, J=7.6 \mathrm{~Hz}, 2 \mathrm{H}), 6.51(\mathrm{~s}$, $1 \mathrm{H}), 4.17(\mathrm{t}, J=5.6 \mathrm{~Hz}, 2 \mathrm{H}), 3.99(\mathrm{~s}, 3 \mathrm{H}), 3.59(\mathrm{t}, J=4.8 \mathrm{~Hz}, 4 \mathrm{H}), 2.72(\mathrm{t}, J=5.6 \mathrm{~Hz}, 2 \mathrm{H}), 2.49-$ $2.51(\mathrm{~m}, 4 \mathrm{H}), 1.31(\mathrm{~s}, 9 \mathrm{H}) .{ }^{13} \mathrm{C}$ NMR (101 MHz, $d^{6}$-DMSO) $\delta 180.6,158.9,158.8,151.7,148.5$, 147.6, 130.6, 128.5, 125.2, 121.9, 119.5, 119.0, 118.1, 115.9, 108.1, 92.8, 66.6, 66.2, 57.4, 56.5, 54.1, 32.9, 28.8. ESI-MS $m / z 562.2(\mathrm{M}+\mathrm{H})^{+}$. HRMS calcd for $\mathrm{C}_{29} \mathrm{H}_{36} \mathrm{~N}_{7} \mathrm{O}_{5}{ }^{+}(\mathrm{M}+\mathrm{H})^{+}$required 562.2772, found 562.2771. HPLC analysis: $\mathrm{MeOH} / \mathrm{H}_{2} \mathrm{O}$ (72:28), RetTime: $7.6 \mathrm{~min}$; purity: $95.4 \%$.

1-(5-(tert-butyl)isoxazol-3-yl)-3-(2-fluoro-4-(1-(4-(2-morpholinoethoxy)phenyl)-1 H-1,2,3triazol-4-yl)phenyl)urea (Compound 17):

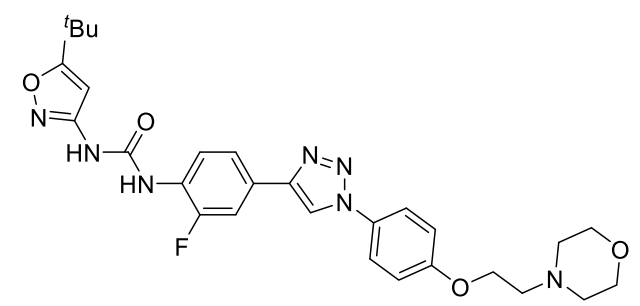

${ }^{1} \mathrm{H}$ NMR (400 MHz, $d^{6}$-DMSO) $\delta 9.94(\mathrm{~s}, 1 \mathrm{H}), 9.20(\mathrm{~s}, 1 \mathrm{H}), 8.96(\mathrm{~s}, 1 \mathrm{H}), 8.26(\mathrm{t}, J=8.4 \mathrm{~Hz}, 1 \mathrm{H})$, $7.82(\mathrm{~d}, J=8.8 \mathrm{~Hz}, 2 \mathrm{H}), 7.77-7.81(\mathrm{~m}, 2 \mathrm{H}), 7.19(\mathrm{~d}, J=8.8 \mathrm{~Hz}, 2 \mathrm{H}), 6.52(\mathrm{~s}, 1 \mathrm{H}), 4.18(\mathrm{t}, J=5.6$ $\mathrm{Hz}, 2 \mathrm{H}), 3.60(\mathrm{t}, J=4.8 \mathrm{~Hz}, 4 \mathrm{H}), 2.72(\mathrm{t}, J=5.6 \mathrm{~Hz}, 2 \mathrm{H}), 2.49-2.51(\mathrm{~m}, 4 \mathrm{H}), 1.31(\mathrm{~s}, 9 \mathrm{H}) .{ }^{13} \mathrm{C} \mathrm{NMR}$ $\left(101 \mathrm{MHz}, d^{6}\right.$-DMSO) $\delta 180.9,159.0,158.6,152.6(\mathrm{~d}, J=240.6 \mathrm{~Hz}), 151.5,146.4(\mathrm{~d}, J=2.3 \mathrm{~Hz})$, $130.4,127.1(\mathrm{~d}, J=10.6 \mathrm{~Hz}), 126.0(\mathrm{~d}, J=8.2 \mathrm{~Hz}), 122.0,121.9(\mathrm{~d}, J=2.4 \mathrm{~Hz}), 121.3,120.1,116.0$, $112.3(\mathrm{~d}, J=20.8 \mathrm{~Hz}), 92.8,66.6,66.2,57.4,54.1,33.0,28.8$. ESI-MS $\mathrm{m} / \mathrm{z}, 550.1(\mathrm{M}+\mathrm{H})^{+}$. HRMS calcd for $\mathrm{C}_{28} \mathrm{H}_{33} \mathrm{FN}_{7} \mathrm{O}_{4}{ }^{+}(\mathrm{M}+\mathrm{H})^{+}$required 550.2573, found 550.2564. HPLC analysis: $\mathrm{MeOH} / \mathrm{H}_{2} \mathrm{O}$ (72:28), RetTime: 7.9 min; purity: $99.7 \%$

1-(5-(tert-butyl)isoxazol-3-yl)-3-(3-fluoro-4-(1-(4-(2-morpholinoethoxy)phenyl)-1H-1,2,3triazol-4-yl)phenyl)urea (Compound 18):

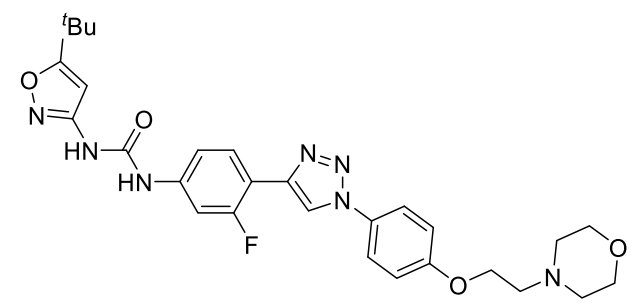

${ }^{1} \mathrm{H}$ NMR (400 MHz, $d^{6}$-DMSO) $\delta 9.68(\mathrm{~s}, 1 \mathrm{H}), 9.18(\mathrm{~s}, 1 \mathrm{H}), 8.89(\mathrm{~d}, J=3.2 \mathrm{~Hz}, 1 \mathrm{H}), 8.08(\mathrm{t}, J=$ $8.4 \mathrm{~Hz}, 1 \mathrm{H}), 7.83(\mathrm{~d}, J=9.2 \mathrm{~Hz}, 2 \mathrm{H}), 7.70(\mathrm{dd}, J=9.2 \mathrm{~Hz}, 2.0 \mathrm{~Hz}, 1 \mathrm{H}), 7.27(\mathrm{dd}, J=8.4 \mathrm{~Hz}, 2.0$ $\mathrm{Hz}, 1 \mathrm{H}), 7.16(\mathrm{~d}, J=9.2 \mathrm{~Hz}, 2 \mathrm{H}), 6.54(\mathrm{~s}, 1 \mathrm{H}), 4.18(\mathrm{t}, J=5.6 \mathrm{~Hz}, 2 \mathrm{H}), 3.59(\mathrm{t}, J=4.4 \mathrm{~Hz}, 4 \mathrm{H})$, 
$2.72(\mathrm{t}, J=5.6 \mathrm{~Hz}, 2 \mathrm{H}), 2.49-2.51(\mathrm{~m}, 4 \mathrm{H}), 1.31(\mathrm{~s}, 9 \mathrm{H}) .{ }^{13} \mathrm{C}$ NMR $\left(101 \mathrm{MHz}, d^{6}-\mathrm{DMSO}\right) \delta 180.8$, $159.1(\mathrm{~d}, J=244.5 \mathrm{~Hz}), 159.0,158.6,151.7,141.2(\mathrm{~d}, J=25.5 \mathrm{~Hz}), 140.9,130.4,128.3(\mathrm{~d}, J=4.7$ $\mathrm{Hz}), 122.3,121.3$ (d, $J=10.1 \mathrm{~Hz}), 115.9,115.2,112.4(\mathrm{~d}, J=13.7 \mathrm{~Hz}), 106.0(\mathrm{~d}, J=26.7 \mathrm{~Hz}), 93.0$, 66.7, 66.2, 57.4, 54.1, 33.0, 28.8. ESI-MS $m / z$ 550.2 $(\mathrm{M}+\mathrm{H})^{+}$. HRMS calcd for $\mathrm{C}_{28} \mathrm{H}_{33} \mathrm{FN}_{7} \mathrm{O}_{4}{ }^{+}(\mathrm{M}$ $+\mathrm{H})^{+}$required 550.2573, found 550.2575. HPLC analysis: $\mathrm{MeOH} / \mathrm{H}_{2} \mathrm{O}(72: 28)$, RetTime: $9.2 \mathrm{~min}$; purity: $97.3 \%$.

1-(5-(tert-butyl)isoxazol-3-yl)-3-(3-chloro-4-(1-(4-(2-morpholinoethoxy)phenyl)-1H-1,2,3triazol-4-yl)phenyl)urea (Compound 19):

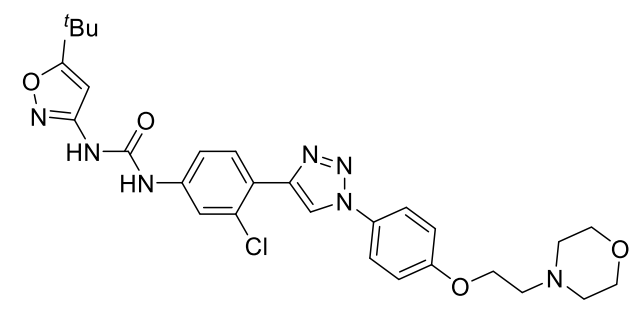

${ }^{1} \mathrm{H}$ NMR (400 MHz, $d^{6}$-DMSO) $\delta 9.71(\mathrm{~s}, 1 \mathrm{H}), 9.15(\mathrm{~s}, 1 \mathrm{H}), 9.05(\mathrm{~s}, 1 \mathrm{H}), 8.01(\mathrm{~d}, J=8.6 \mathrm{~Hz}, 1 \mathrm{H})$, $7.90(\mathrm{~d}, J=2.6 \mathrm{~Hz}, 2 \mathrm{H}), 7.88(\mathrm{~d}, J=2.2 \mathrm{~Hz}, 1 \mathrm{H}), 7.43(\mathrm{dd}, J=8.6,2.2 \mathrm{~Hz}, 1 \mathrm{H}), 7.24-7.11(\mathrm{~m}$, 2H), $6.55(\mathrm{~s}, 1 \mathrm{H}), 4.17(\mathrm{t}, J=5.7 \mathrm{~Hz}, 2 \mathrm{H}), 3.66-3.56(\mathrm{~m}, 4 \mathrm{H}), 2.72(\mathrm{t}, J=5.7 \mathrm{~Hz}, 2 \mathrm{H}), 2.51-2.44$ $(\mathrm{m}, 4 \mathrm{H}), 1.30(\mathrm{~s}, 9 \mathrm{H}) .{ }^{13} \mathrm{C}$ NMR (101 MHz, $d^{6}$-DMSO) $\delta 180.8,159.0,158.7,151.7,144.1,140.5$, 131.3, 130.6, 130.4, 123.3, 122.4, 122.0, 119.5, 117.9, 115.9, 93.0, 66.6, 66.2, 57.4, 54.1, 33.0, 28.8. ESI-MS $m / z 566.2(\mathrm{M}+\mathrm{H})^{+}$. HRMS calcd for $\mathrm{C}_{28} \mathrm{H}_{33} \mathrm{ClN}_{7} \mathrm{O}_{4}{ }^{+}(\mathrm{M}+\mathrm{H})^{+}$required 566.2277, found 566.2273. HPLC analysis: MeOH/H2O (72:28), RetTime: 9.4 min; purity: $95.5 \%$.

1-(5-(tert-butyl)isoxazol-3-yl)-3-(4-(1-(3-methoxy-4-(2-morpholinoethoxy)phenyl)-1H-1,2,3triazol-4-yl)phenyl)urea (Compound 20):

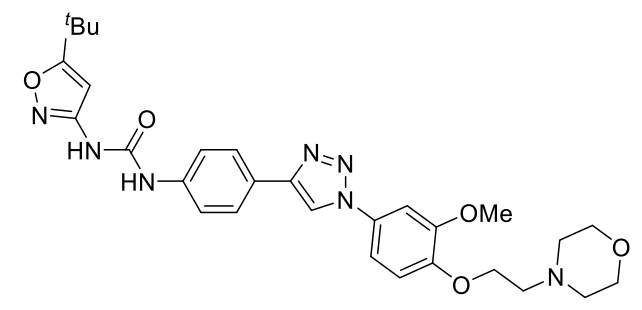

${ }^{1} \mathrm{H}$ NMR (400 MHz, $d^{6}$-DMSO) $\delta 9.57(\mathrm{~s}, 1 \mathrm{H}), 9.15(\mathrm{~s}, 1 \mathrm{H}), 8.96(\mathrm{~s}, 1 \mathrm{H}), 7.87(\mathrm{~d}, J=8.8 \mathrm{~Hz}, 2 \mathrm{H})$, $7.59(\mathrm{~d}, J=8.8 \mathrm{~Hz}, 2 \mathrm{H}), 7.52(\mathrm{~d}, J=2.4 \mathrm{~Hz}, 1 \mathrm{H}), 7.43(\mathrm{dd}, J=8.8 \mathrm{~Hz}, 2.4 \mathrm{~Hz}, 1 \mathrm{H}), 7.20(\mathrm{~d}, J=8.8$ $\mathrm{Hz}, 1 \mathrm{H}), 6.53(\mathrm{~s}, 1 \mathrm{H}), 4.16(\mathrm{t}, J=5.6 \mathrm{~Hz}, 2 \mathrm{H}), 3.89(\mathrm{~s}, 3 \mathrm{H}), 3.59(\mathrm{t}, J=4.4 \mathrm{~Hz}, 4 \mathrm{H}), 2.73(\mathrm{t}, J=5.6$ $\mathrm{Hz}, 2 \mathrm{H}), 2.49-2.51(\mathrm{~m}, 4 \mathrm{H}), 1.31(\mathrm{~s}, 9 \mathrm{H}) .{ }^{13} \mathrm{C}$ NMR (101 MHz, $d^{6}$-DMSO) $\delta 177.4,158.8,151.8$, 150.1, 148.5, 147.4, 139.3, 130.7, 126.4, 125.1, 119.4, 119.2, 114.0, 112.4, 105.1, 92.9, 67.0, 66.7, 57.4, 56.4, 54.1, 33.0, 28.8. ESI-MS $m / z$ 562.2 $(\mathrm{M}+\mathrm{H})^{+}$. HRMS calcd for $\mathrm{C}_{29} \mathrm{H}_{36} \mathrm{~N}_{7} \mathrm{O}_{5}{ }^{+}(\mathrm{M}+\mathrm{H})^{+}$ required 562.2772, found 562.2770. HPLC analysis: $\mathrm{MeOH} / \mathrm{H}_{2} \mathrm{O}$ (72:28), RetTime: 5.1 min; purity: $97.6 \%$.

1-(5-(tert-butyl)isoxazol-3-yl)-3-(4-(1-(3-methyl-4-(2-morpholinoethoxy)phenyl)-1H-1,2,3triazol-4-yl)phenyl)urea (Compound 21):

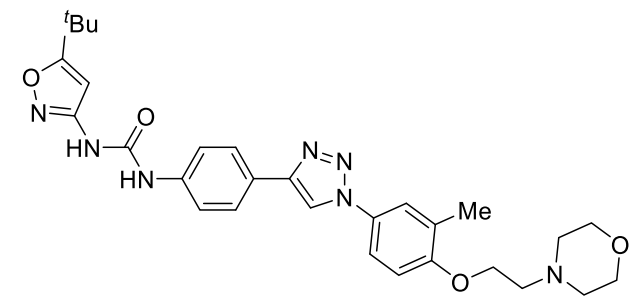

${ }^{1} \mathrm{H}$ NMR (400 MHz, $d^{6}$-DMSO) $\delta 9.58(\mathrm{~s}, 1 \mathrm{H}), 9.09(\mathrm{~s}, 1 \mathrm{H}), 8.97(\mathrm{~s}, 1 \mathrm{H}), 7.87(\mathrm{~d}, J=8.8 \mathrm{~Hz}, 2 \mathrm{H})$, $7.74(\mathrm{~d}, J=2.4 \mathrm{~Hz}, 1 \mathrm{H}), 7.70(\mathrm{dd}, J=8.8 \mathrm{~Hz}, 2.4 \mathrm{~Hz}, 1 \mathrm{H}), 7.58(\mathrm{~d}, J=8.8 \mathrm{~Hz}, 2 \mathrm{H}), 7.17(\mathrm{~d}, J=8.8$ 
$\mathrm{Hz}, 1 \mathrm{H}), 6.53(\mathrm{~s}, 1 \mathrm{H}), 4.19(\mathrm{t}, J=5.6 \mathrm{~Hz}, 2 \mathrm{H}), 3.59$ (t, $J=4.4 \mathrm{~Hz}, 4 \mathrm{H}), 2.73(\mathrm{t}, J=5.6 \mathrm{~Hz}, 2 \mathrm{H})$, 2.49-2.51 (m, 4H), 2.26 (s, 3H), 1.31 (s, 9H). ${ }^{13} \mathrm{C} \mathrm{NMR} \mathrm{(101} \mathrm{MHz,} d^{6}$-DMSO) $\delta 180.7,158.8,157.0$, 151.8, 147.4, 139.3, 130.1, 127.9, 126.4, 125.2, 122.7, 119.2, 119.2, 112.5, 92.9, 66.8, 66.7, 57.4, 54.1, 33.0, 28.8, 16.6. ESI-MS $m / z$ 546.2 $(\mathrm{M}+\mathrm{H})^{+}$. HRMS calcd for $\mathrm{C}_{29} \mathrm{H}_{36} \mathrm{~N}_{7} \mathrm{O}_{4}{ }^{+}(\mathrm{M}+\mathrm{H})^{+}$ required 546.2823, found 546.2827. HPLC analysis: $\mathrm{MeOH} / \mathrm{H}_{2} \mathrm{O}$ (72:28), RetTime: $8.7 \mathrm{~min}$; purity: $95.3 \%$.

1-(5-(tert-butyl)isoxazol-3-yl)-3-(4-(1-(3-chloro-4-(2-morpholinoethoxy)phenyl)-1H-1,2,3triazol-4-yl)phenyl)urea (Compound 22):

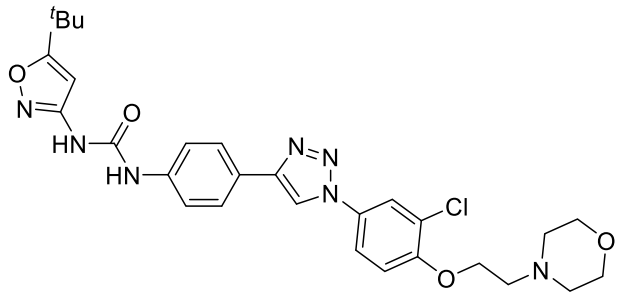

${ }^{1} \mathrm{H}$ NMR $\left(400 \mathrm{MHz}, d^{6}\right.$-DMSO) $\delta 9.58(\mathrm{~s}, 1 \mathrm{H}), 9.18(\mathrm{~s}, 1 \mathrm{H}), 8.98(\mathrm{~s}, 1 \mathrm{H}), 8.05(\mathrm{~d}, J=2.4 \mathrm{~Hz}, 1 \mathrm{H})$, $7.83-7.89(\mathrm{~m}, 3 \mathrm{H}), 7.58(\mathrm{~d}, J=8.8 \mathrm{~Hz}, 2 \mathrm{H}), 7.41(\mathrm{~d}, J=8.8 \mathrm{~Hz}, 1 \mathrm{H}), 6.53(\mathrm{~s}, 1 \mathrm{H}), 4.27(\mathrm{t}, J=5.6$ $\mathrm{Hz}, 2 \mathrm{H}), 3.58(\mathrm{t}, J=4.4 \mathrm{~Hz}, 4 \mathrm{H}), 2.76(\mathrm{t}, J=5.6 \mathrm{~Hz}, 2 \mathrm{H}), 2.49-2.51(\mathrm{~m}, 4 \mathrm{H}), 1.30(\mathrm{~s}, 9 \mathrm{H}) .{ }^{13} \mathrm{C} \mathrm{NMR}$ (101 MHz, $d^{6}$-DMSO) $\delta 180.7,158.8,154.3,151.8,147.6,139.4,130.7,126.4,124.9,122.6,122.0$, $120.4,119.4,119.2,115.1,92.9,67.9,66.7,57.2,54.2,33.0,28.8$. ESI-MS $m / z 566.2(\mathrm{M}+\mathrm{H})^{+}$ HRMS calcd for $\mathrm{C}_{28} \mathrm{H}_{33} \mathrm{ClN}_{7} \mathrm{O}_{4}{ }^{+}(\mathrm{M}+\mathrm{H})^{+}$required 566.2277, found 566.2270. HPLC analysis: $\mathrm{MeOH} / \mathrm{H}_{2} \mathrm{O}$ (72:28), RetTime: 9.3 min; purity: $98.6 \%$.

1-(5-(tert-butyl)isoxazol-3-yl)-3-(4-(1-(4-(2-morpholinoethoxy)-3-(trifluoromethyl)phenyl)$1 H-1,2,3-$ triazol-4-yl)phenyl)urea (Compound 23):

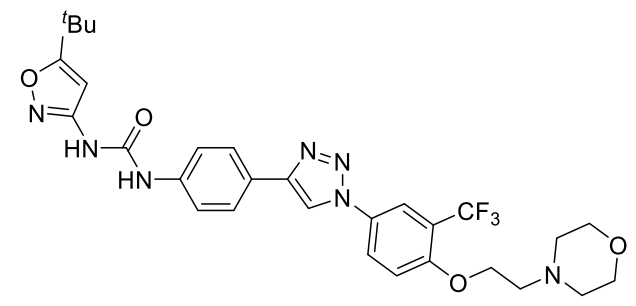

${ }^{1} \mathrm{H}$ NMR (400 MHz, $d^{6}$-DMSO) $\delta 9.59(\mathrm{~s}, 1 \mathrm{H}), 9.28(\mathrm{~s}, 1 \mathrm{H}), 8.97(\mathrm{~s}, 1 \mathrm{H}), 8.16-8.21(\mathrm{~m}, 2 \mathrm{H}), 7.86$ $(\mathrm{d}, J=8.8 \mathrm{~Hz}, 2 \mathrm{H}), 7.59(\mathrm{dd}, J=8.8 \mathrm{~Hz}, 2.4 \mathrm{~Hz}, 2 \mathrm{H}), 7.53-7.56(\mathrm{~m}, 1 \mathrm{H}), 6.53(\mathrm{~s}, 1 \mathrm{H}), 4.33(\mathrm{t}, J=$ $5.6 \mathrm{~Hz}, 2 \mathrm{H}), 3.57(\mathrm{t}, J=4.4 \mathrm{~Hz}, 4 \mathrm{H}), 2.75(\mathrm{t}, J=5.6 \mathrm{~Hz}, 2 \mathrm{H}), 2.49-2.51(\mathrm{~m}, 4 \mathrm{H}), 1.31(\mathrm{~s}, 9 \mathrm{H}) .{ }^{13} \mathrm{C}$ NMR (101 MHz, $d^{6}$-DMSO) $\delta 180.7,158.8,156.5,151.7,147.7,139.4,129.9,126.4,126.1,124.9$, $123.6(\mathrm{q}, J=270.5 \mathrm{~Hz}), 119.6,119.2,119.1,118.3(\mathrm{q}, J=30.7 \mathrm{~Hz}), 115.6,92.9,68.0,66.7,57.1$, 54.0, 33.0, 28.8. ESI-MS $m / z 600.2(\mathrm{M}+\mathrm{H})^{+} \mathrm{HRMS}$ calcd for $\mathrm{C}_{29} \mathrm{H}_{33} \mathrm{~F}_{3} \mathrm{~N}_{7} \mathrm{O}_{4}{ }^{+}(\mathrm{M}+\mathrm{H})^{+}$required 600.2541, found 600.2533. HPLC analysis: $\mathrm{MeOH} / \mathrm{H}_{2} \mathrm{O}$ (72:28), RetTime: 10.9 min; purity: $99.1 \%$.

1-(5-(tert-butyl)isoxazol-3-yl)-3-(4-(1-(4-(2-morpholinoethoxy)-3-nitrophenyl)-1H-1,2,3triazol-4-yl)phenyl)urea (Compound 24):

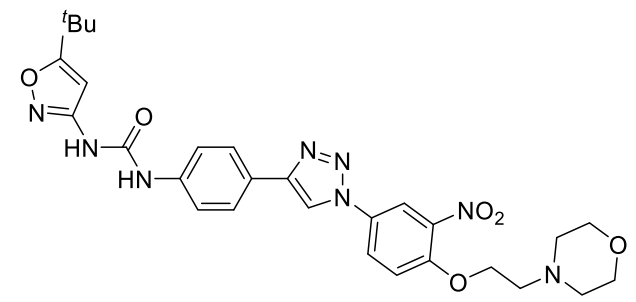

${ }^{1} \mathrm{H}$ NMR (400 MHz, $d^{6}$-DMSO) $\delta 9.58(\mathrm{~s}, 1 \mathrm{H}), 9.27$ (s, 1H), 8.97 (s, 1H), 8.49 (d, $\left.J=2.8 \mathrm{~Hz}, 1 \mathrm{H}\right)$, $8.25(\mathrm{dd}, J=8.8 \mathrm{~Hz}, 2.8 \mathrm{~Hz}, 1 \mathrm{H}), 7.86(\mathrm{~d}, J=8.4 \mathrm{~Hz}, 2 \mathrm{H}), 7.67(\mathrm{~d}, J=8.8 \mathrm{~Hz}, 1 \mathrm{H}), 7.59(\mathrm{~d}, J=8.8$ $\mathrm{Hz}, 2 \mathrm{H}), 6.53(\mathrm{~s}, 1 \mathrm{H}), 4.38(\mathrm{t}, J=5.6 \mathrm{~Hz}, 2 \mathrm{H}), 3.57(\mathrm{t}, J=4.4 \mathrm{~Hz}, 4 \mathrm{H}), 2.75(\mathrm{t}, J=5.6 \mathrm{~Hz}, 2 \mathrm{H})$, 
2.49-2.51 (m, 4H), 1.31 (s, 9H). ${ }^{13} \mathrm{C}$ NMR (101 MHz, $d^{6}$-DMSO) $\delta 180.7,158.8,151.8,151.4,147.8$, 140.0, 139.5, 129.7, 126.4, 125.9, 124.8, 119.6, 119.3, 117.4, 117.1, 92.9, 68.7, 66.7, 57.0, 54.0, 33.0, 28.8. ESI-MS $m / z 577.2(\mathrm{M}+\mathrm{H})^{+}$. HRMS calcd for $\mathrm{C}_{28} \mathrm{H}_{33} \mathrm{~N}_{8} \mathrm{O}_{6}{ }^{+}(\mathrm{M}+\mathrm{H})^{+}$required 577.2518, found 577.2518. HPLC analysis: $\mathrm{MeOH} / \mathrm{H}_{2} \mathrm{O}$ (72:28), RetTime: 6.4 min; purity: 97.6\%.

1-(5-(tert-butyl)isoxazol-3-yl)-3-(4-(1-(4-(2-morpholinoethoxy)-2-(trifluoromethyl)phenyl)$1 H-1,2,3-$ triazol-4-yl)phenyl)urea (Compound 25):

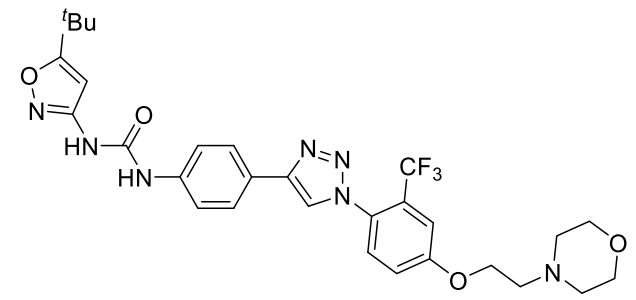

${ }^{1} \mathrm{H}$ NMR (400 MHz, $d^{6}$-DMSO) $\delta 9.57$ (s, 1H), 8.97 (s, 1H), $8.84(\mathrm{~s}, 1 \mathrm{H}), 7.87$ (d, $\left.J=8.8 \mathrm{~Hz}, 2 \mathrm{H}\right)$, $7.71(\mathrm{~d}, J=8.8 \mathrm{~Hz}, 1 \mathrm{H}), 7.58(\mathrm{~d}, J=8.8 \mathrm{~Hz}, 2 \mathrm{H}), 7.49-7.52(\mathrm{~m}, 1 \mathrm{H}), 7.46-7.48(\mathrm{~m}, 1 \mathrm{H}), 6.53(\mathrm{~s}$, $1 \mathrm{H}), 4.30(\mathrm{t}, J=5.6 \mathrm{~Hz}, 2 \mathrm{H}), 3.59(\mathrm{t}, J=4.4 \mathrm{~Hz}, 4 \mathrm{H}), 2.73(\mathrm{t}, J=5.6 \mathrm{~Hz}, 2 \mathrm{H}), 2.49-2.51(\mathrm{~m}, 4 \mathrm{H})$, $1.30(\mathrm{~s}, 9 \mathrm{H}) .{ }^{13} \mathrm{C}$ NMR $\left(101 \mathrm{MHz}, d^{6}\right.$-DMSO) $\delta 180.7,160.1,158.8,151.8,146.7,139.4,131.4$, 127.3, 126.9, 126.6, 126.4, 124.9, 124.1, 123.0 (q, J = 272.4 Hz), 119.2, 113.9 (q, $J=5.4 \mathrm{~Hz}), 92.9$, 66.9, 66.6, 57.3, 54.0, 33.0, 28.8. ESI-MS $m / z 600.2(\mathrm{M}+\mathrm{H})^{+}$. HRMS calcd for $\mathrm{C}_{29} \mathrm{H}_{33} \mathrm{~F}_{3} \mathrm{~N}_{7} \mathrm{O}_{4}{ }^{+}(\mathrm{M}$ $+\mathrm{H})^{+}$required 600.2541, found 600.2539. HPLC analysis: $\mathrm{MeOH} / \mathrm{H}_{2} \mathrm{O}(72: 28)$, RetTime: 6.4 min; purity: $95.7 \%$.

1-(4-(1-(2-bromo-4-(2-morpholinoethoxy)phenyl)-1H-1,2,3-triazol-4-yl)phenyl)-3-(5-(tertbutyl)isoxazol-3-yl)urea (Compound 26):

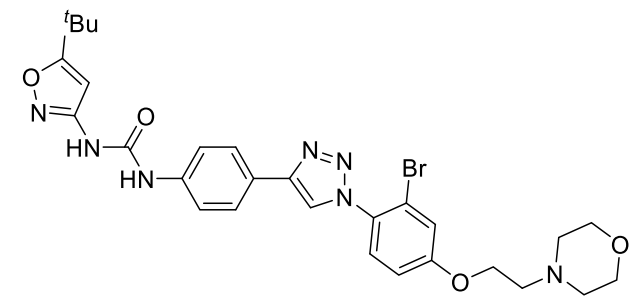

${ }^{1} \mathrm{H}$ NMR (400 MHz, $d^{6}$-DMSO) $\delta 9.57(\mathrm{~s}, 1 \mathrm{H}), 8.96(\mathrm{~s}, 1 \mathrm{H}), 8.84(\mathrm{~s}, 1 \mathrm{H}), 7.88(\mathrm{~d}, J=8.7 \mathrm{~Hz}, 2 \mathrm{H})$, 7.56-7.63 (m, 3H), $7.51(\mathrm{~d}, J=2.7 \mathrm{~Hz}, 1 \mathrm{H}), 7.21(\mathrm{dd}, J=8.7 \mathrm{~Hz}, J=2.7 \mathrm{~Hz}, 1 \mathrm{H}), 6.53(\mathrm{~s}, 1 \mathrm{H}), 4.24$ $(\mathrm{t}, J=5.7 \mathrm{~Hz}, 2 \mathrm{H}), 3.60(\mathrm{t}, J=5.7 \mathrm{~Hz}, 4 \mathrm{H}), 2.73(\mathrm{t}, J=5.7 \mathrm{~Hz}, 2 \mathrm{H}), 2.49-2.51(\mathrm{~m}, 4 \mathrm{H}), 1.31(\mathrm{~s}, 9 \mathrm{H})$. ${ }^{13} \mathrm{C}$ NMR (101 MHz, $d^{6}$-DMSO) $\delta 180.7,160.5,158.8,151.8,146.6,139.3,129.8,129.7,126.4$, 125.0, 123.6, 120.4, 119.3, 119.2, 115.4, 92.9, 66.8, 66.6, 57.3, 54.0, 33.0, 28.8. ESI-MS m/z 610.2 $(\mathrm{M}+\mathrm{H})^{+}$. HRMS calcd for $\mathrm{C}_{28} \mathrm{H}_{33} \mathrm{BrN}_{7} \mathrm{O}_{4}{ }^{+}(\mathrm{M}+\mathrm{H})^{+}$required 610.1772, found 610.1760. HPLC analysis: $\mathrm{MeOH} / \mathrm{H}_{2} \mathrm{O}$ (72:28), RetTime: 6.3 min; purity: $96.3 \%$.

1-(5-(tert-butyl)isoxazol-3-yl)-3-(4-(1-(2-fluoro-4-(2-morpholinoethoxy)phenyl)-1H-1,2,3triazol-4-yl)phenyl)urea (Compound 27):

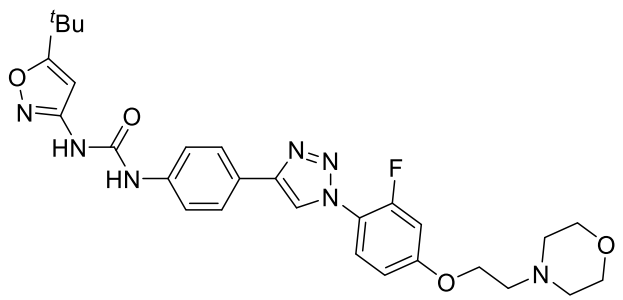

${ }^{1} \mathrm{H}$ NMR (400 MHz, $d^{6}$-DMSO) $\delta 9.58(\mathrm{~s}, 1 \mathrm{H}), 8.98(\mathrm{~s}, 1 \mathrm{H}), 8.90(\mathrm{~s}, 1 \mathrm{H}), 7.89(\mathrm{~d}, J=8.8 \mathrm{~Hz}, 2 \mathrm{H})$, $7.75(\mathrm{t}, J=8.8 \mathrm{~Hz}, 1 \mathrm{H}), 7.58(\mathrm{~d}, J=8.8 \mathrm{~Hz}, 2 \mathrm{H}), 7.22-7.25(\mathrm{~m}, 1 \mathrm{H}), 7.01-7.04(\mathrm{~m}, 1 \mathrm{H}), 6.53(\mathrm{~s}$, $1 \mathrm{H}), 4.21(\mathrm{t}, J=5.6 \mathrm{~Hz}, 2 \mathrm{H}), 3.59(\mathrm{t}, J=4.8 \mathrm{~Hz}, 4 \mathrm{H}), 2.73(\mathrm{t}, J=5.6 \mathrm{~Hz}, 2 \mathrm{H}), 2.49-2.51(\mathrm{~m}, 4 \mathrm{H})$, $1.30(\mathrm{~s}, 9 \mathrm{H}) .{ }^{13} \mathrm{C}$ NMR $\left(101 \mathrm{MHz}, d^{6}\right.$-DMSO) $\delta 180.7,160.8(\mathrm{~d}, J=10.5 \mathrm{~Hz}), 158.8,155.3(\mathrm{~d}, J=$ 
$248.3 \mathrm{~Hz}), 151.8,147.0,139.4,127.3,126.5,124.9,122.7$ (d, $J=3.0 \mathrm{~Hz}), 119.2,118.3(\mathrm{~d}, J=11.7$ $\mathrm{Hz}), 112.2(\mathrm{~d}, J=2.9 \mathrm{~Hz}), 103.8(\mathrm{~d}, J=22.9 \mathrm{~Hz}), 92.9,66.8,66.6,57.2,54.0,33.0,28.8$. ESI-MS $\mathrm{m} / \mathrm{z} 550.2(\mathrm{M}+\mathrm{H})^{+}$. HRMS calcd for $\mathrm{C}_{28} \mathrm{H}_{33} \mathrm{FlN}_{7} \mathrm{O}_{4}{ }^{+}(\mathrm{M}+\mathrm{H})^{+}$required 550.2573, found 550.2570. HPLC analysis: $\mathrm{MeOH} / \mathrm{H}_{2} \mathrm{O}$ (72:28), RetTime: 6.1 min; purity: 99.6\%.

1-(5-(tert-butyl)isoxazol-3-yl)-3-(4-(1-(2-chloro-4-(2-morpholinoethoxy)phenyl)-1H-1,2,3triazol-4-yl)phenyl)urea (Compound 28):

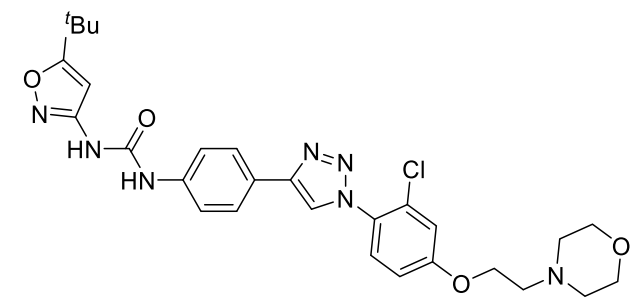

${ }^{1} \mathrm{H}$ NMR (400 MHz, $d^{6}$-DMSO) $\delta 9.56(\mathrm{~s}, 1 \mathrm{H}), 8.95(\mathrm{~s}, 1 \mathrm{H}), 8.87(\mathrm{~s}, 1 \mathrm{H}), 7.88(\mathrm{~d}, J=8.8 \mathrm{~Hz}, 2 \mathrm{H})$, $7.65(\mathrm{~d}, J=8.8 \mathrm{~Hz}, 1 \mathrm{H}), 7.58(\mathrm{~d}, J=8.8 \mathrm{~Hz}, 2 \mathrm{H}), 7.39(\mathrm{~d}, J=2.8 \mathrm{~Hz}, 1 \mathrm{H}), 7.16(\mathrm{dd}, J=8.8 \mathrm{~Hz}, J$ $=2.8 \mathrm{~Hz}, 1 \mathrm{H}), 6.53(\mathrm{~s}, 1 \mathrm{H}), 4.24(\mathrm{t}, J=6.4 \mathrm{~Hz}, 2 \mathrm{H}), 3.60(\mathrm{t}, J=4.8 \mathrm{~Hz}, 4 \mathrm{H}), 2.73(\mathrm{t}, J=6.0 \mathrm{~Hz}$, $2 \mathrm{H}), 2.49-2.51(\mathrm{~m}, 4 \mathrm{H}), 1.31(\mathrm{~s}, 9 \mathrm{H}) .{ }^{13} \mathrm{C}$ NMR $\left(101 \mathrm{MHz}, d^{6}\right.$-DMSO) $\delta 180.7,160.5,158.8,151.8$, 146.7, 139.3, 130.2, 129.7, 128.0, 126.4, 125.0, 123.6, 119.2, 116.4, 115.1, 92.9, 66.8, 66.6, 57.2, 54.0, 33.0, 28.8. ESI-MS $m / z 566.2(\mathrm{M}+\mathrm{H})^{+}$. HRMS calcd for $\mathrm{C}_{28} \mathrm{H}_{33} \mathrm{ClN}_{7} \mathrm{O}_{4}{ }^{+}(\mathrm{M}+\mathrm{H})^{+}$required 566.2277, found 566.2275. HPLC analysis: $\mathrm{MeOH} / \mathrm{H}_{2} \mathrm{O}$ (72:28), RetTime: $6.3 \mathrm{~min}$; purity: $96.6 \%$.

1-(5-(tert-butyl)isoxazol-3-yl)-3-(4-(1-(2-chloro-4-(3-morpholinopropoxy)phenyl)-1H-1,2,3triazol-4-yl)phenyl)urea (Compound 29):

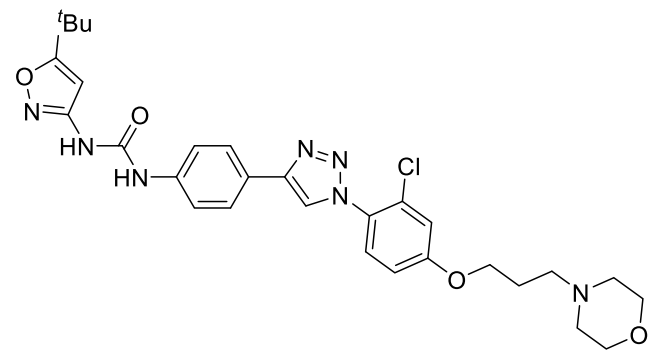

${ }^{1} \mathrm{H}$ NMR (400 MHz, $d^{6}$-DMSO) $\delta 9.59(\mathrm{~s}, 1 \mathrm{H}), 9.01(\mathrm{~s}, 1 \mathrm{H}), 8.86(\mathrm{~s}, 1 \mathrm{H}), 7.89(\mathrm{~d}, J=8.8 \mathrm{~Hz}, 2 \mathrm{H})$, $7.65(\mathrm{~d}, J=8.8 \mathrm{~Hz}, 1 \mathrm{H}), 7.58(\mathrm{~d}, J=8.8 \mathrm{~Hz}, 2 \mathrm{H}), 7.36(\mathrm{~d}, J=2.4 \mathrm{~Hz}, 1 \mathrm{H}), 7.14(\mathrm{dd}, J=8.8 \mathrm{~Hz}, 2.4$ $\mathrm{Hz}, 1 \mathrm{H}), 6.54(\mathrm{~s}, 1 \mathrm{H}), 4.15(\mathrm{t}, J=6.0 \mathrm{~Hz}, 2 \mathrm{H}), 3.59(\mathrm{t}, J=4.4 \mathrm{~Hz}, 4 \mathrm{H}), 2.43(\mathrm{t}, J=6.0 \mathrm{~Hz}, 2 \mathrm{H})$, 2.39-2.41 (m, 4H), 1.88-1.95 (m, 2H), 1.31 (s, 9H). ${ }^{13} \mathrm{C}$ NMR (101 MHz, $d^{6}$-DMSO) $\delta 180.7,160.6$, $158.8,151.8,146.7,139.4,130.2,129.7,127.9,126.4,125.0,123.5,119.2,116.3,114.9,92.9,67.4$, 66.7, 55.1, 53.8, 33.0, 28.8, 26.1. ESI-MS $m / z$ 580.2 $(\mathrm{M}+\mathrm{H})^{+}$. HRMS calcd for $\mathrm{C}_{29} \mathrm{H}_{35} \mathrm{ClN}_{7} \mathrm{O}_{4}{ }^{+}(\mathrm{M}$ $+\mathrm{H})^{+}$required 580.2434, found 580.2432. HPLC analysis: $\mathrm{MeOH} / \mathrm{H}_{2} \mathrm{O}$ (72:28), RetTime: $8.2 \mathrm{~min}$; purity: $99.5 \%$.

1-(5-(tert-butyl)isoxazol-3-yl)-3-(4-(1-(2-chloro-4-(2-(dimethylamino)ethoxy)phenyl)-1H1,2,3-triazol-4-yl)phenyl)urea (Compound 30):

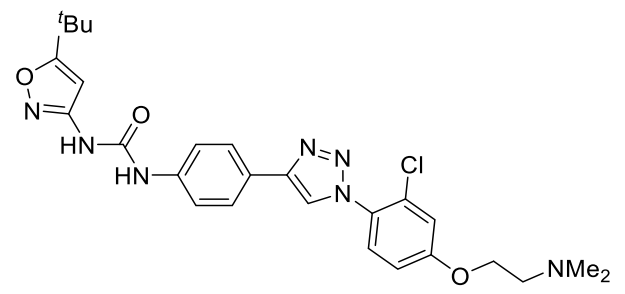

${ }^{1} \mathrm{H}$ NMR (400 MHz, $d^{6}$-DMSO) $\delta 9.57(\mathrm{~s}, 1 \mathrm{H}), 8.97(\mathrm{~s}, 1 \mathrm{H}), 8.86(\mathrm{~s}, 1 \mathrm{H}), 7.87(\mathrm{~d}, J=8.8 \mathrm{~Hz}, 2 \mathrm{H})$, $7.64(\mathrm{~d}, J=8.8 \mathrm{~Hz}, 1 \mathrm{H}), 7.56(\mathrm{~d}, J=8.8 \mathrm{~Hz}, 2 \mathrm{H}), 7.38(\mathrm{~d}, J=2.4 \mathrm{~Hz}, 1 \mathrm{H}), 7.15(\mathrm{dd}, J=8.8 \mathrm{~Hz}, 2.4$ $\mathrm{Hz}, 1 \mathrm{H}), 6.53(\mathrm{~s}, 1 \mathrm{H}), 4.19(\mathrm{t}, J=5.6 \mathrm{~Hz}, 2 \mathrm{H}), 2.65(\mathrm{t}, J=5.6 \mathrm{~Hz}, 2 \mathrm{H}), 2.23(\mathrm{~s}, 6 \mathrm{H}), 1.30(\mathrm{~s}, 9 \mathrm{H})$. 
${ }^{13} \mathrm{C}$ NMR (101 MHz, $d^{6}$-DMSO) $\delta 180.7,160.5,158.8,151.8,146.7,139.4,130.2,129.7,128.0$, 126.4, 125.0, 123.6, 119.2, 116.3, 115.0, 92.9, 67.2, 57.9, 45.9, 33.0, 28.8. ESI-MS $m / z 524.2(\mathrm{M}+$ $\mathrm{H})^{+}$. HRMS calcd for $\mathrm{C}_{26} \mathrm{H}_{31} \mathrm{ClN}_{7} \mathrm{O}_{3}{ }^{+}(\mathrm{M}+\mathrm{H})^{+}$required 524.2171, found 524.2175. HPLC analysis: $\mathrm{MeOH} / \mathrm{H}_{2} \mathrm{O} / \mathrm{Et}_{3} \mathrm{~N}$ (78:22:0.3), RetTime: $5.1 \mathrm{~min}$; purity: $96.3 \%$.

1-(5-(tert-butyl)isoxazol-3-yl)-3-(4-(1-(2-chloro-4-(2-(piperidin-1-yl)ethoxy)phenyl)-1H-1,2,3triazol-4-yl)phenyl)urea (Compound 31):

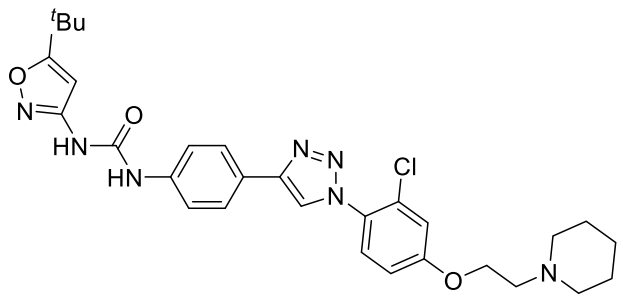

${ }^{1} \mathrm{H}$ NMR (400 MHz, $d^{6}$-DMSO) $\delta 9.56(\mathrm{~s}, 1 \mathrm{H}), 8.95(\mathrm{~s}, 1 \mathrm{H}), 8.86(\mathrm{~s}, 1 \mathrm{H}), 7.87(\mathrm{~d}, J=8.5 \mathrm{~Hz}, 2 \mathrm{H})$, $7.64(\mathrm{~d}, J=8.8 \mathrm{~Hz}, 1 \mathrm{H}), 7.57(\mathrm{~d}, J=8.5 \mathrm{~Hz}, 2 \mathrm{H}), 7.39(\mathrm{~d}, J=2.4 \mathrm{~Hz}, 1 \mathrm{H}), 7.15(\mathrm{dd}, J=8.8,2.4$ $\mathrm{Hz}, 1 \mathrm{H}), 6.52(\mathrm{~s}, 1 \mathrm{H}), 4.20(\mathrm{t}, J=5.7 \mathrm{~Hz}, 2 \mathrm{H}), 2.68(\mathrm{t}, J=5.6 \mathrm{~Hz}, 2 \mathrm{H}), 2.44(\mathrm{~s}, 4 \mathrm{H}), 1.54-1.45(\mathrm{~m}$, $4 \mathrm{H}), 1.42-1.35(\mathrm{~m}, 2 \mathrm{H}), 1.30(\mathrm{~s}, 9 \mathrm{H}) .{ }^{13} \mathrm{C}$ NMR (101 MHz, $d^{6}$-DMSO) $\delta 180.7,160.5,158.8,151.8$, 146.7, 139.3, 130.2, 129.6, 128.0, 126.4, 125.0, 123.6, 119.2, 116.4, 115.1, 92.9, 67.1, 57.6, 54.8, 33.0, 28.8, 26.1, 24.4. ESI-MS $m / z$ 564.2 $(\mathrm{M}+\mathrm{H})^{+}$. HRMS calcd for $\mathrm{C}_{29} \mathrm{H}_{35} \mathrm{ClN}_{7} \mathrm{O}_{3}{ }^{+}(\mathrm{M}+\mathrm{H})^{+}$ required 564.2484, found 564.2484. HPLC analysis: $\mathrm{MeOH} / \mathrm{H}_{2} \mathrm{O} / \mathrm{Et}_{3} \mathrm{~N}$ (78:22:0.3), RetTime: 7.3 min; purity: $95.5 \%$.

1-(5-(tert-butyl)isoxazol-3-yl)-3-(4-(1-(2-chloro-4-(2-(pyrrolidin-1-yl)ethoxy)phenyl)-1H1,2,3-triazol-4-yl)phenyl)urea (Compound 32):

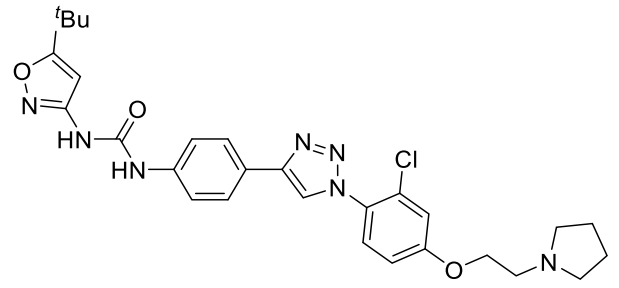

${ }^{1} \mathrm{H}$ NMR (400 MHz, $d^{6}$-DMSO) $\delta 9.58(\mathrm{~s}, 1 \mathrm{H}), 9.01(\mathrm{~s}, 1 \mathrm{H}), 8.87(\mathrm{~s}, 1 \mathrm{H}), 7.88(\mathrm{~d}, J=8.4 \mathrm{~Hz}, 2 \mathrm{H})$, $7.66(\mathrm{~d}, J=8.8 \mathrm{~Hz}, 1 \mathrm{H}), 7.58(\mathrm{~d}, J=8.8 \mathrm{~Hz}, 2 \mathrm{H}), 7.39(\mathrm{~d}, J=2.4 \mathrm{~Hz}, 1 \mathrm{H}), 7.16(\mathrm{dd}, J=8.8 \mathrm{~Hz}, J$ $=2.4 \mathrm{~Hz}, 1 \mathrm{H}), 6.53(\mathrm{~s}, 1 \mathrm{H}), 4.23(\mathrm{t}, J=5.6 \mathrm{~Hz}, 2 \mathrm{H}), 2.87(\mathrm{t}, J=5.6 \mathrm{~Hz}, 2 \mathrm{H}), 2.53-2.59(\mathrm{~m}, 4 \mathrm{H})$, $1.70-1.74(\mathrm{~m}, 4 \mathrm{H}), 1.31(\mathrm{~s}, 9 \mathrm{H}) .{ }^{13} \mathrm{C}$ NMR (101 MHz, $d^{6}$-DMSO) $\delta 180.7,160.4,158.8,151.8,146.7$, 139.4, 130.2, 129.7, 128.0, 126.4, 125.0, 123.6, 119.2, 116.3, 115.0, 92.9, 68.1, 54.4, 33.0, 28.8, 23.6. ESI-MS $m / z 550.2(\mathrm{M}+\mathrm{H})^{+}$. HRMS calcd for $\mathrm{C}_{28} \mathrm{H}_{33} \mathrm{ClN}_{7} \mathrm{O}_{3}{ }^{+}(\mathrm{M}+\mathrm{H})^{+}$required 550.2328, found 550.2330. $\mathrm{HPLC}$ analysis: $\mathrm{MeOH} / \mathrm{H}_{2} \mathrm{O} / \mathrm{Et}_{3} \mathrm{~N}$ (88:12:0.5), RetTime: $6.6 \mathrm{~min}$; purity: $95.7 \%$.

\section{Reference:}

(1) Fabian, M.A. et al. A small molecule-kinase interaction map for clinical kinase inhibitors. Nat. Biotechnol. 2005, 23, 329-336.

(2) Feldman, A. K.; Colasson, B.; Fokin, V. V. One-Pot Synthesis of 1,4-Disubstituted 1,2,3Triazoles from In Situ Generated Azides. Org. Lett. 2004, 6, 3897-3899.

(3) Chao, Q. et al. Identification of $N$-(5-tert-Butyl-isoxazol-3-yl)- $N$ '-\{4-[7-(2-morpholin-4-ylethoxy)imidazo[2,1-b][1,3]benzothiazol-2-yl]phenyl\}urea Dihydrochloride (AC220), a Uniquely Potent, Selective, and Efficacious FMS-Like Tyrosine Kinase-3 (FLT3) Inhibitor. $J$. Med. Chem. 2009, 52, 7808-7816.

(4) Bhagwat, S. et al. Imidazolothiazole Compounds for the Treatment of Disease. WO 2007/109120 
5. NMR Spectra 


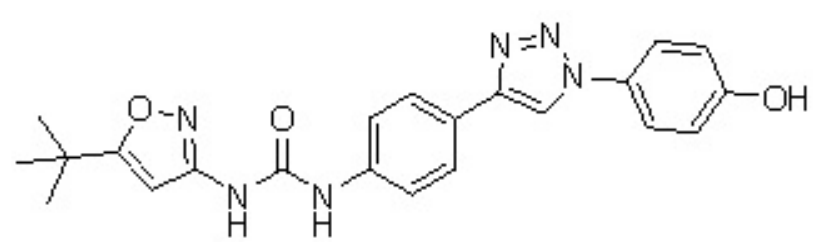

S2 a

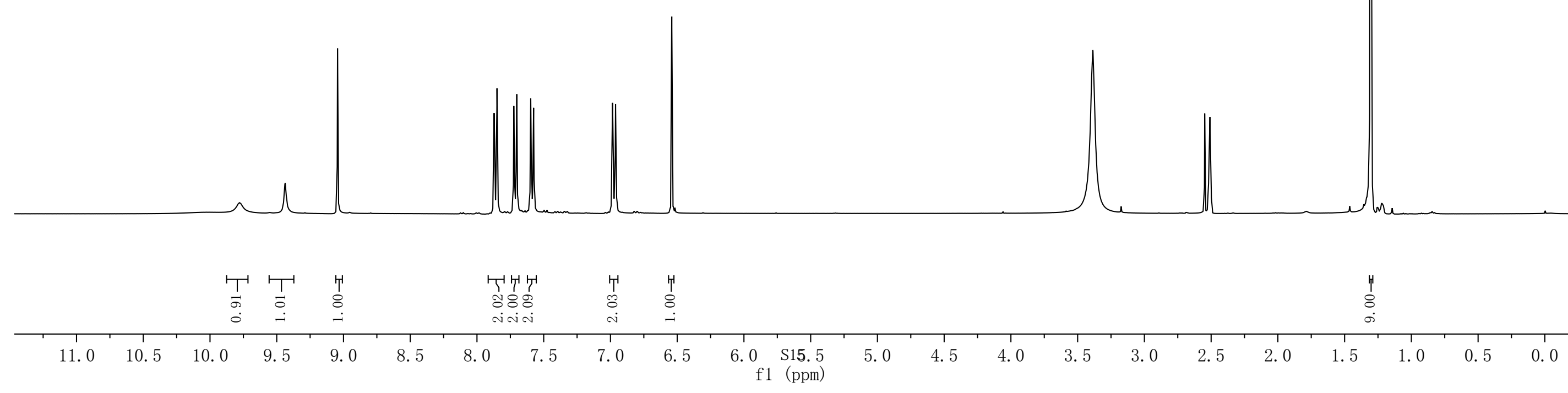




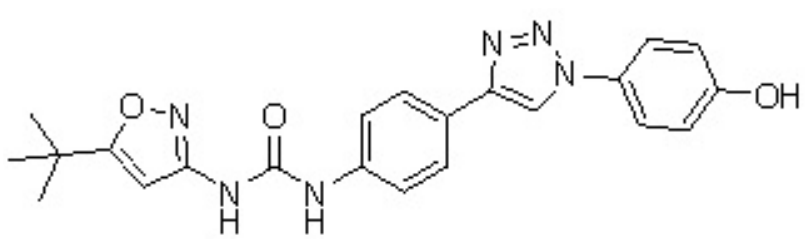

S2-a

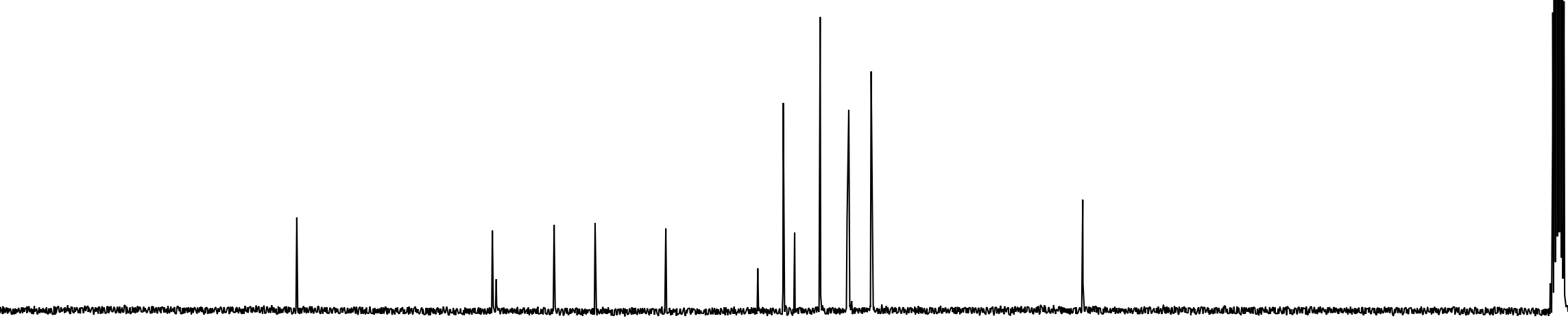


<smiles>O=[N+]([O-])c1ccc(-c2cn(-c3ccc(O)cc3)nn2)cc1</smiles>

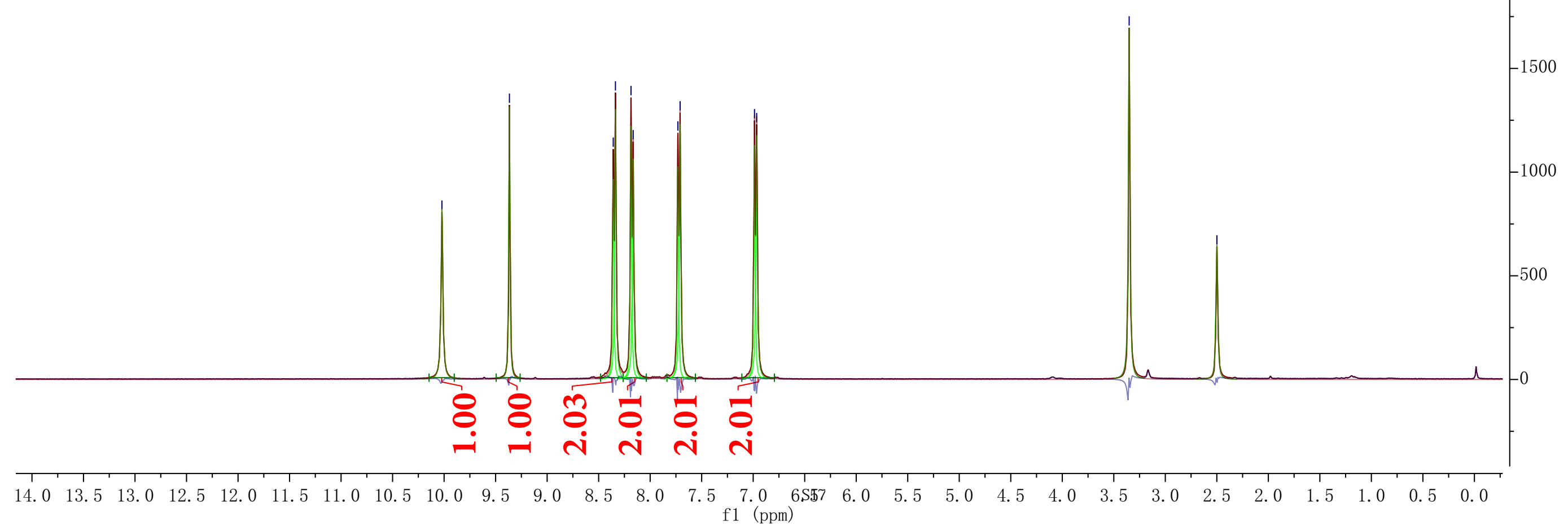


<smiles>O=[N+]([O-])c1ccc(-c2cn(-c3ccc(O)cc3)nn2)cc1</smiles>

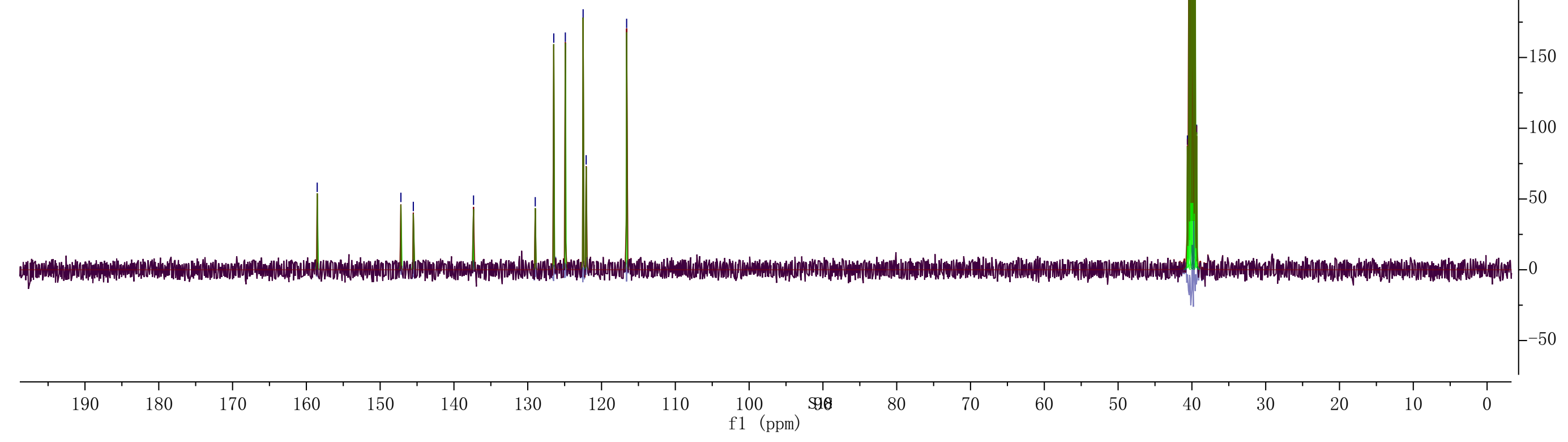




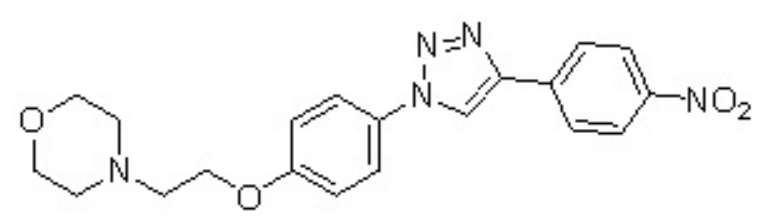

S7
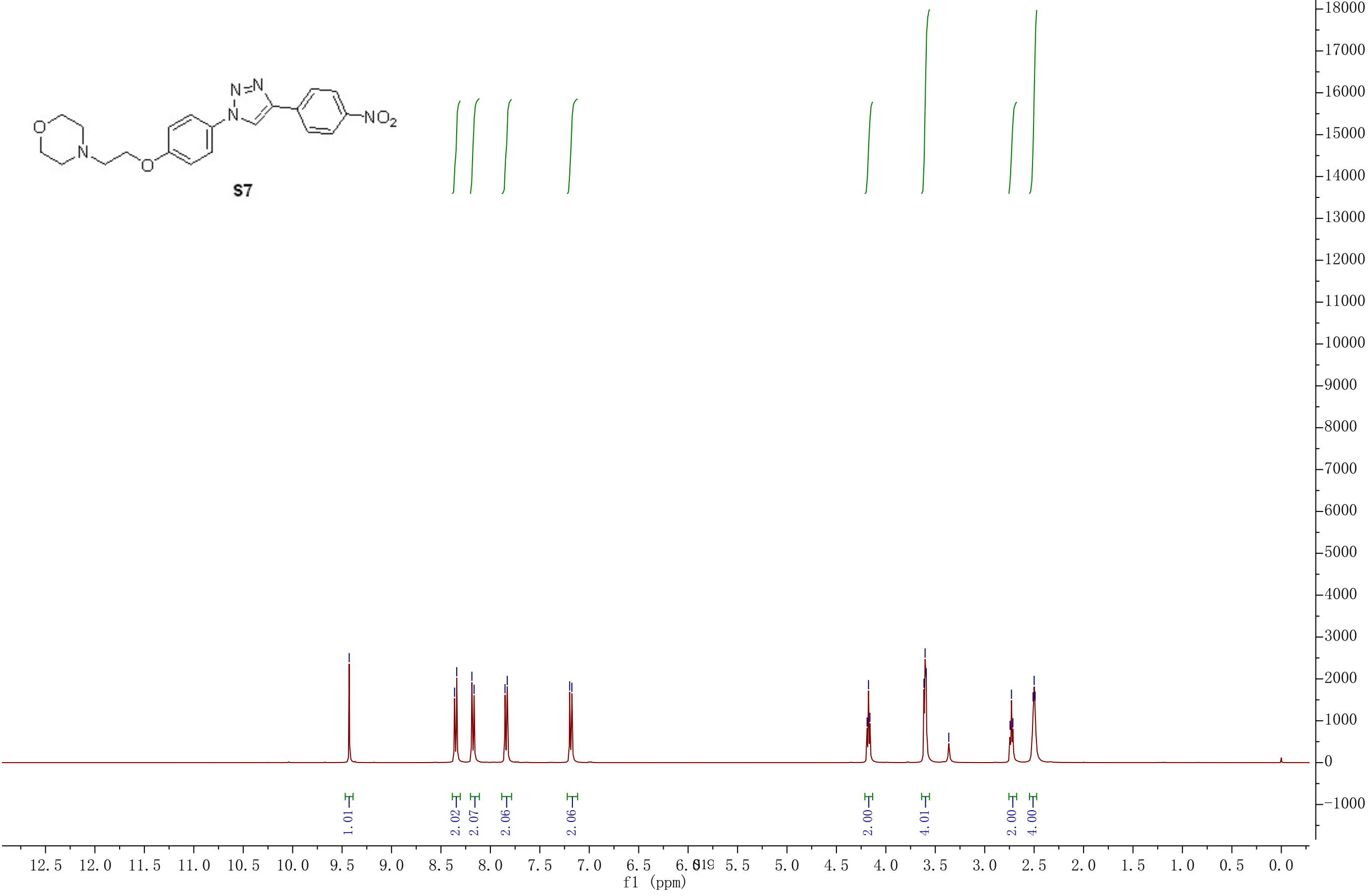


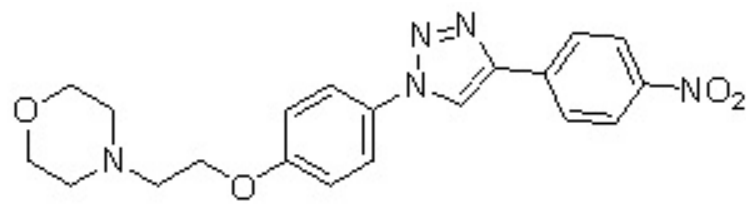

s7

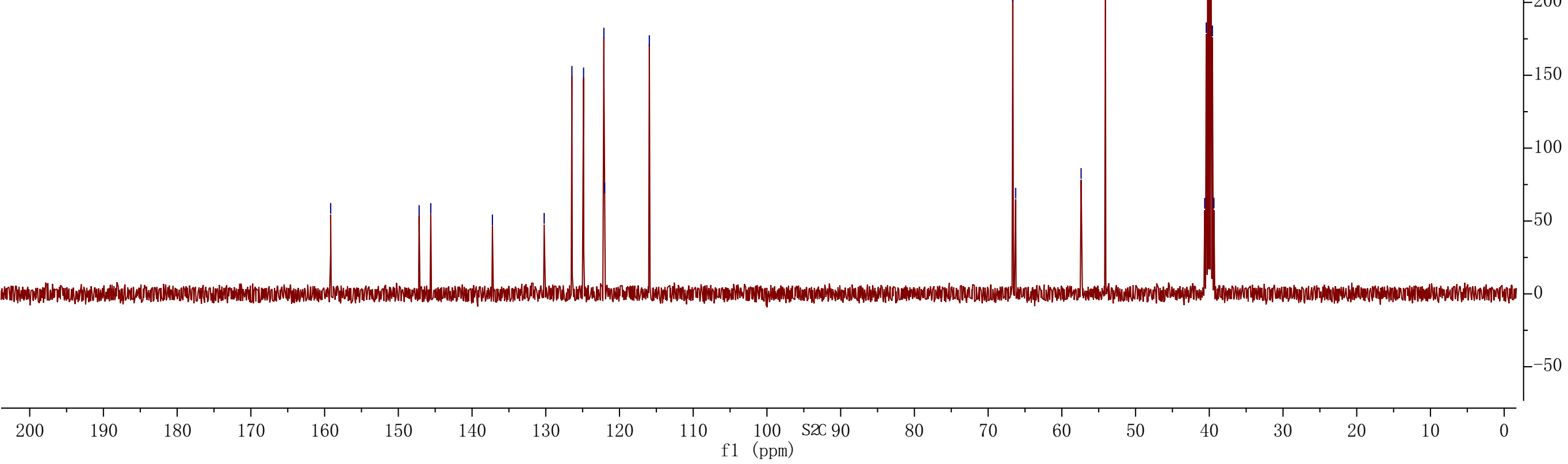


<smiles>Nc1ccc(-c2cn(-c3ccc(OCCN4CCOCC4)cc3)nn2)cc1</smiles>

\$8
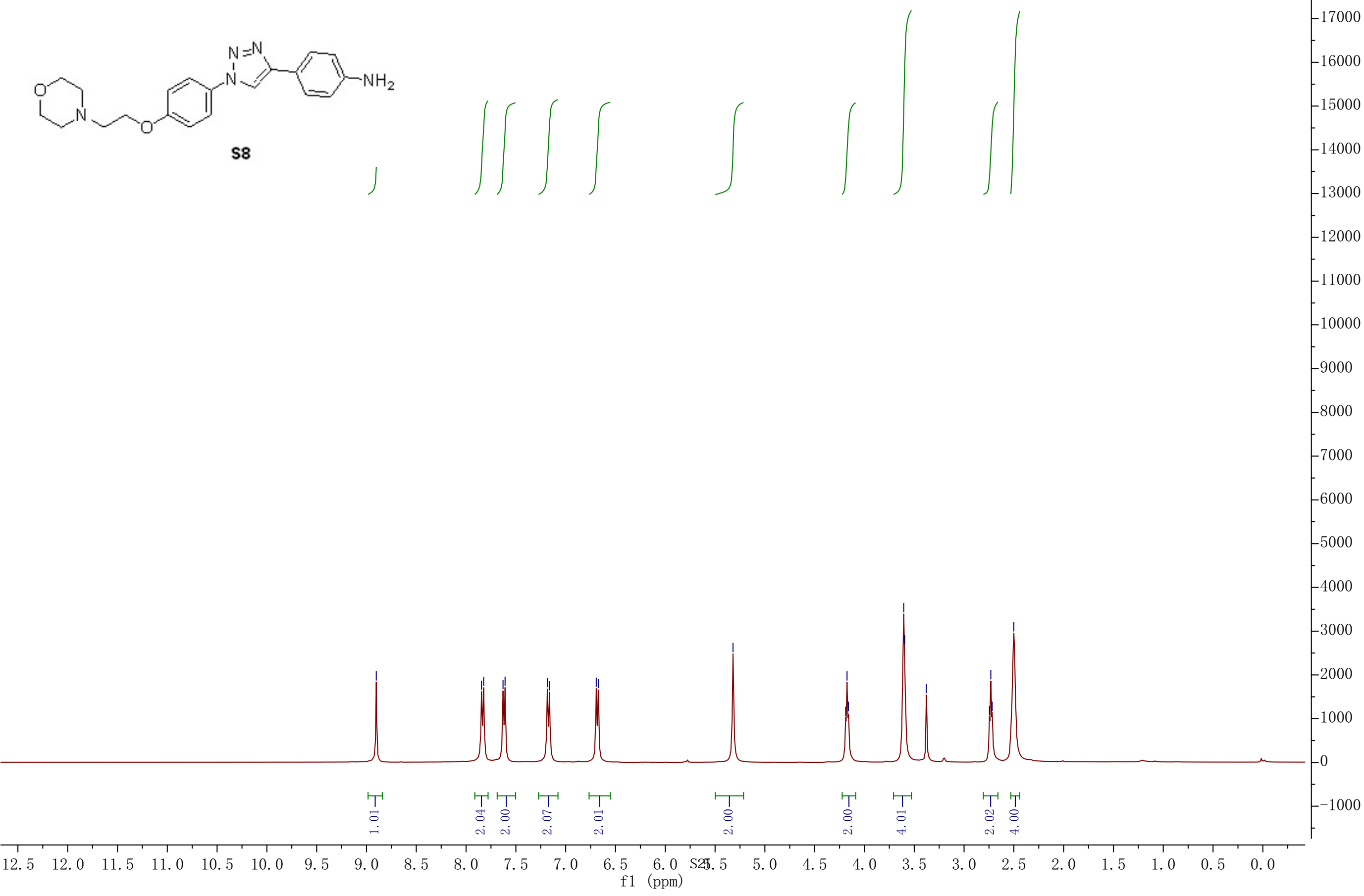

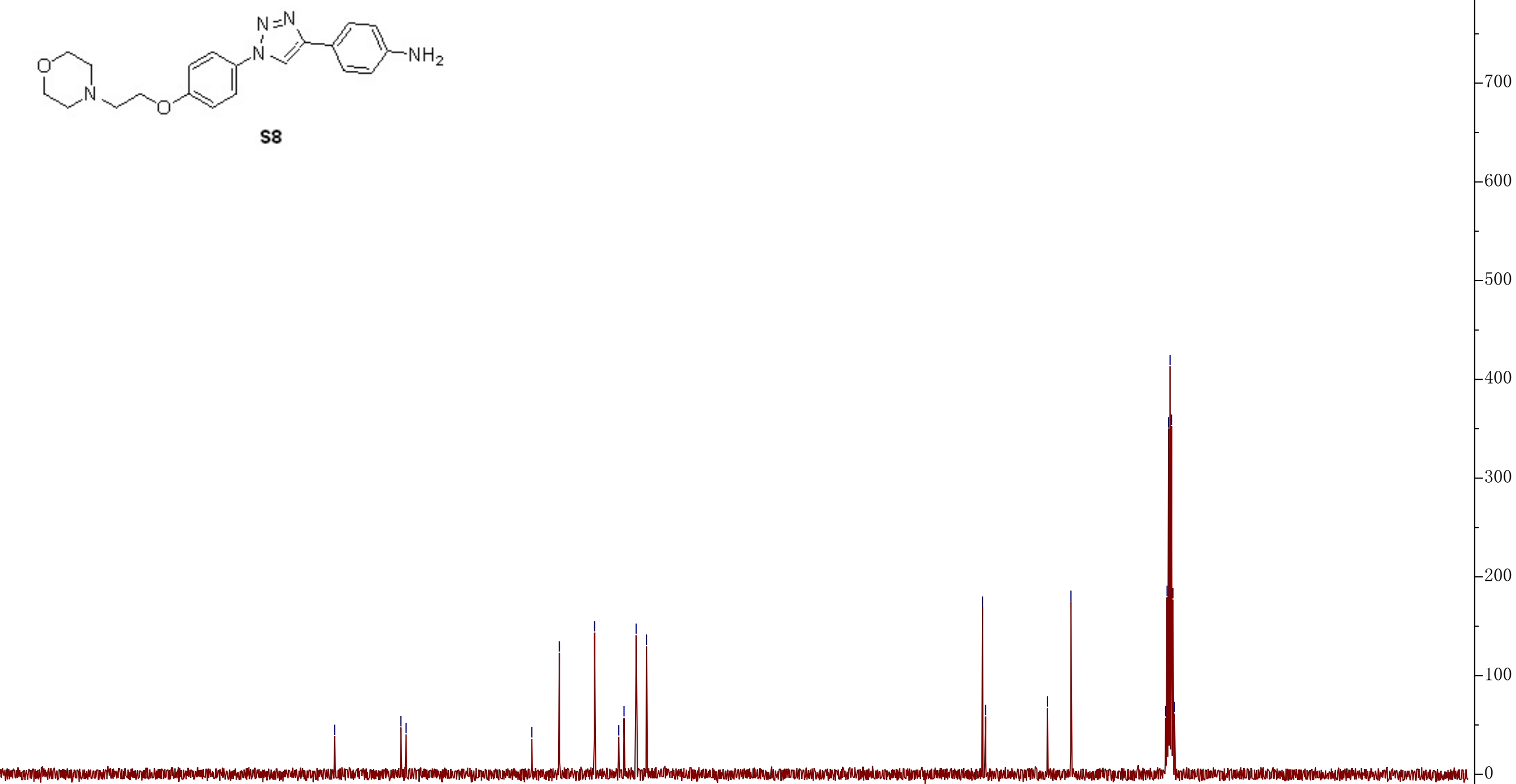

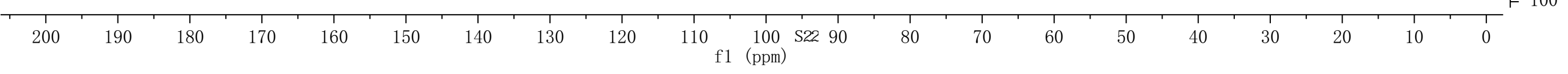



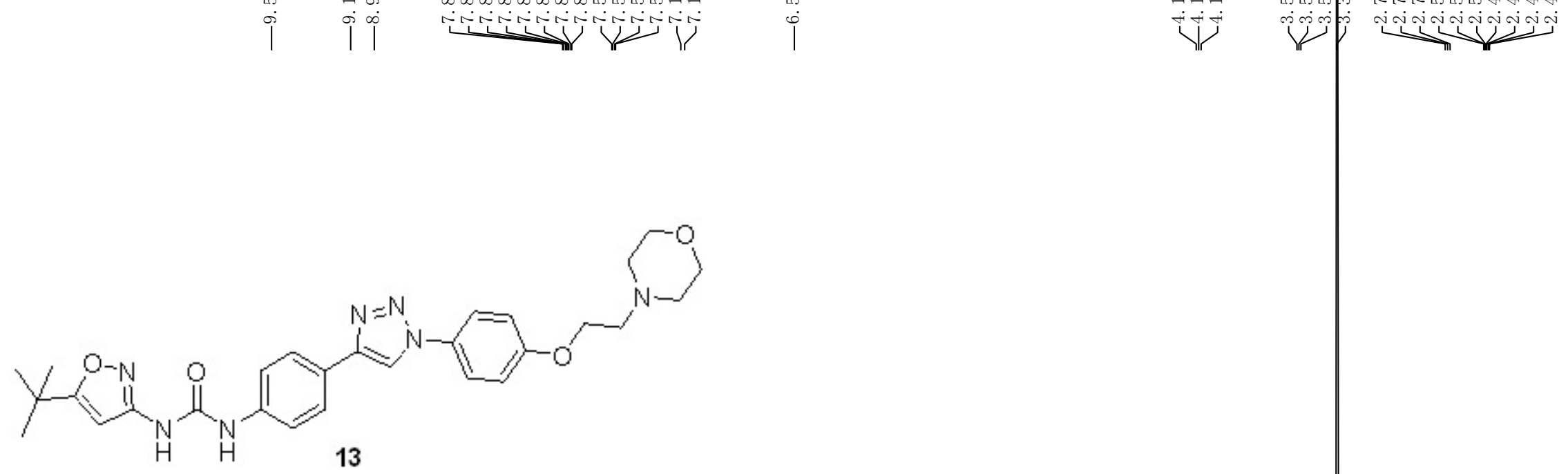

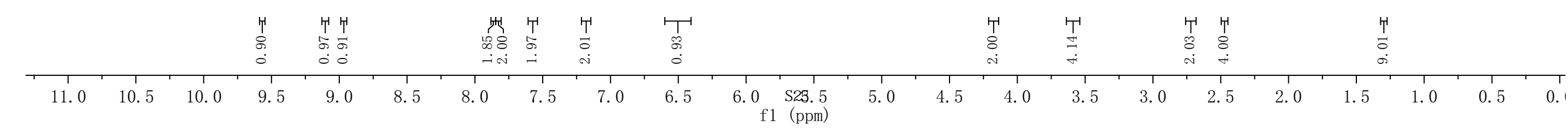



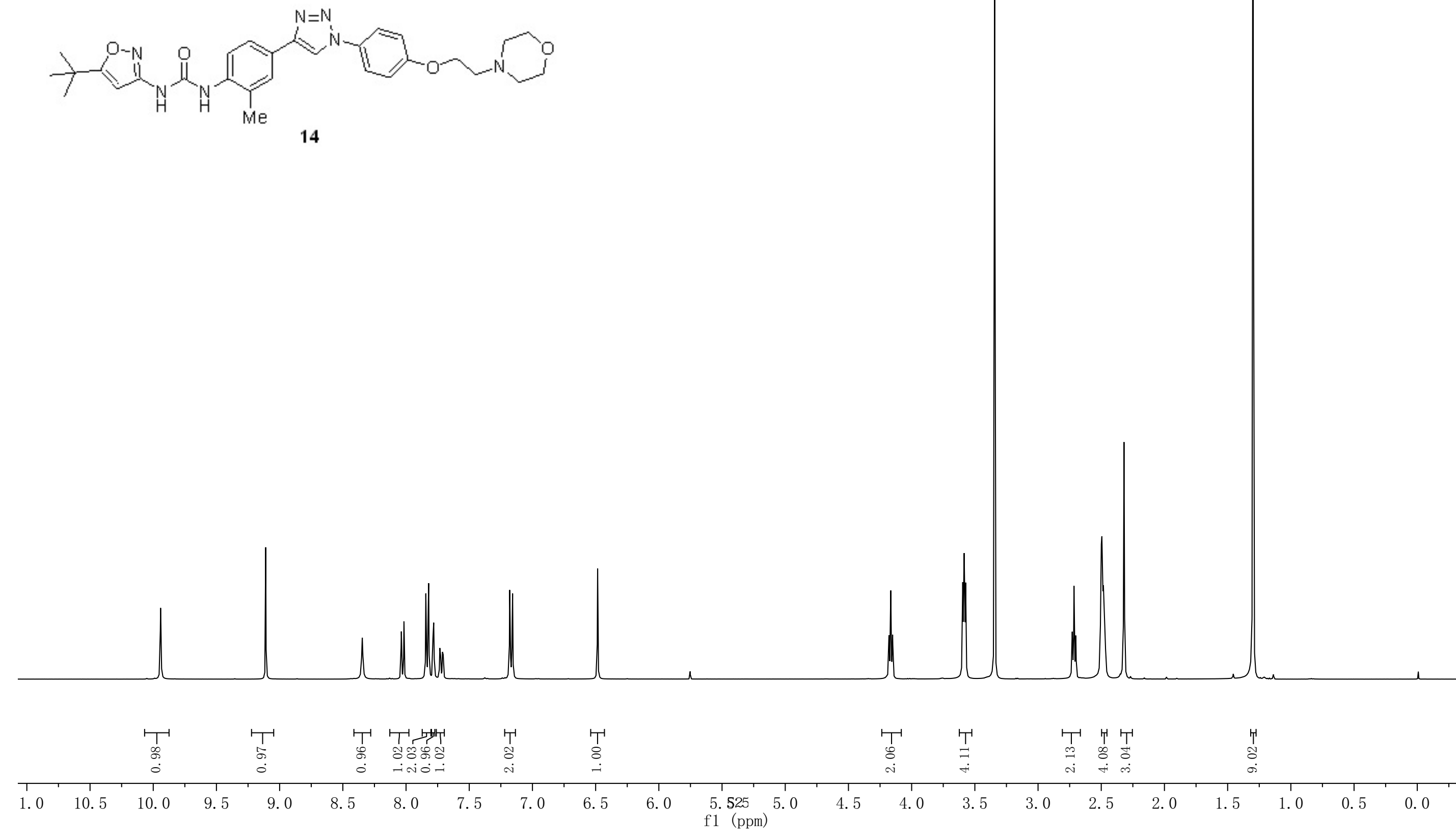


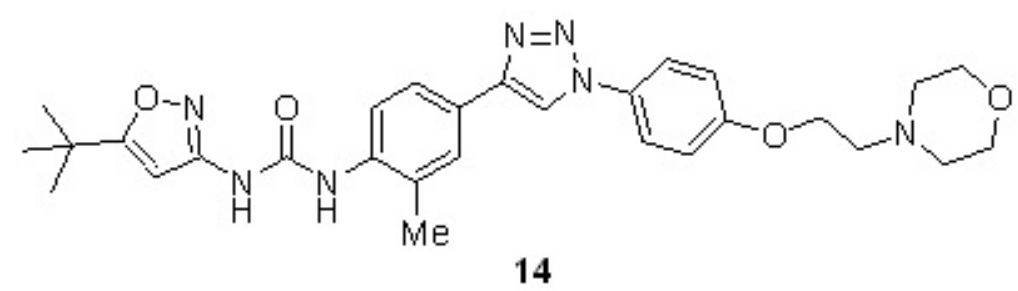

14

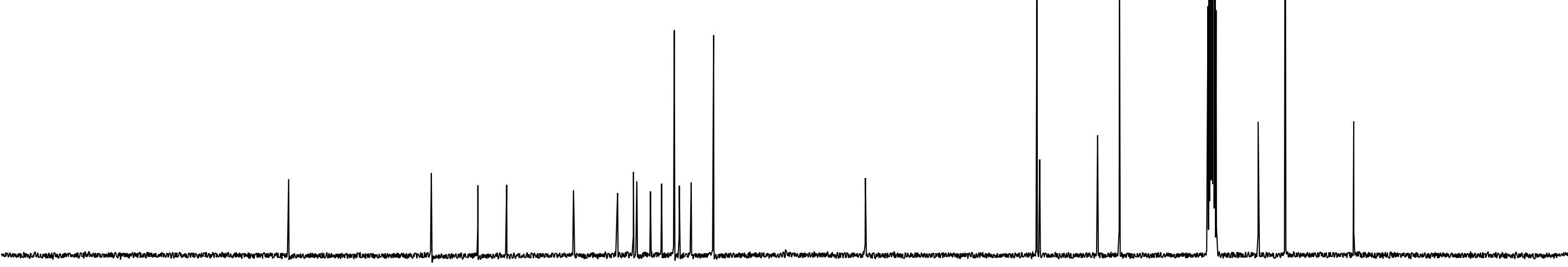




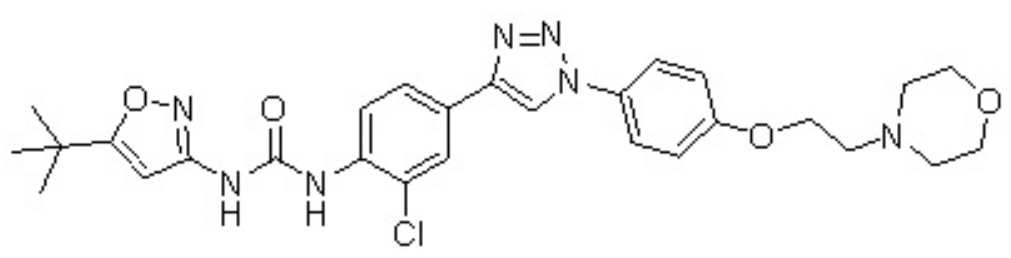

15
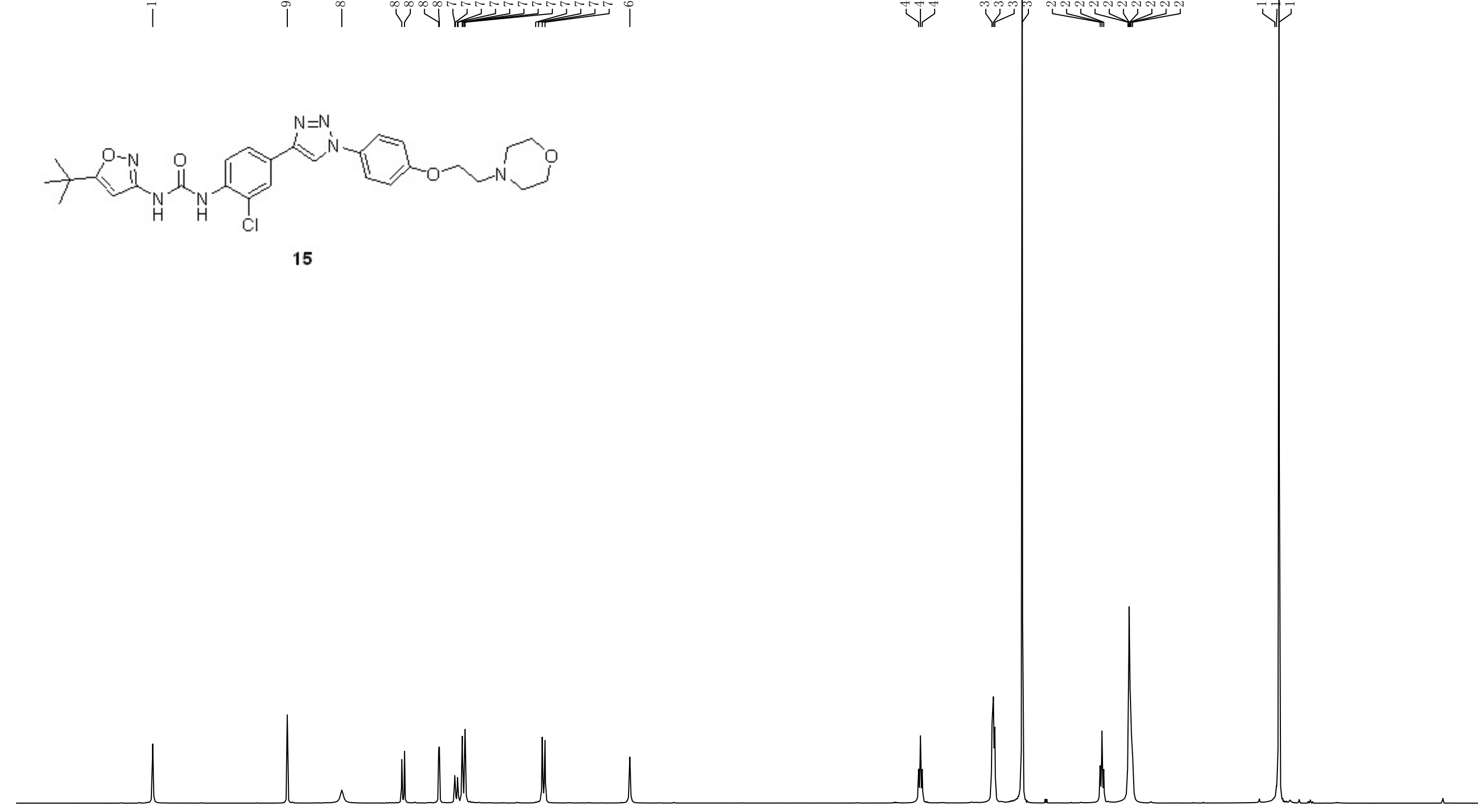

\begin{tabular}{|c|c|c|c|c|c|c|c|c|c|c|c|c|c|c|c|c|c|c|c|c|c|c|}
\hline & $\begin{array}{l}1 \\
1 \\
0 \\
0 \\
0\end{array}$ & & $\begin{array}{l}1 \\
1 \\
\infty \\
0 \\
0\end{array}$ & $\begin{array}{l}T \\
\vec{\sigma} \\
\dot{0}\end{array}$ & $\begin{array}{l}\stackrel{T}{T} \\
\overrightarrow{0} \\
\dot{-}\end{array}$ & $\begin{array}{l}\text { T' HلT } \\
5.50 \\
5000 \\
000\end{array}$ & & 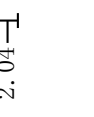 & $\begin{array}{l}\text { T' } \\
8 \\
\stackrel{-}{-}\end{array}$ & & & & & 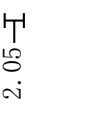 & 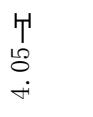 & & 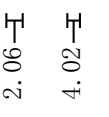 & & $\begin{array}{l}1 \\
\stackrel{1}{0} \\
0^{\circ}\end{array}$ & & & \\
\hline 11.0 & 10.5 & 10.0 & 9.5 & 9.0 & 8.5 & 8.0 & 7.5 & 7.0 & 6.5 & 6.0 & $\begin{array}{l}\text { \$2 } 25 \\
(\mathrm{ppm})\end{array}$ & 5.0 & 4.5 & 4.0 & 3.5 & 3.0 & 2.5 & 2.0 & 1.5 & 1.0 & 0.5 & 0.0 \\
\hline
\end{tabular}



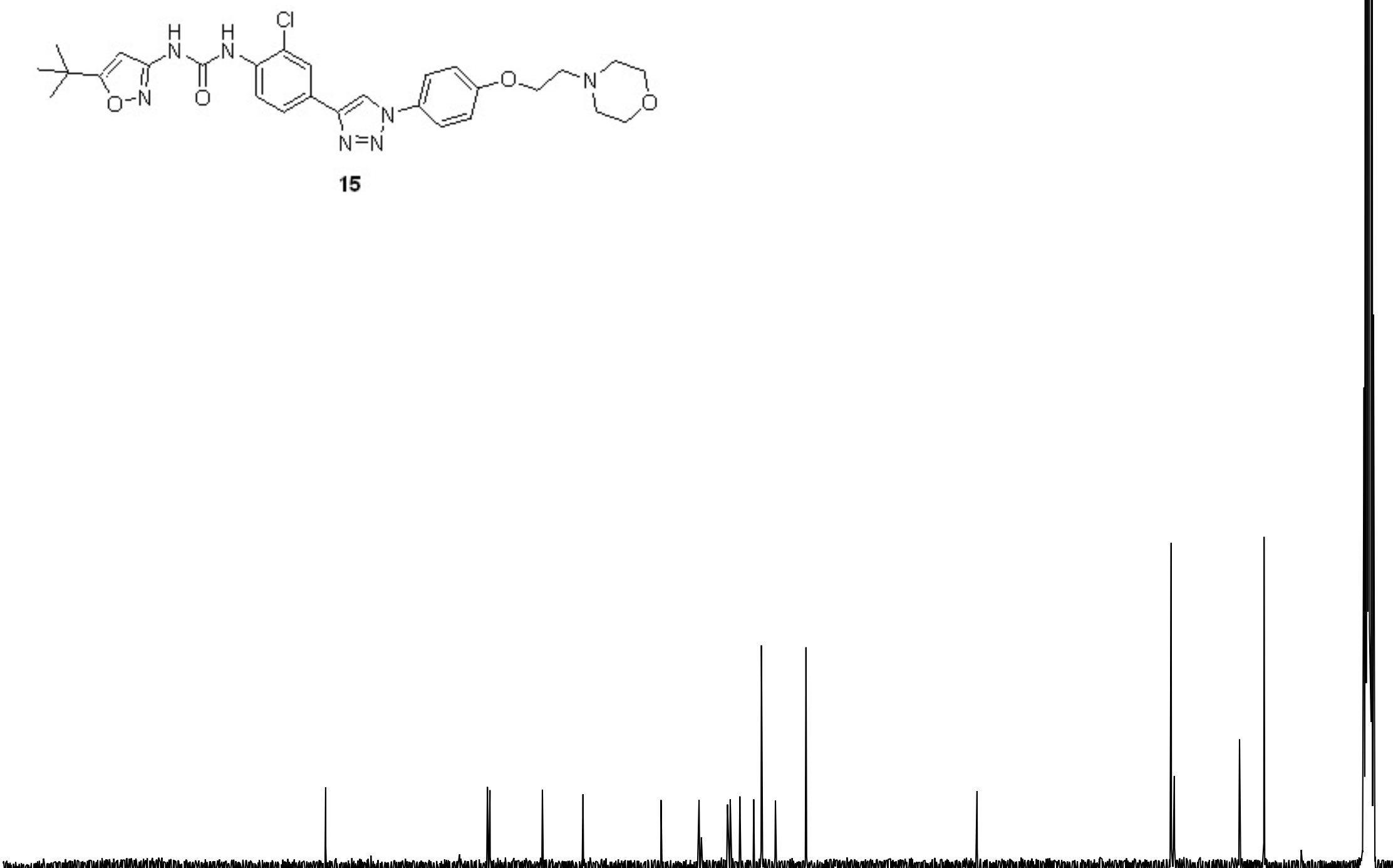

ming

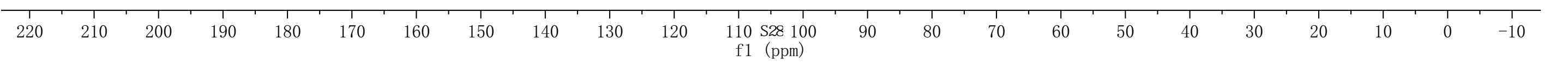




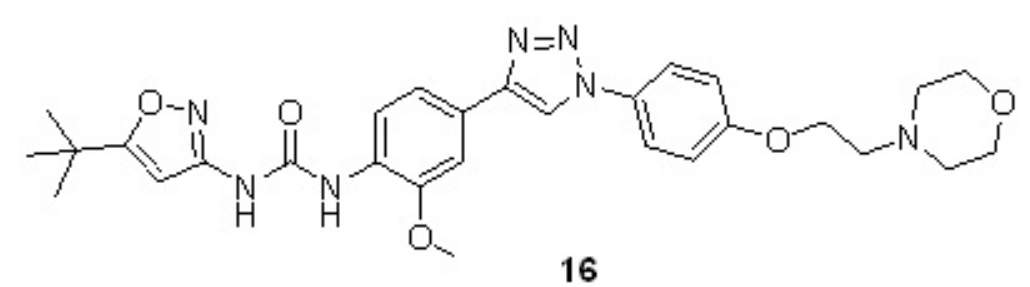

16

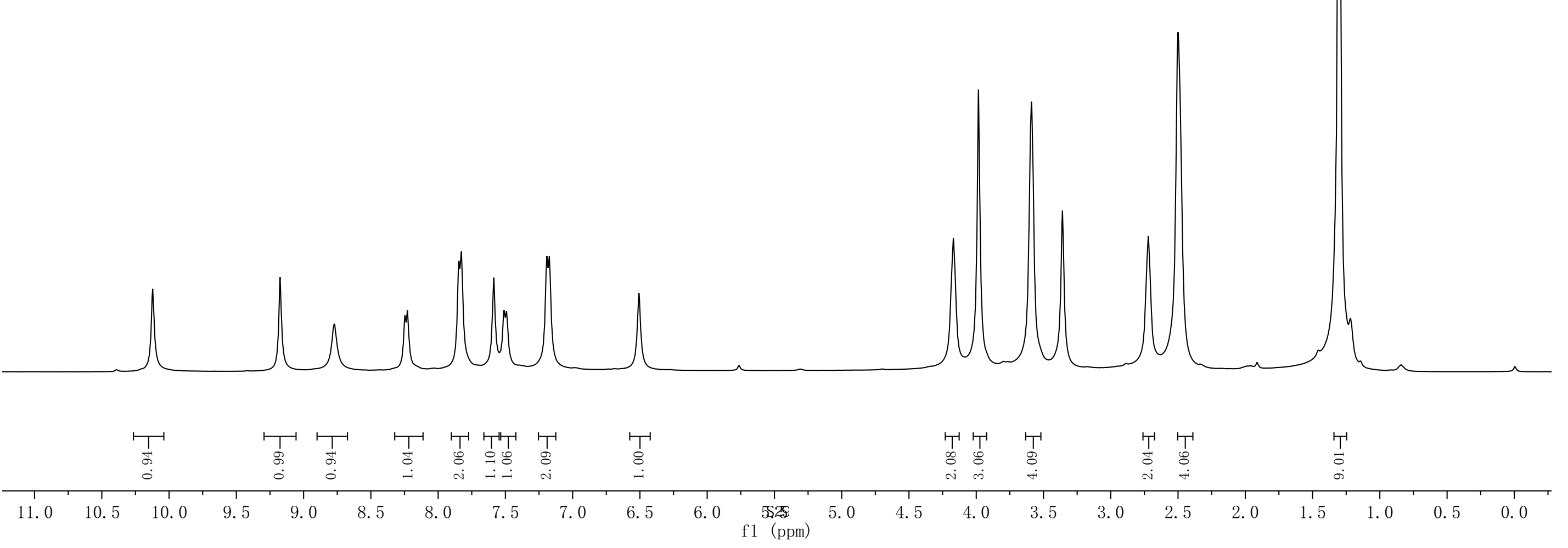




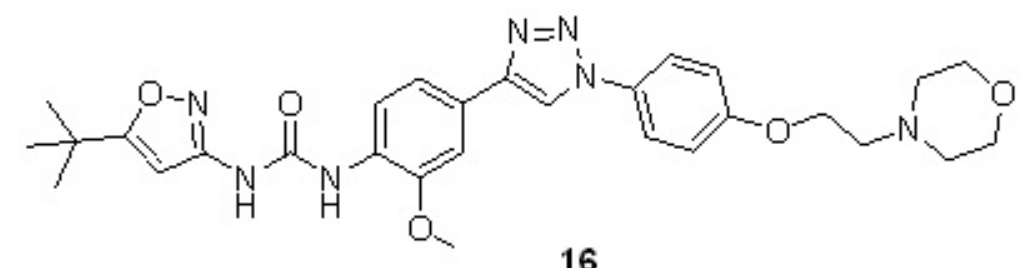

16

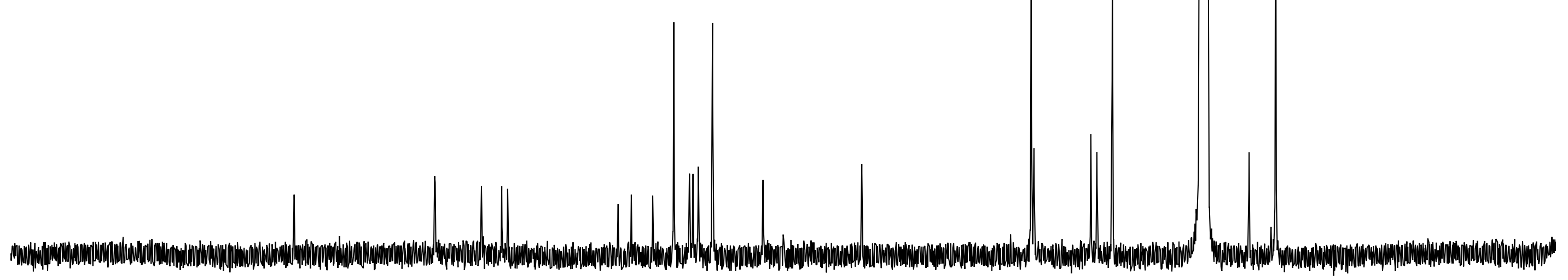

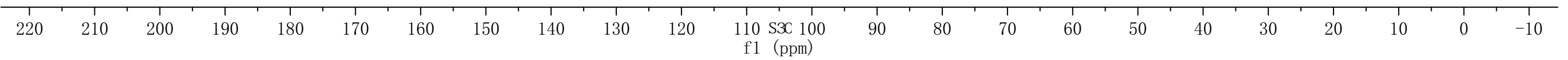



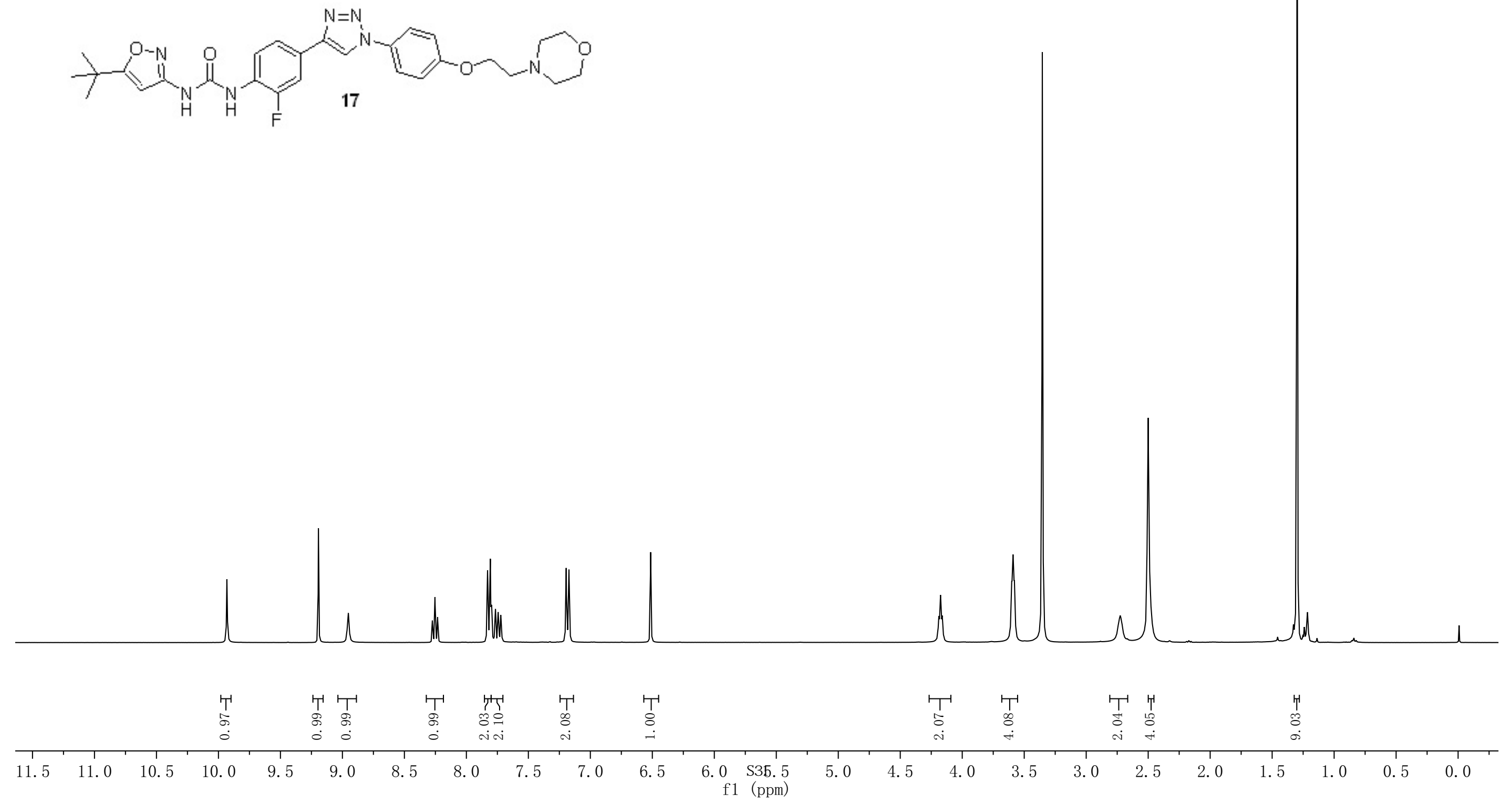

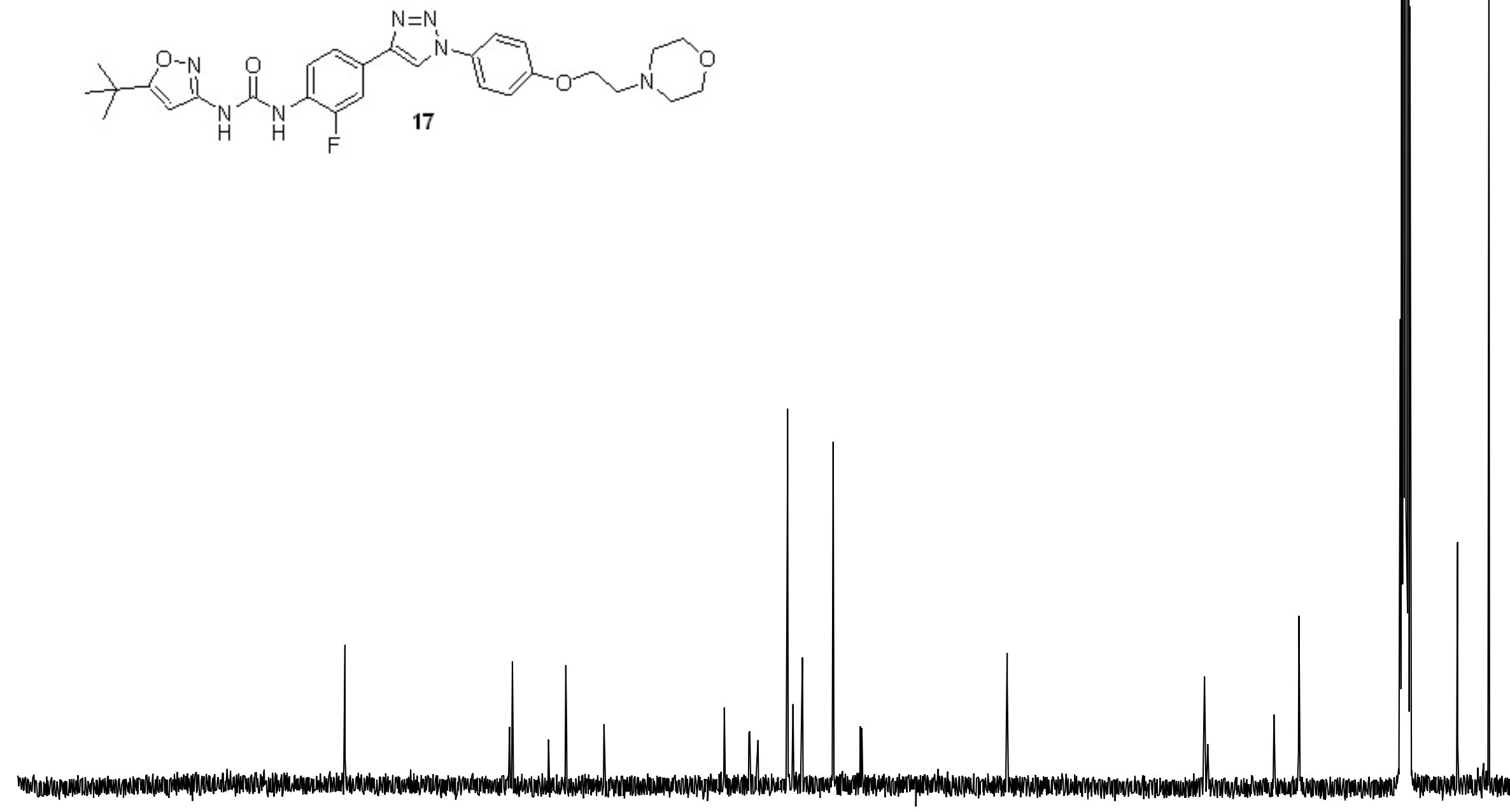

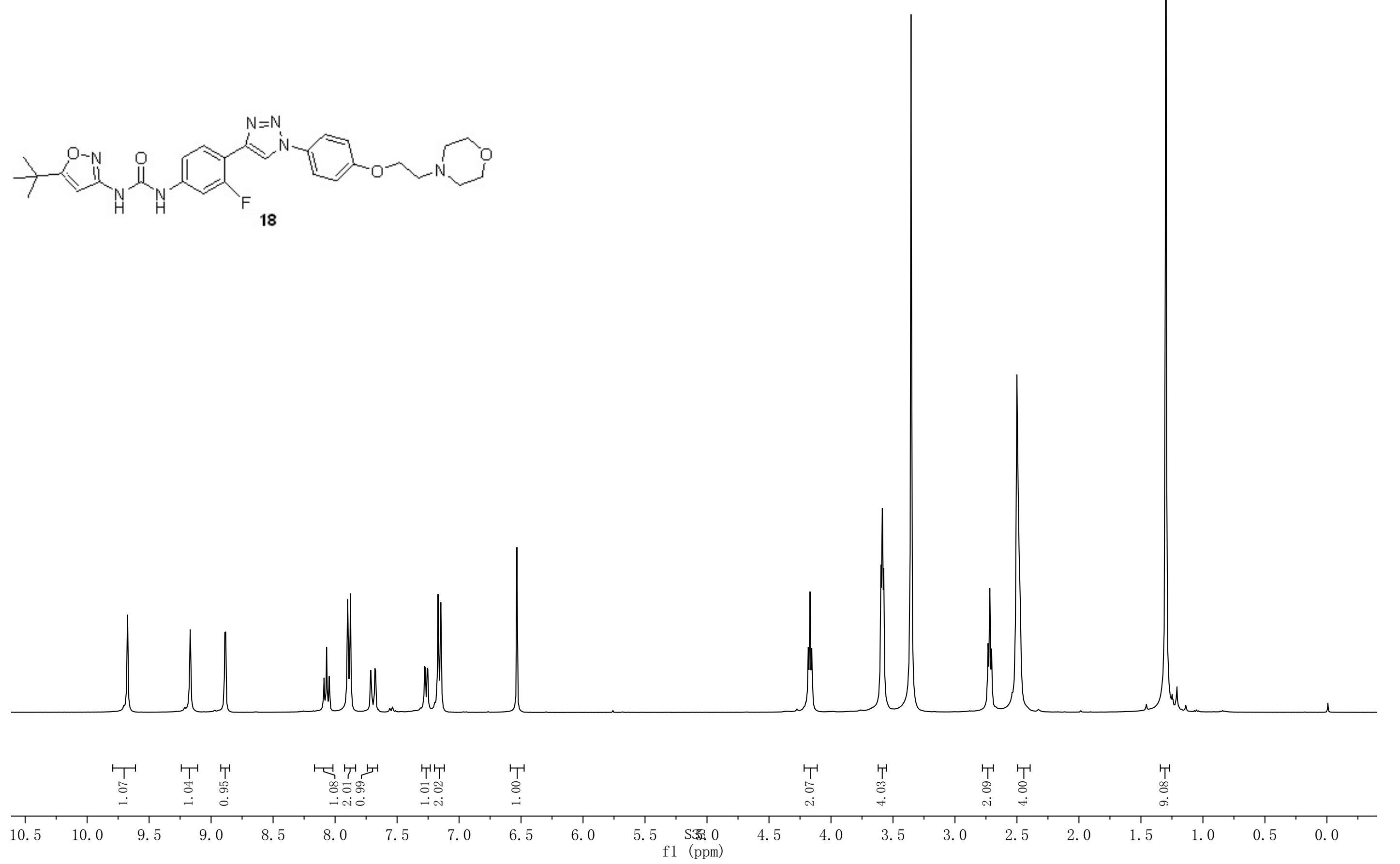

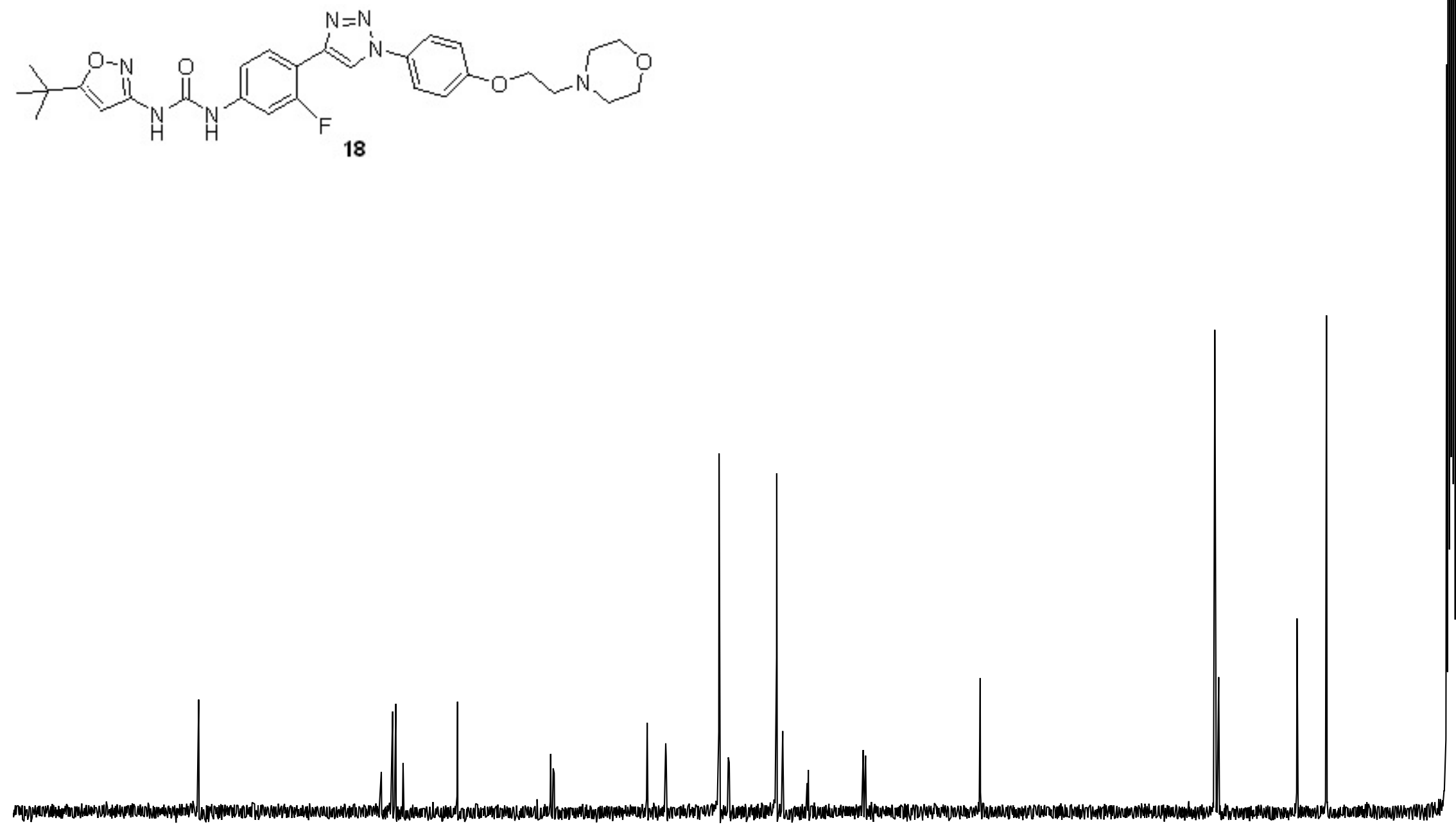

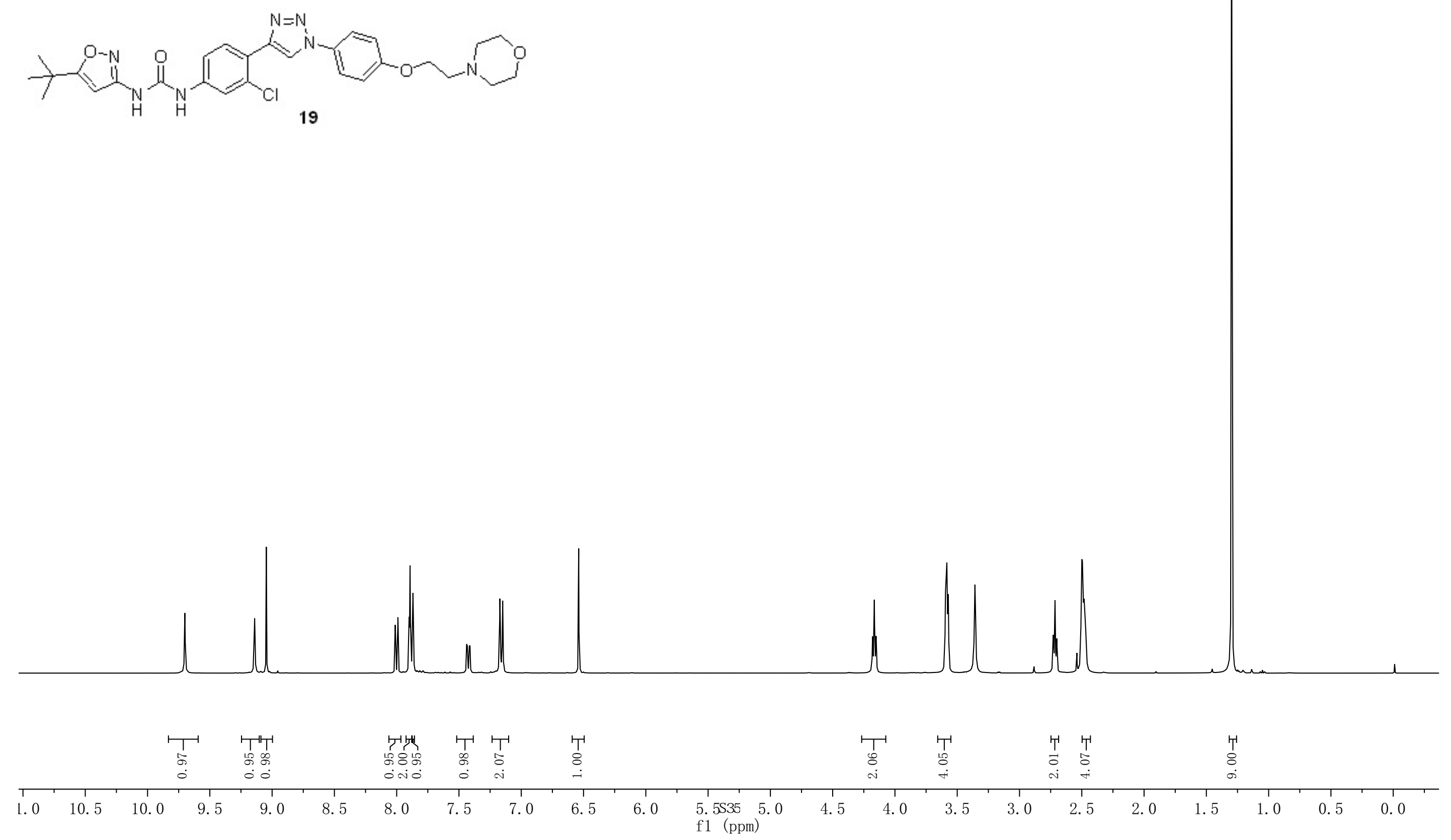


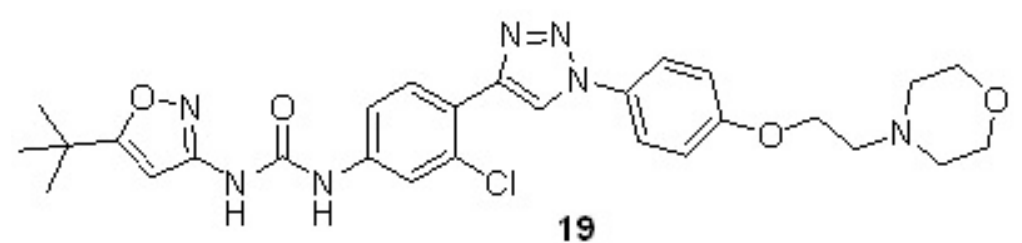

19
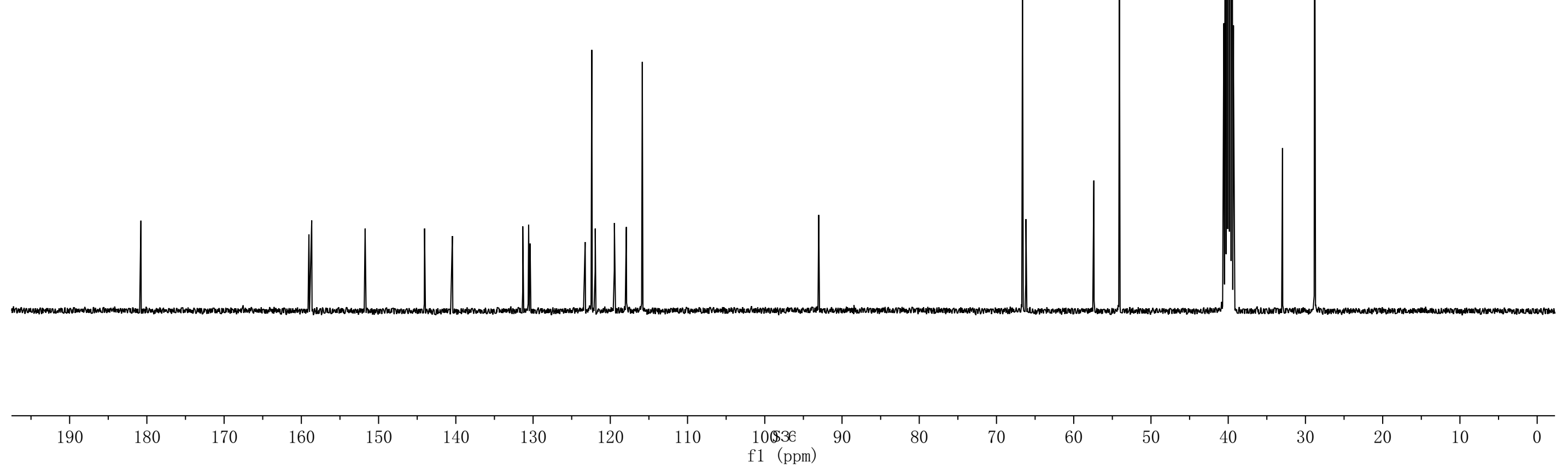


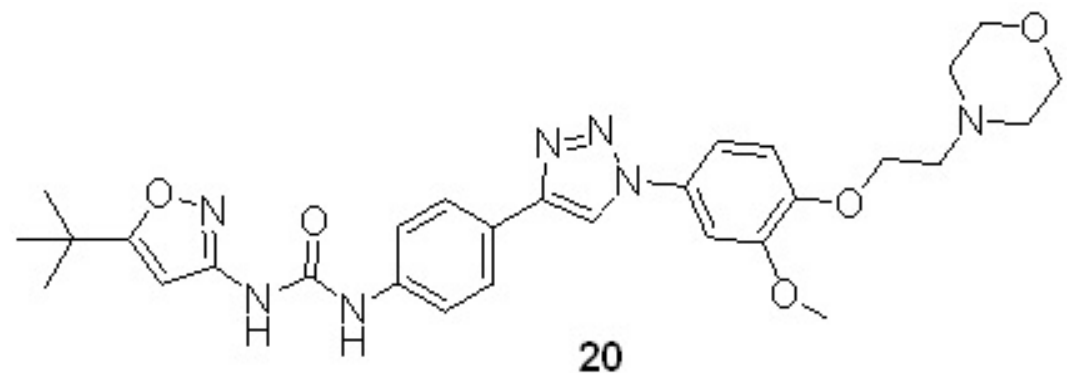

20

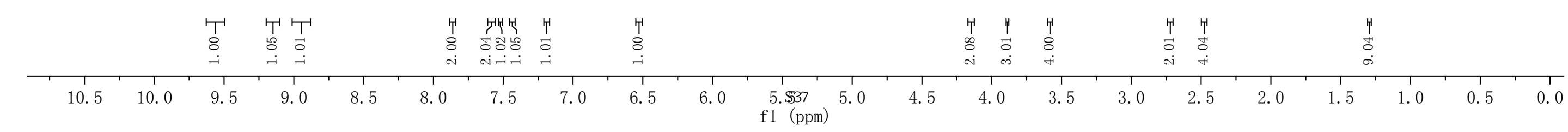




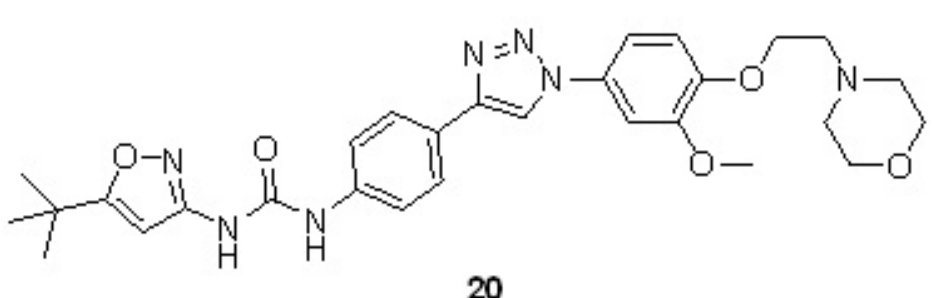

20

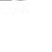
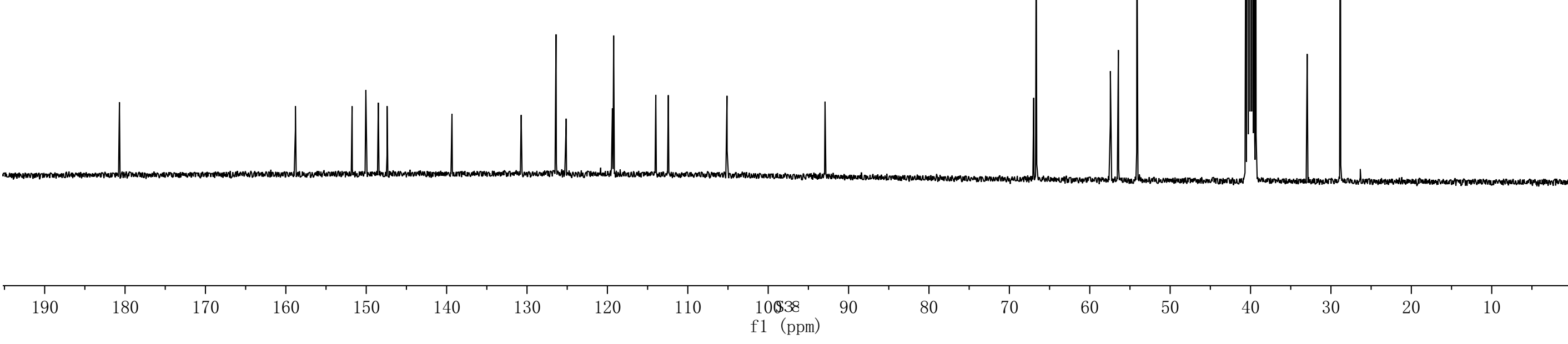

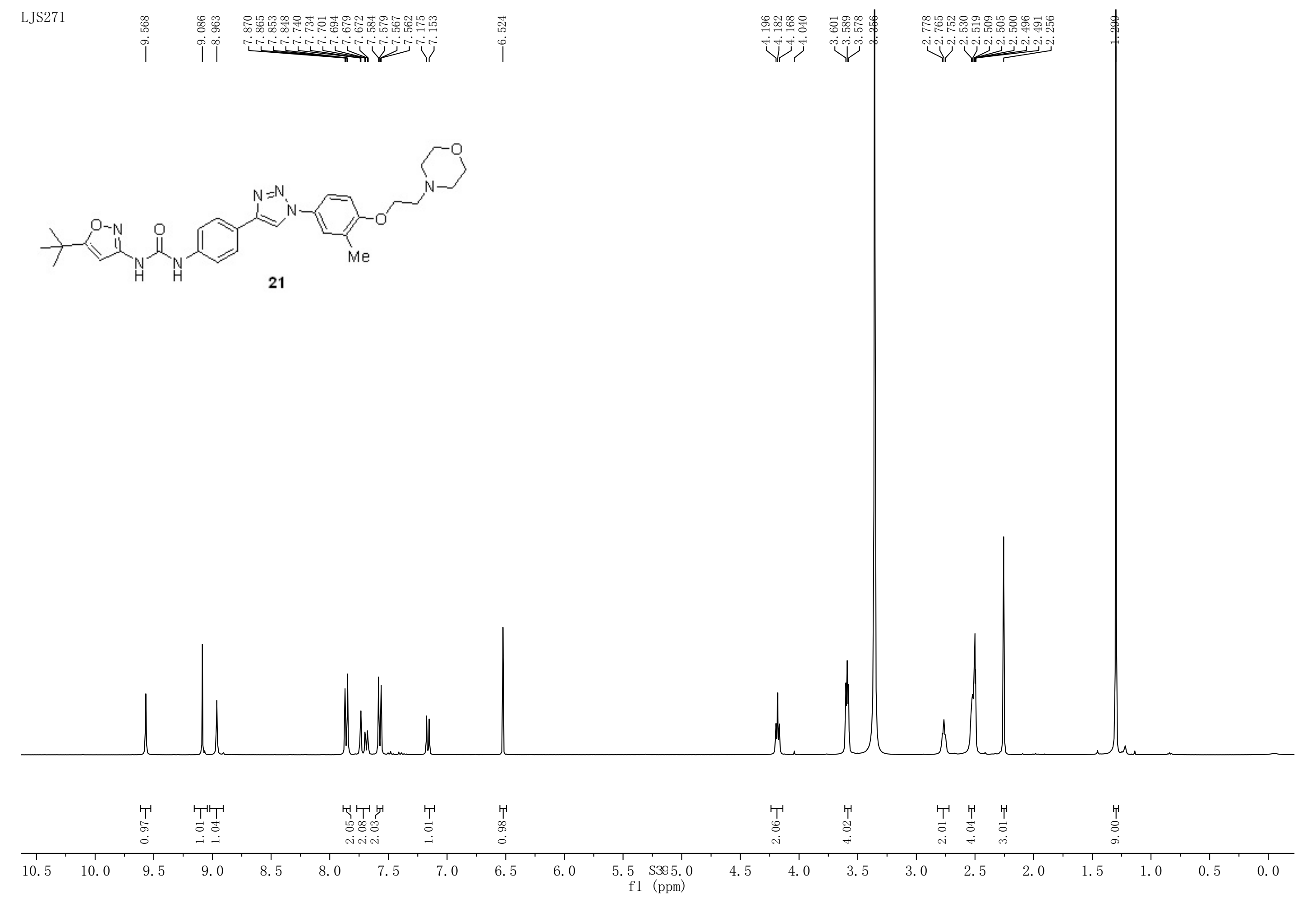


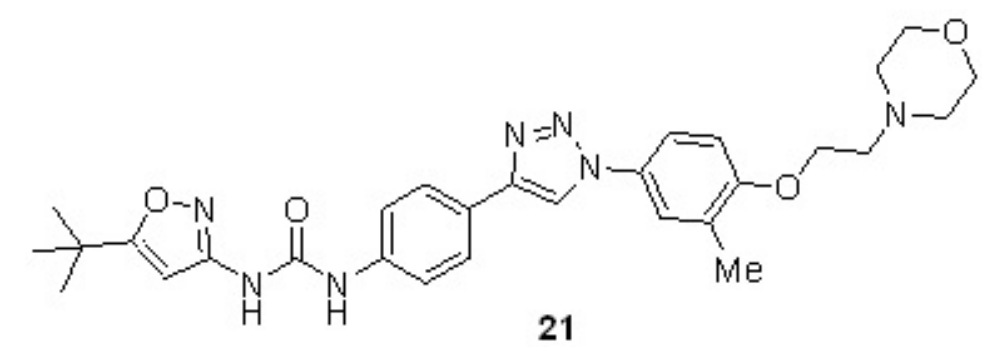

21

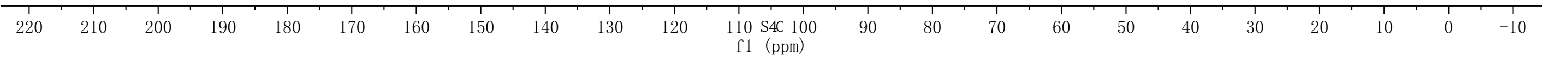




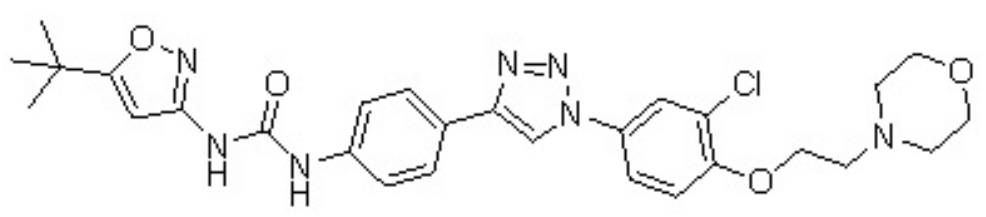

22

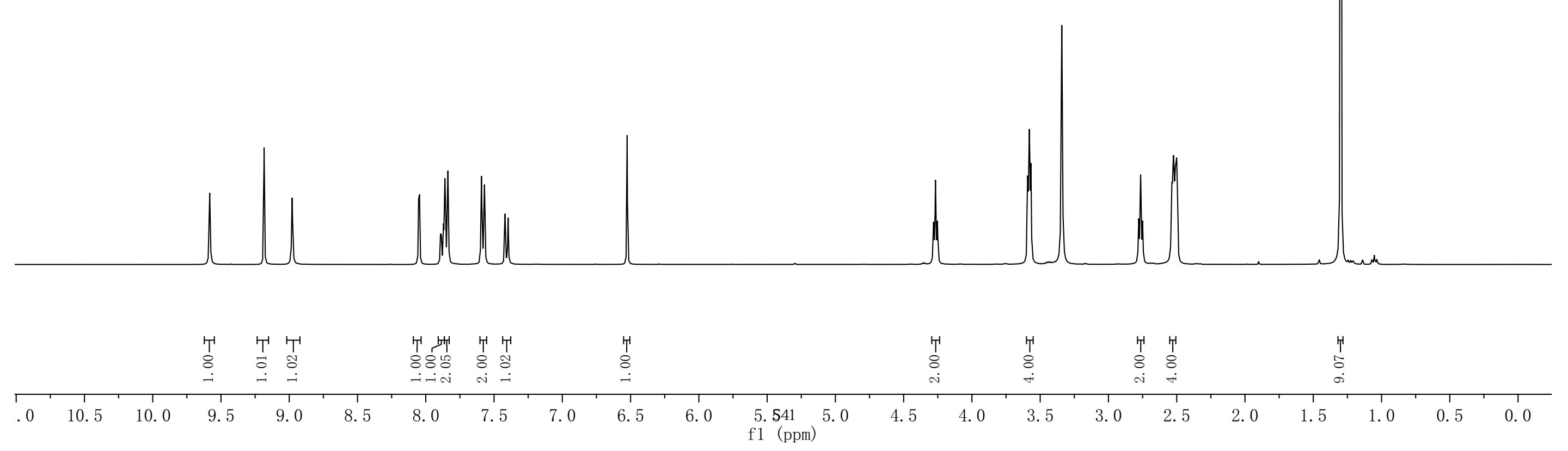




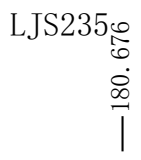

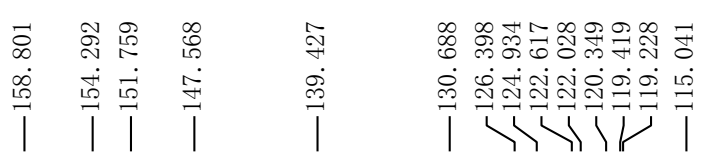

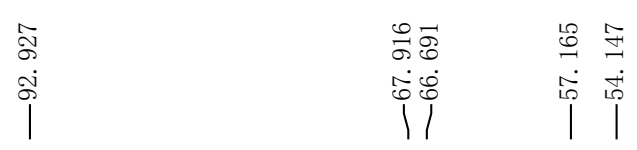

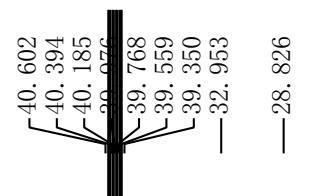<smiles>CC(C)(C)c1cc(NC(=O)Nc2ccc(-c3cn(-c4ccc(OCCN5CCOCC5)c(Cl)c4)nn3)cc2)no1</smiles>

22

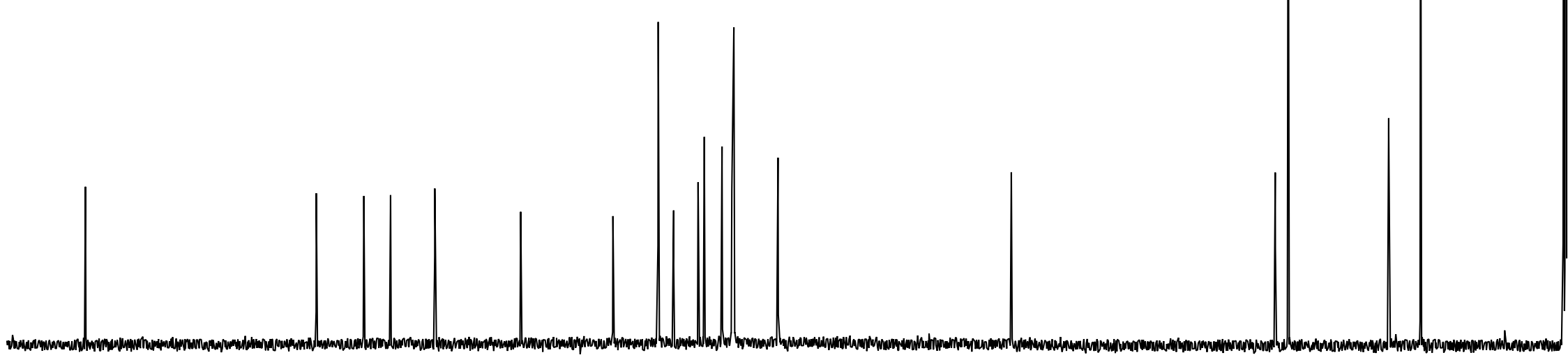

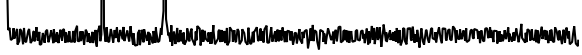
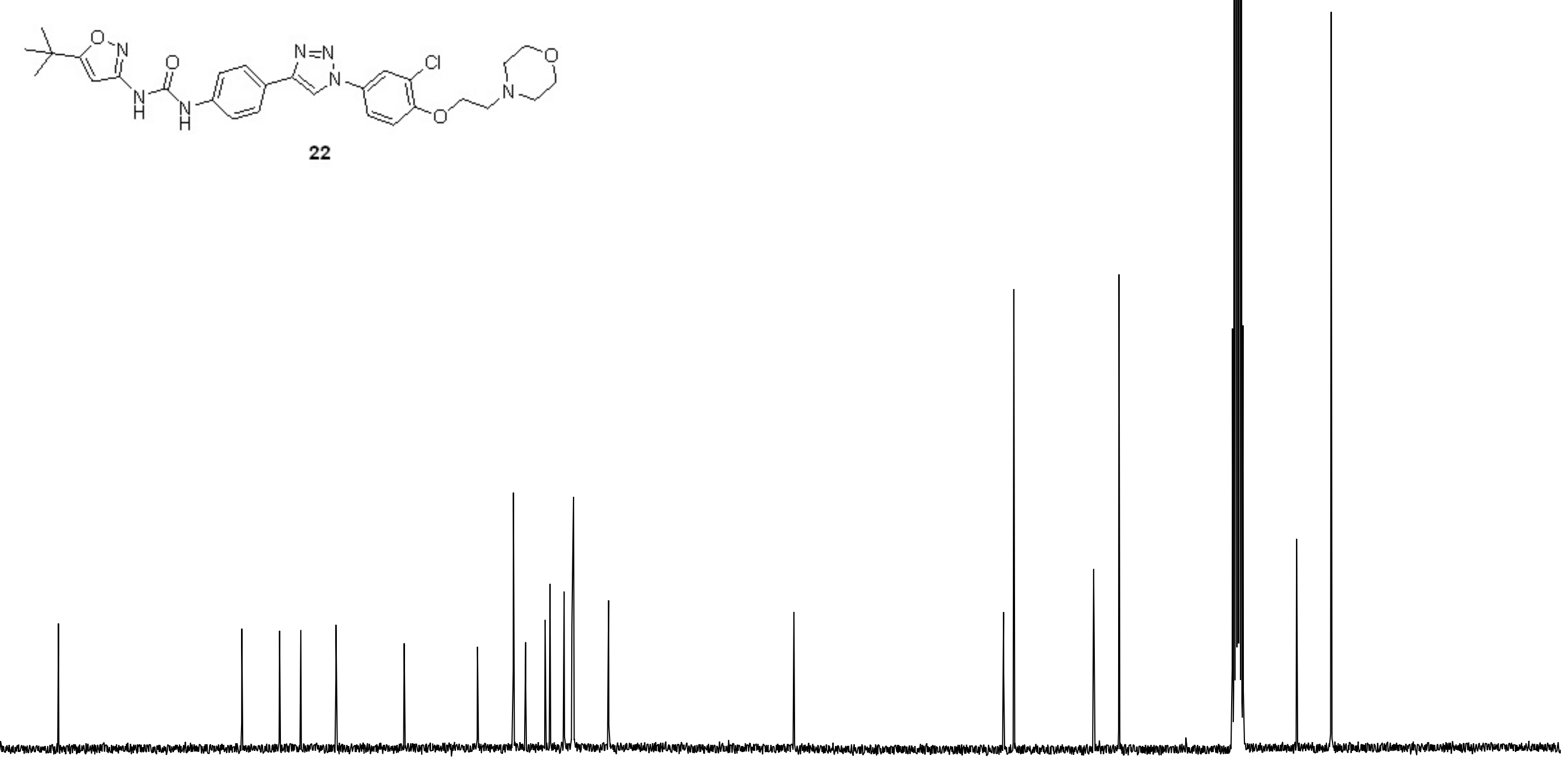

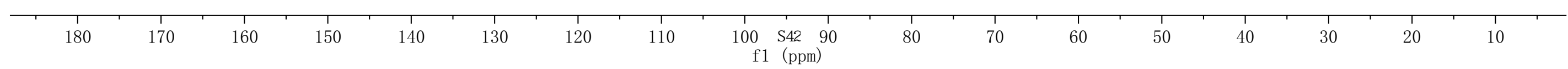




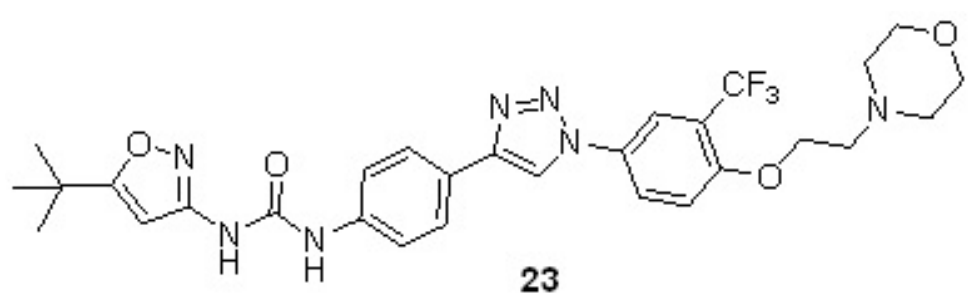

23

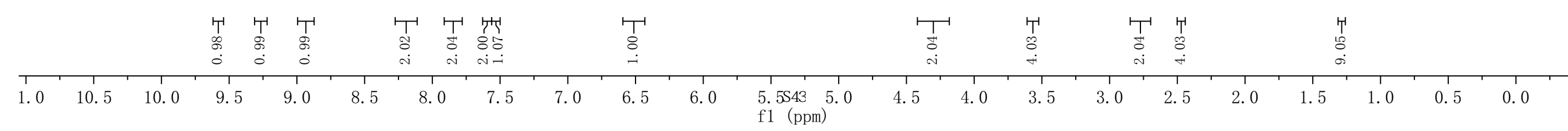



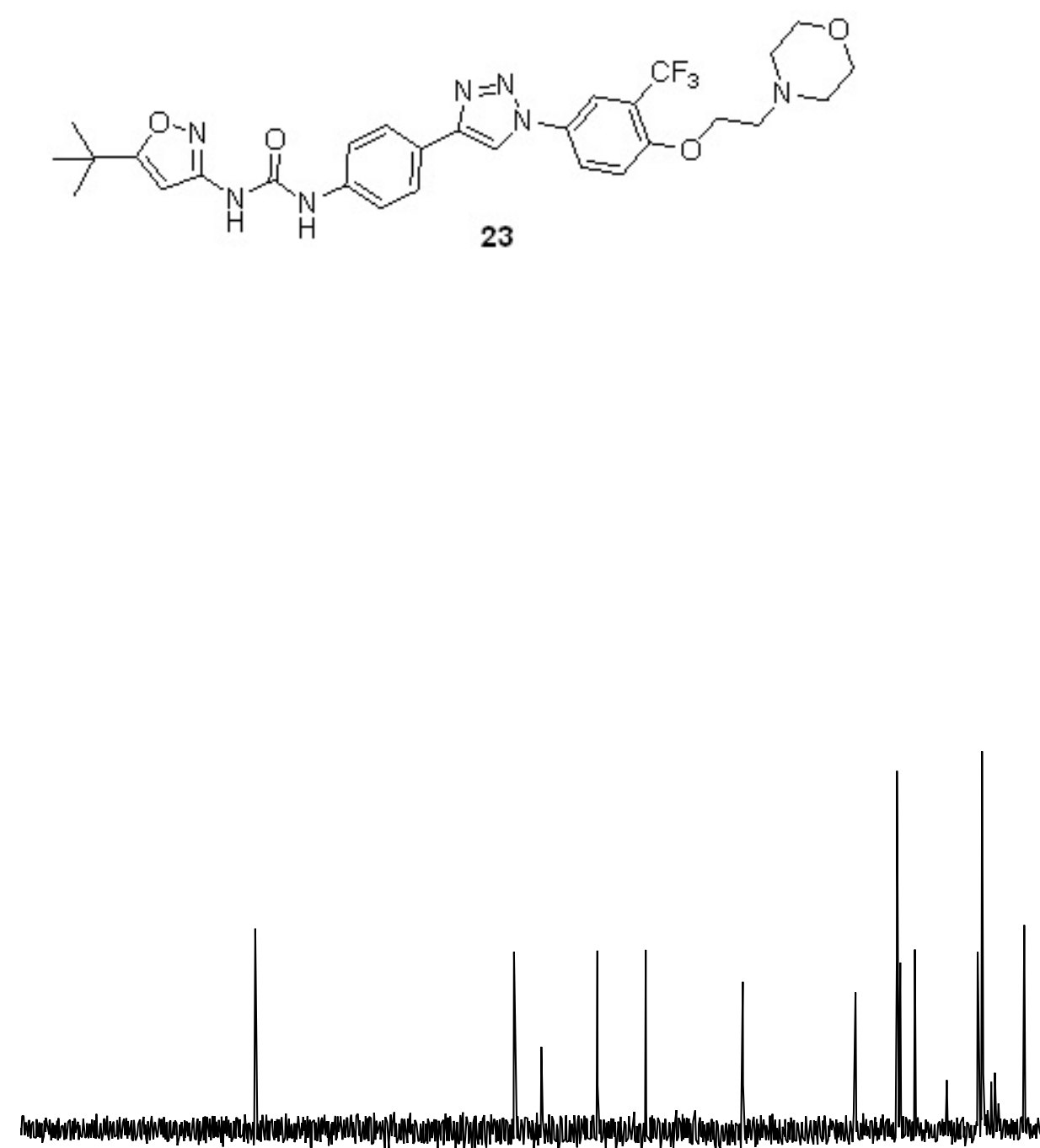

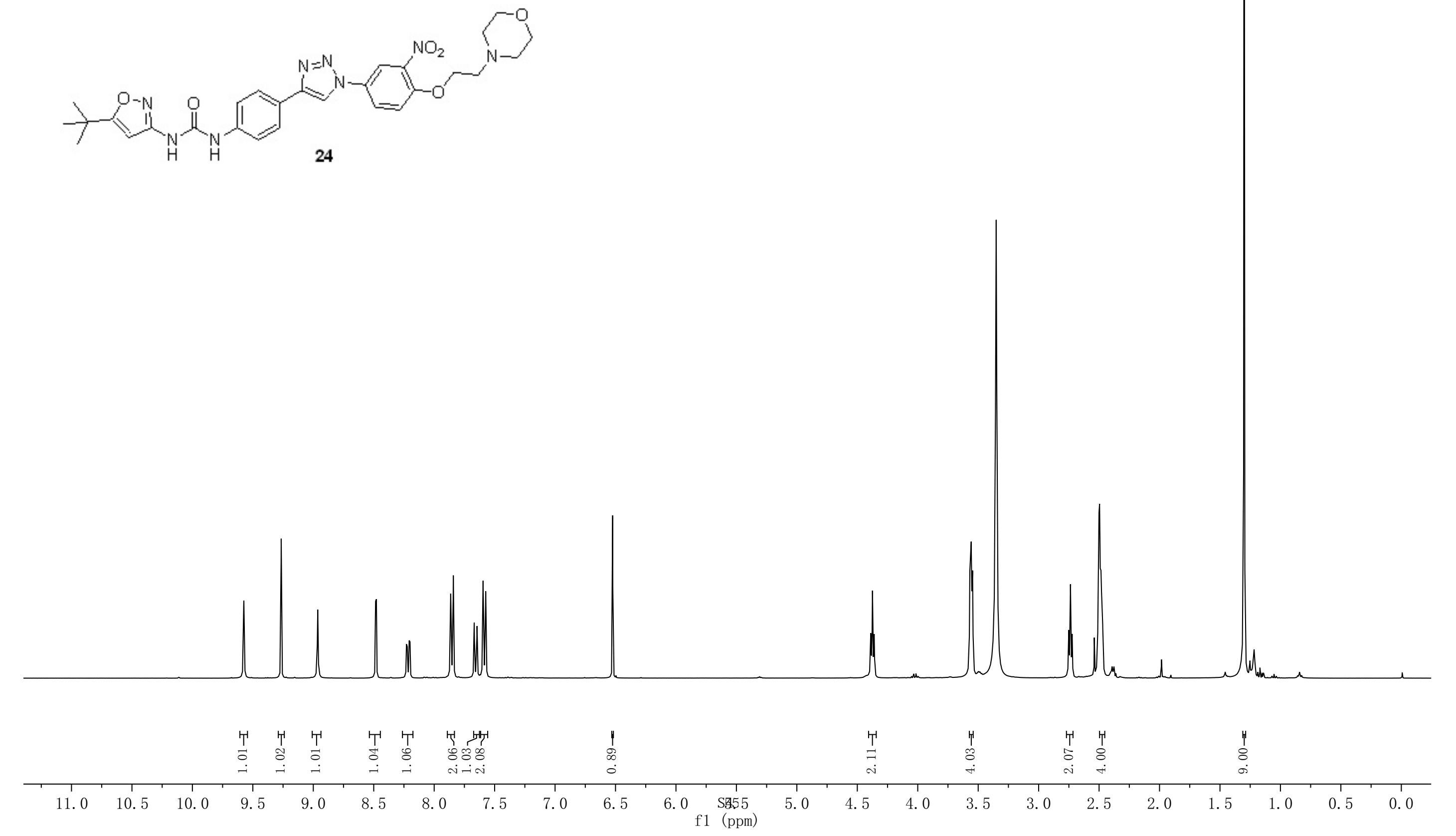

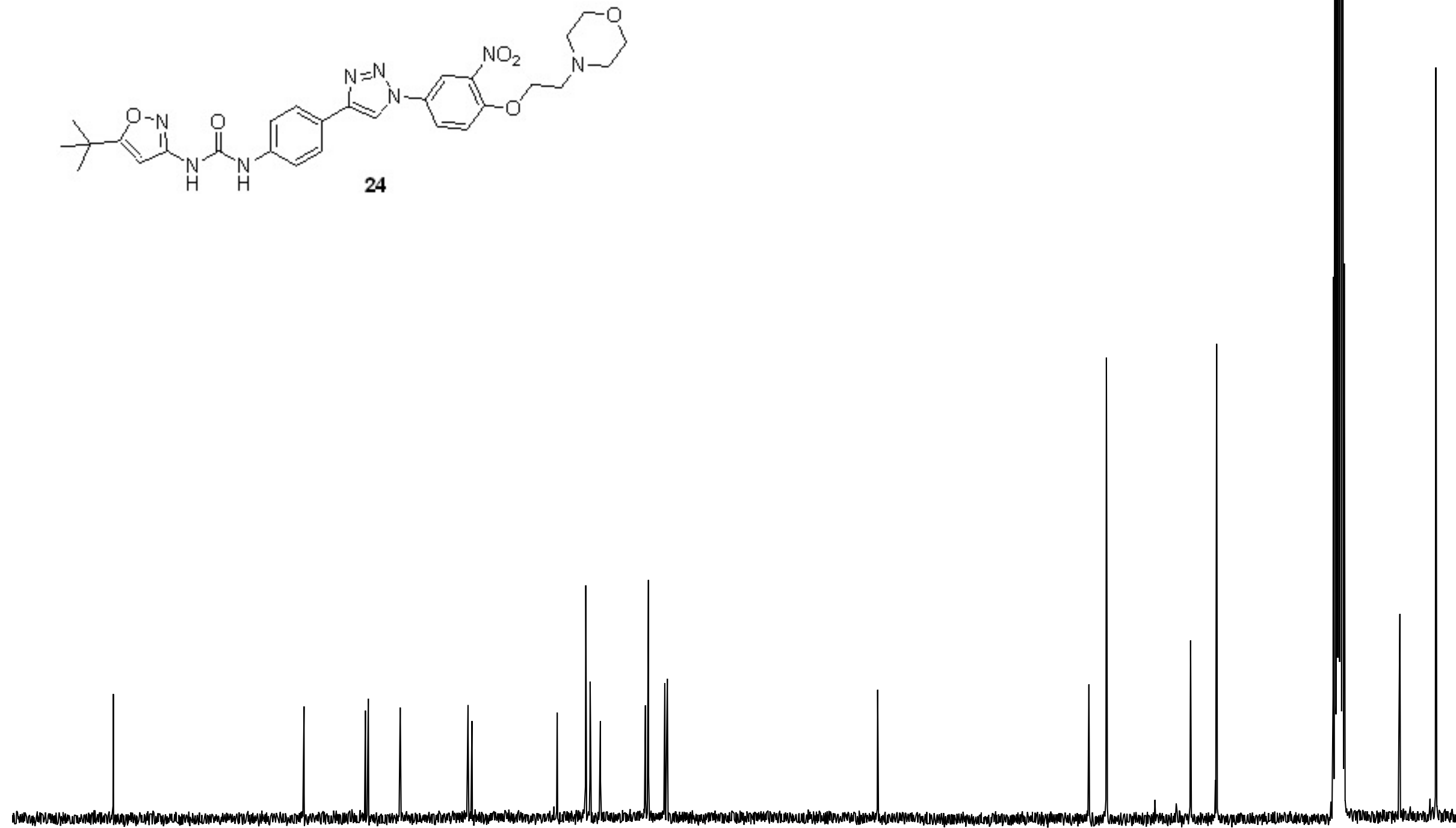


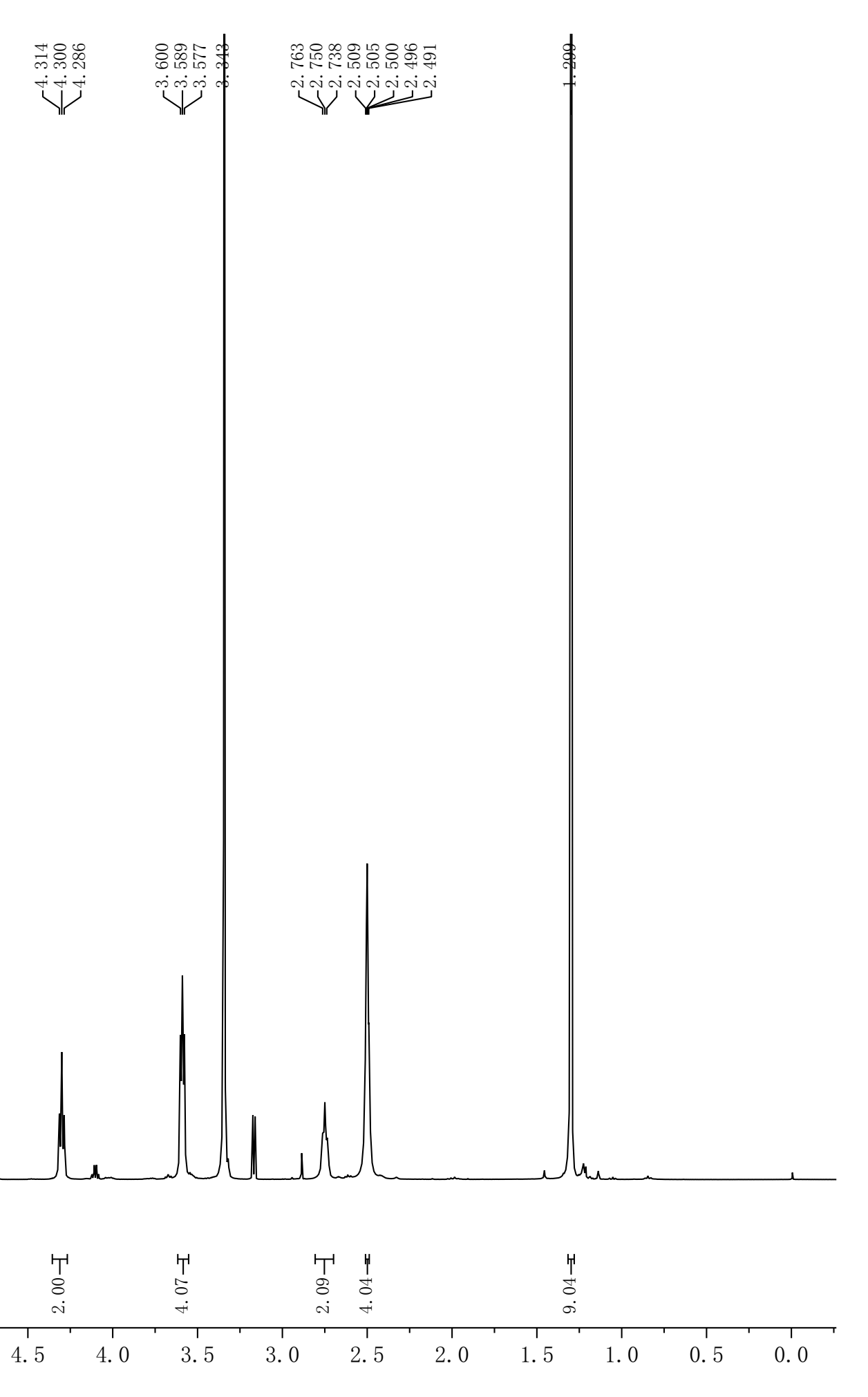




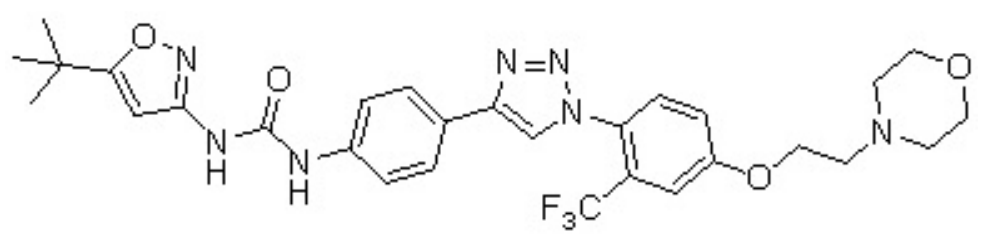

25

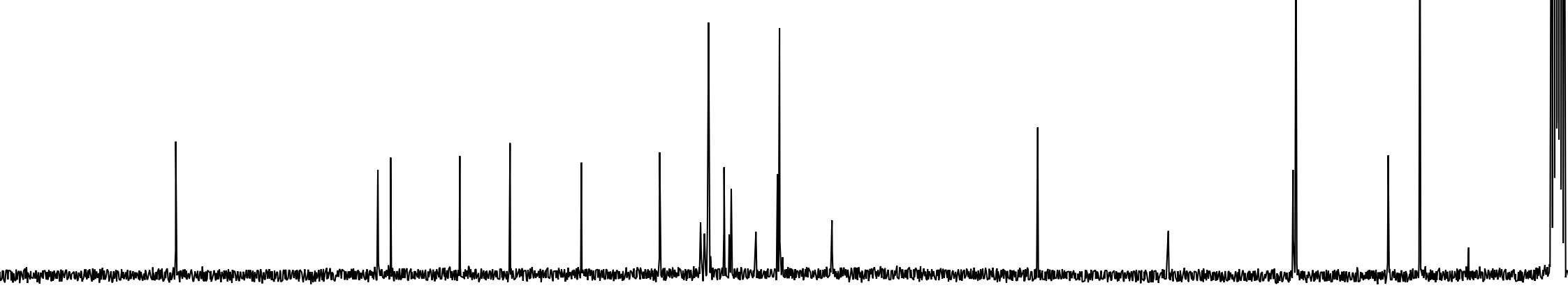

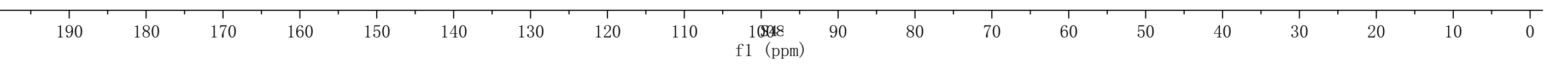




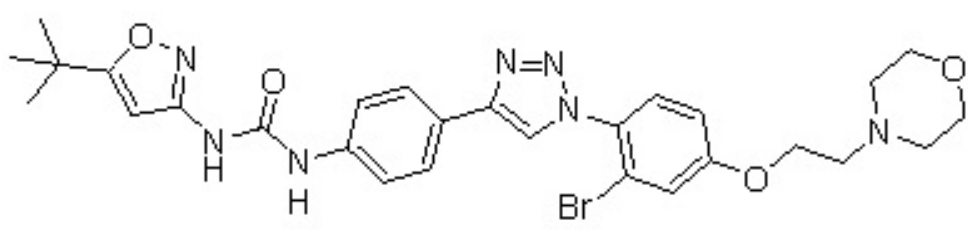

26

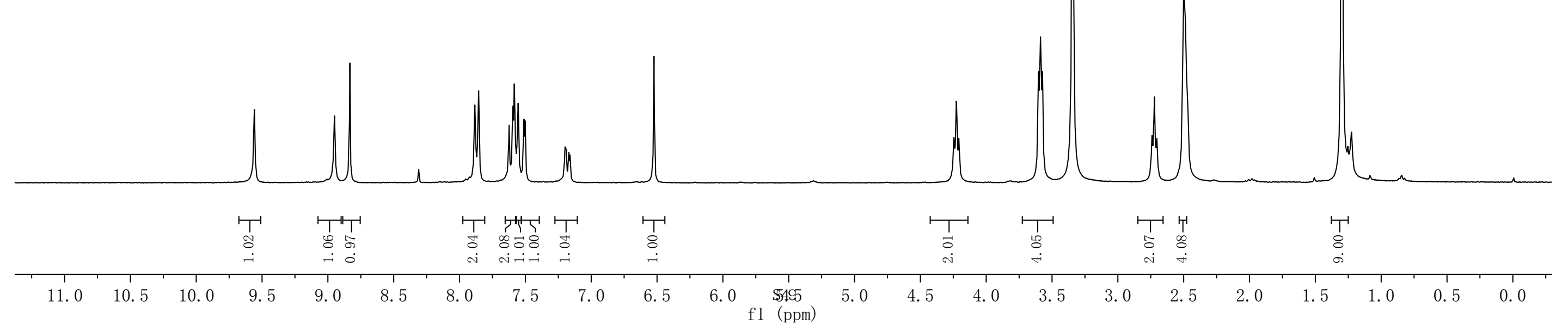




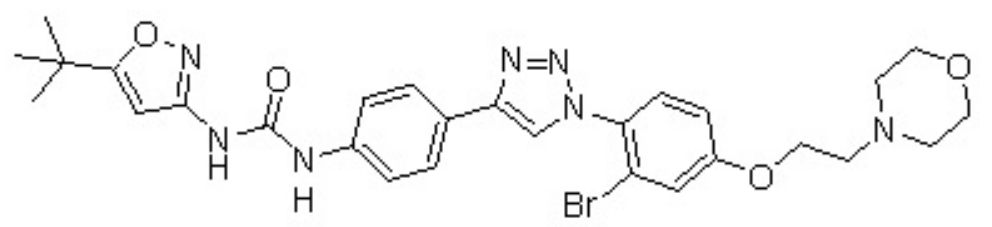

26

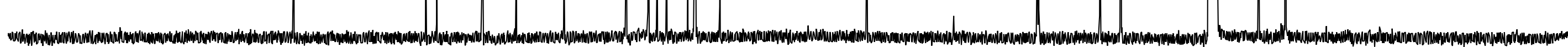

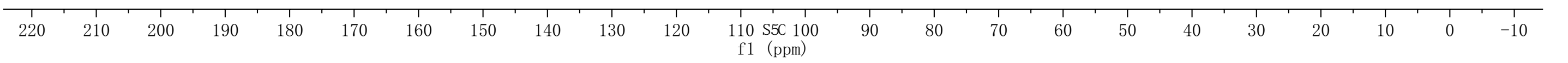




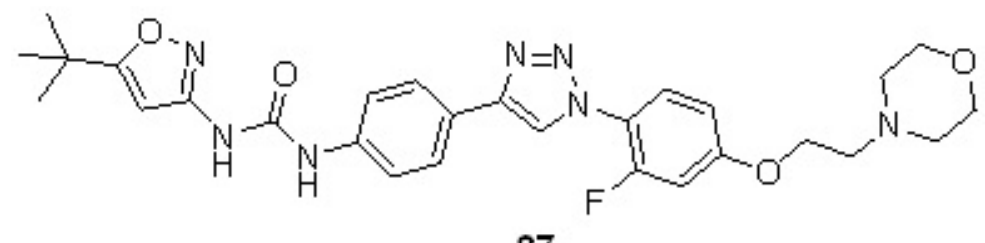

27

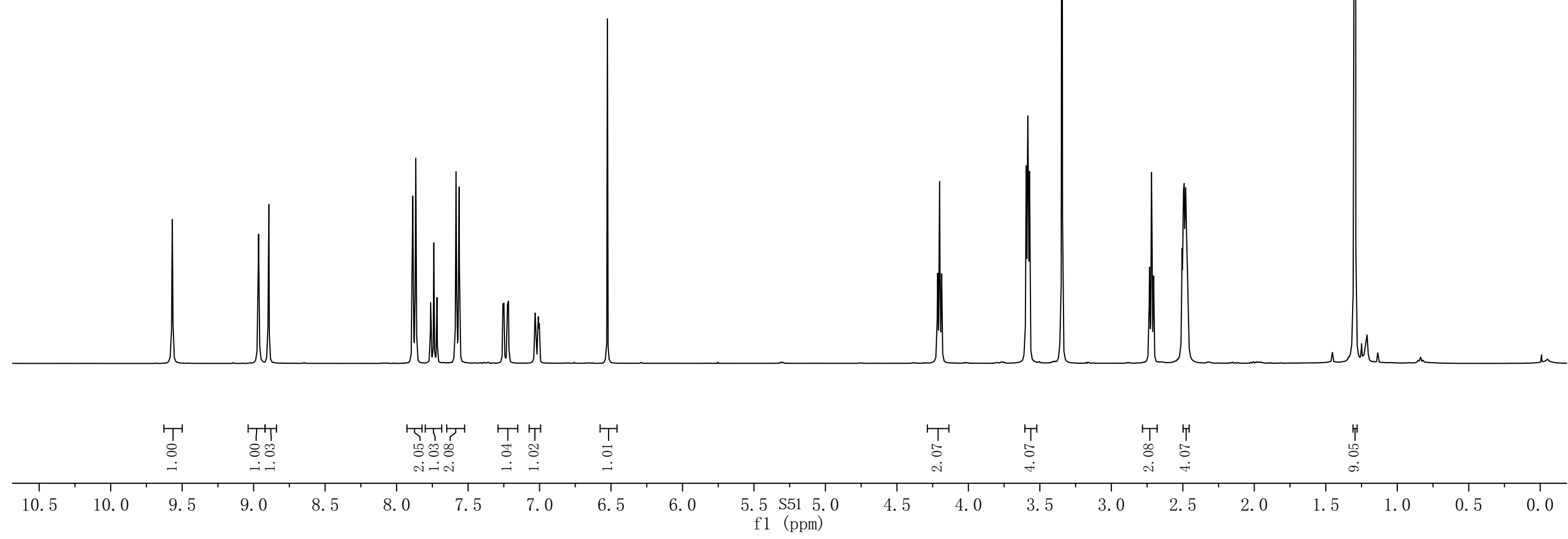




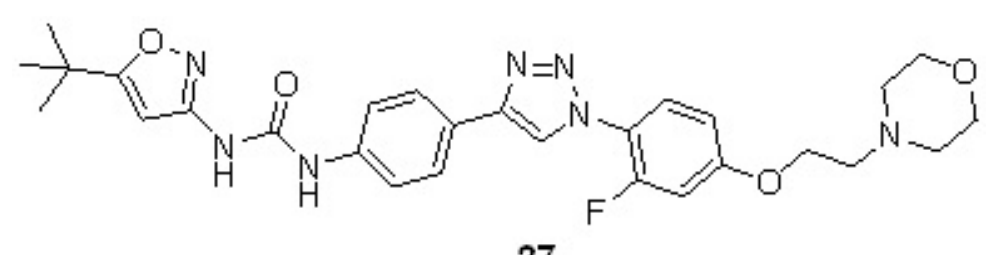

27
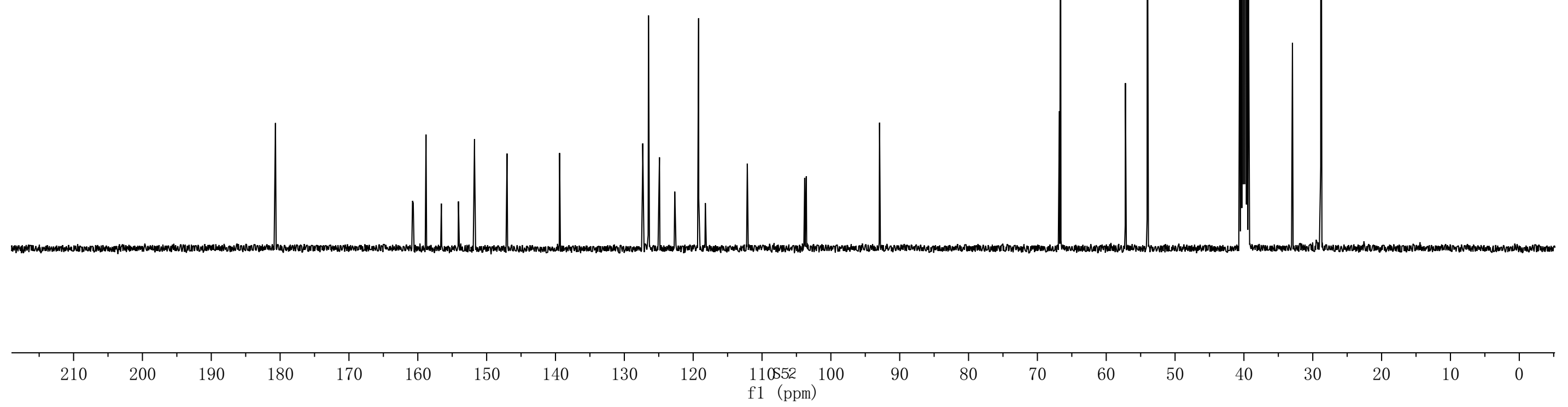


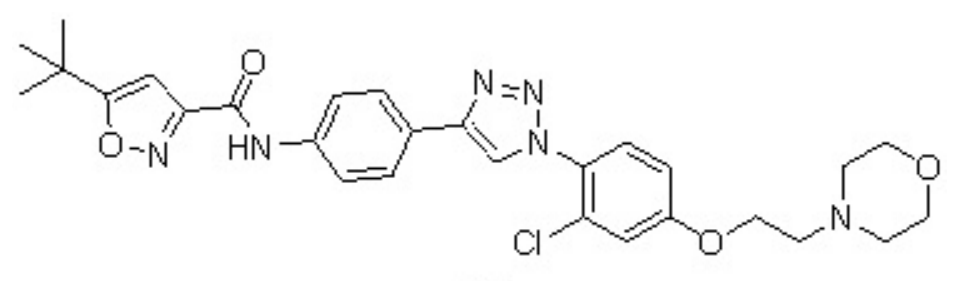

\begin{tabular}{|c|c|c|c|c|c|c|c|c|c|c|c|c|c|c|c|c|c|c|c|c|c|c|}
\hline & & & $\begin{array}{l}\stackrel{1}{\top} \\
\stackrel{8}{ } \\
-\end{array}$ & 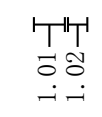 & & & 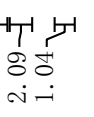 & $\begin{array}{l}T^{1} \\
\text { O⿱ } \\
- \\
-\end{array}$ & $\begin{array}{l}T^{1} \\
\stackrel{2}{-} \\
-\end{array}$ & & & & & & $\begin{array}{l}\stackrel{T}{1} \\
\text { og } \\
\stackrel{\leftrightarrow}{+}\end{array}$ & & 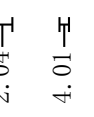 & & $\begin{array}{l}T \\
\infty \\
\infty \\
0 \\
0\end{array}$ & & & \\
\hline L1. 0 & 10.5 & 10.0 & 9.5 & 9.0 & 8.5 & 8. 0 & 7.5 & 7. 0 & 6.5 & 6.0 & $\begin{array}{c}5.553 \\
\mathrm{f} 1 \quad(\mathrm{ppm})\end{array}$ & 5. 0 & 4.5 & 4. 0 & 3.5 & 3.0 & 2.5 & 2.0 & 1.5 & 1.0 & 0.5 & 0.0 \\
\hline
\end{tabular}



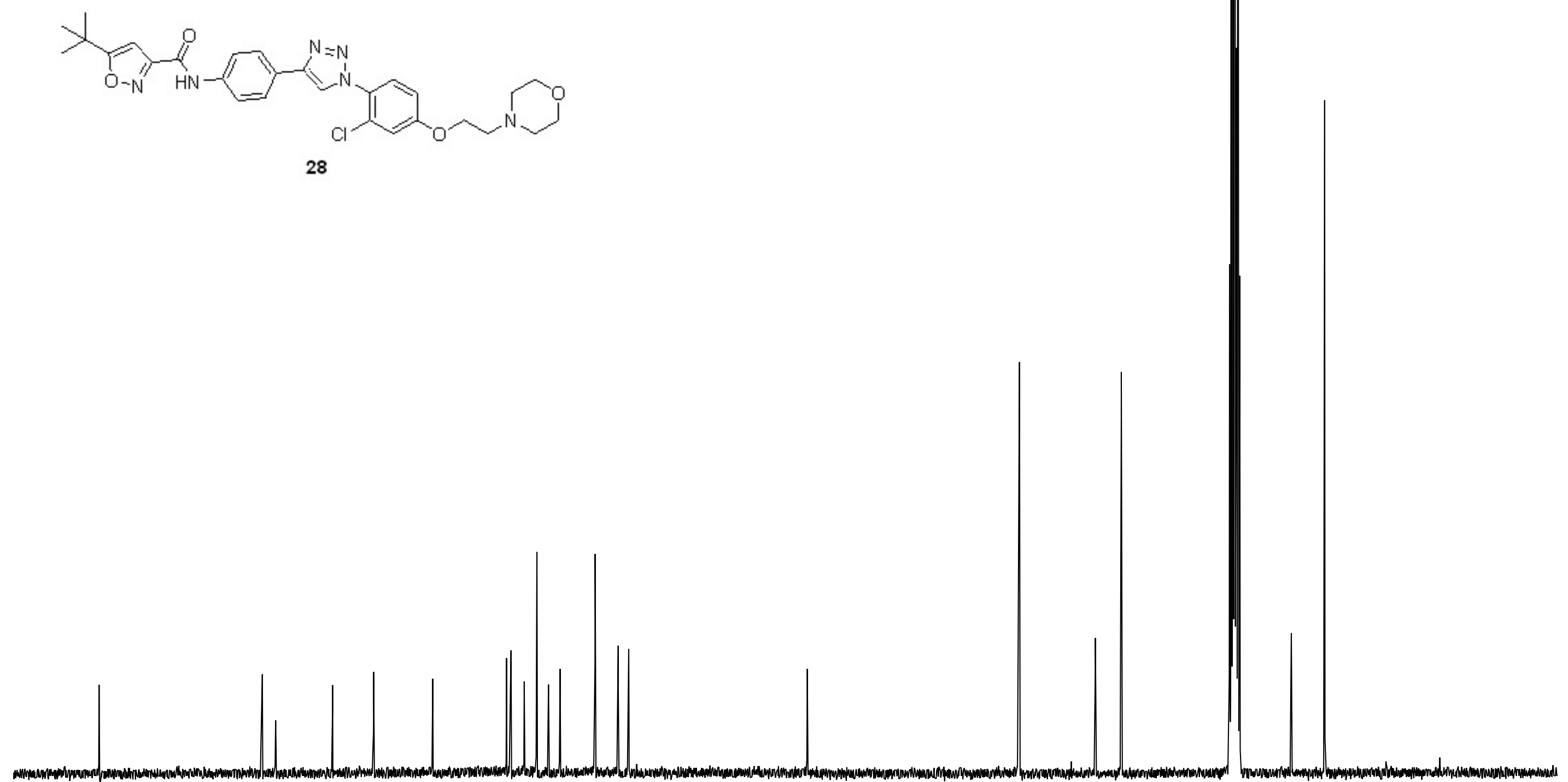


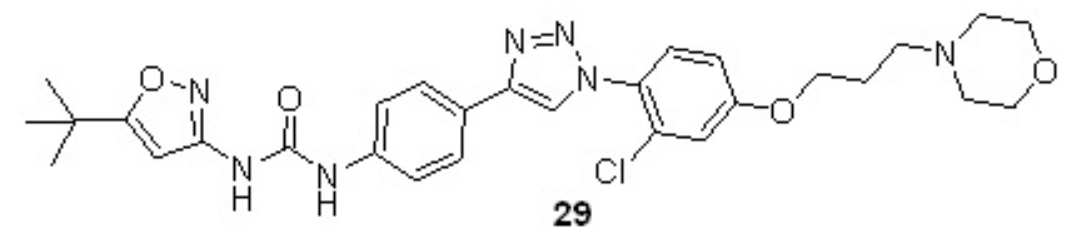

\begin{tabular}{|c|c|c|c|c|c|c|c|c|c|c|c|c|c|c|c|c|c|c|c|c|c|c|}
\hline & & & $\begin{array}{l}11 \\
8 \\
8 \\
0\end{array}$ & 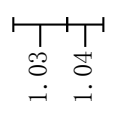 & & $\begin{array}{l}T_{1}^{1} \\
\infty \\
\stackrel{\infty}{i}\end{array}$ & 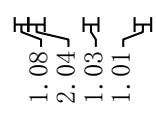 & & $\begin{array}{l}T \\
\stackrel{T}{8} \\
\dot{-}\end{array}$ & & & & & $\begin{array}{l}T^{1} \\
8 \\
0 \\
i\end{array}$ & $\begin{array}{l}\text { Tr } \\
\text { g } \\
+ \\
+\end{array}$ & & 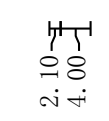 & 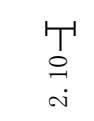 & $\begin{array}{l}T \\
0 \\
0 \\
0\end{array}$ & & & \\
\hline 11.0 & 10.5 & 10.0 & 9.5 & 9.0 & 8.5 & 8.0 & 7.5 & 7.0 & 6.5 & 6.0 & $\begin{array}{c}5 \mathrm{~s} 55 \\
\mathrm{f} 1 \stackrel{(\mathrm{ppm})}{ }\end{array}$ & 5.0 & 4.5 & 4.0 & 3.5 & 3.0 & 2.5 & 2.0 & 1.5 & 1.0 & 0.5 & 0.0 \\
\hline
\end{tabular}



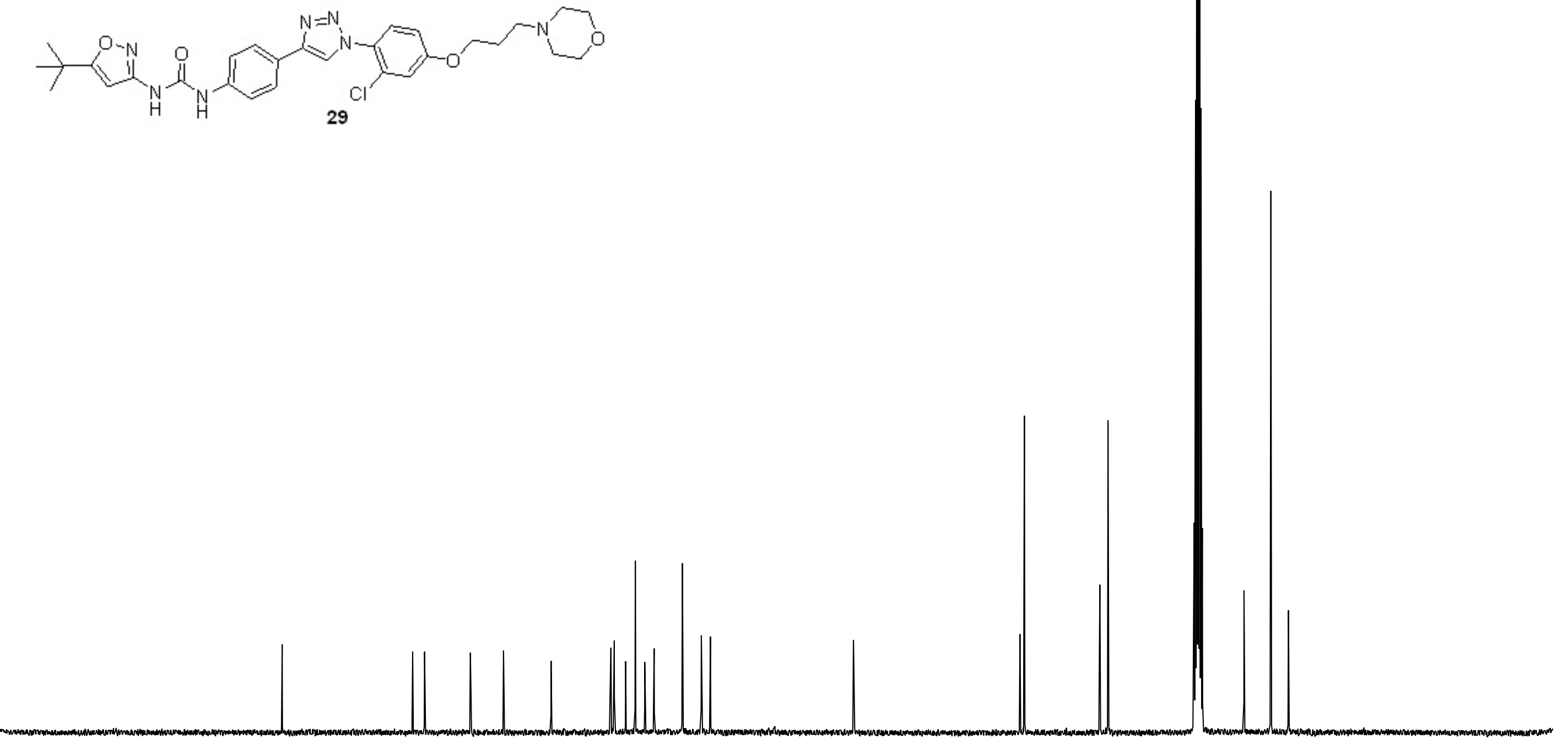

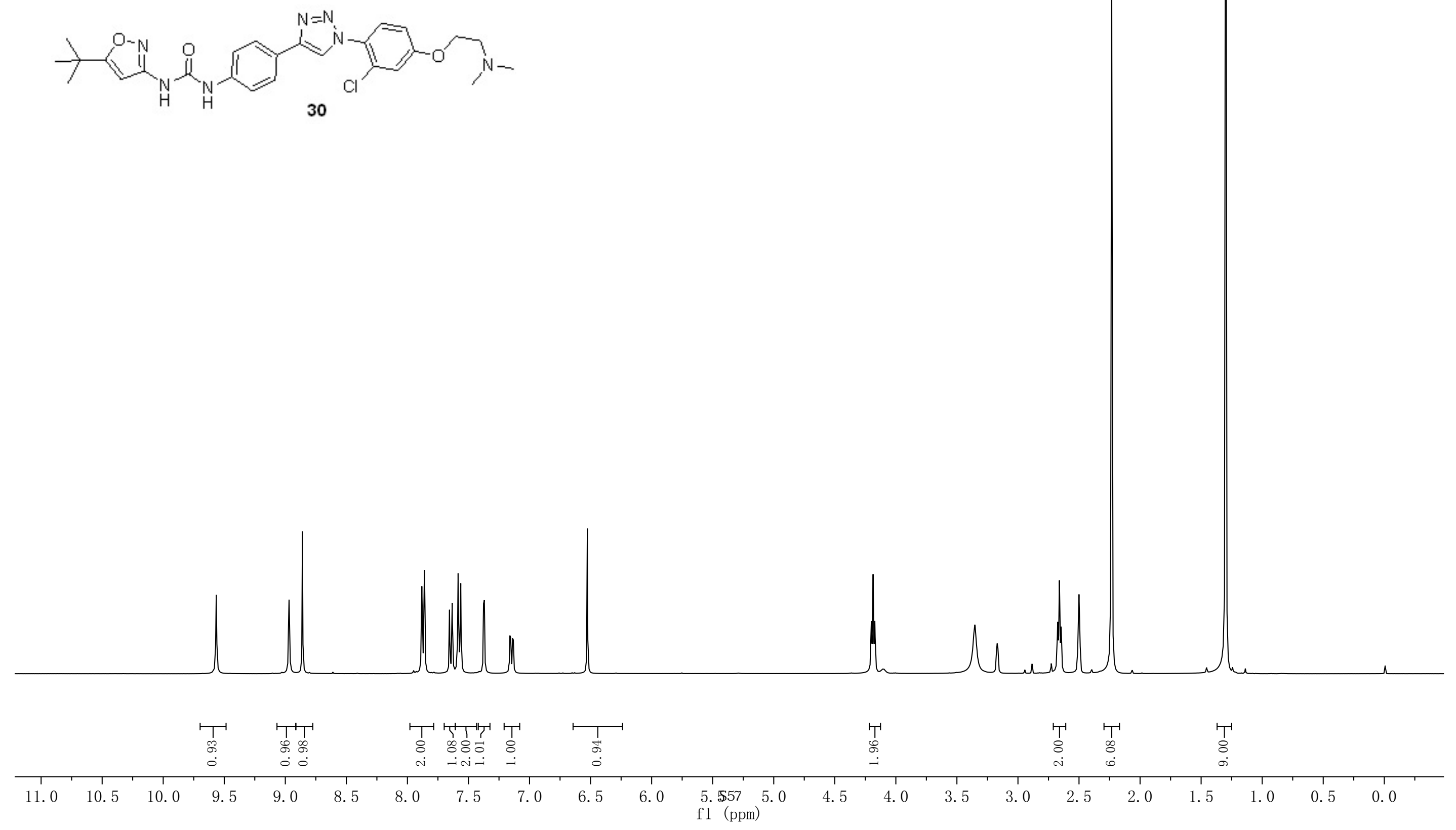


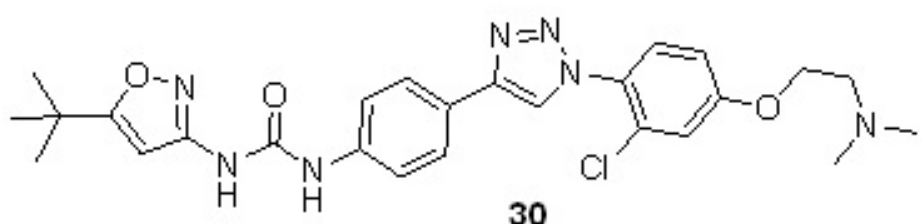

30

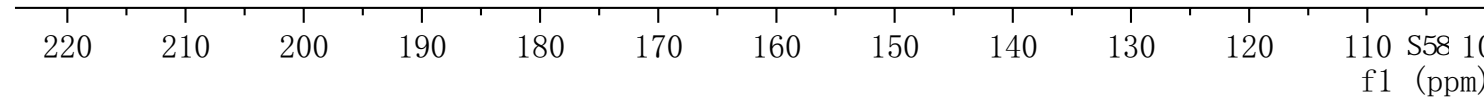



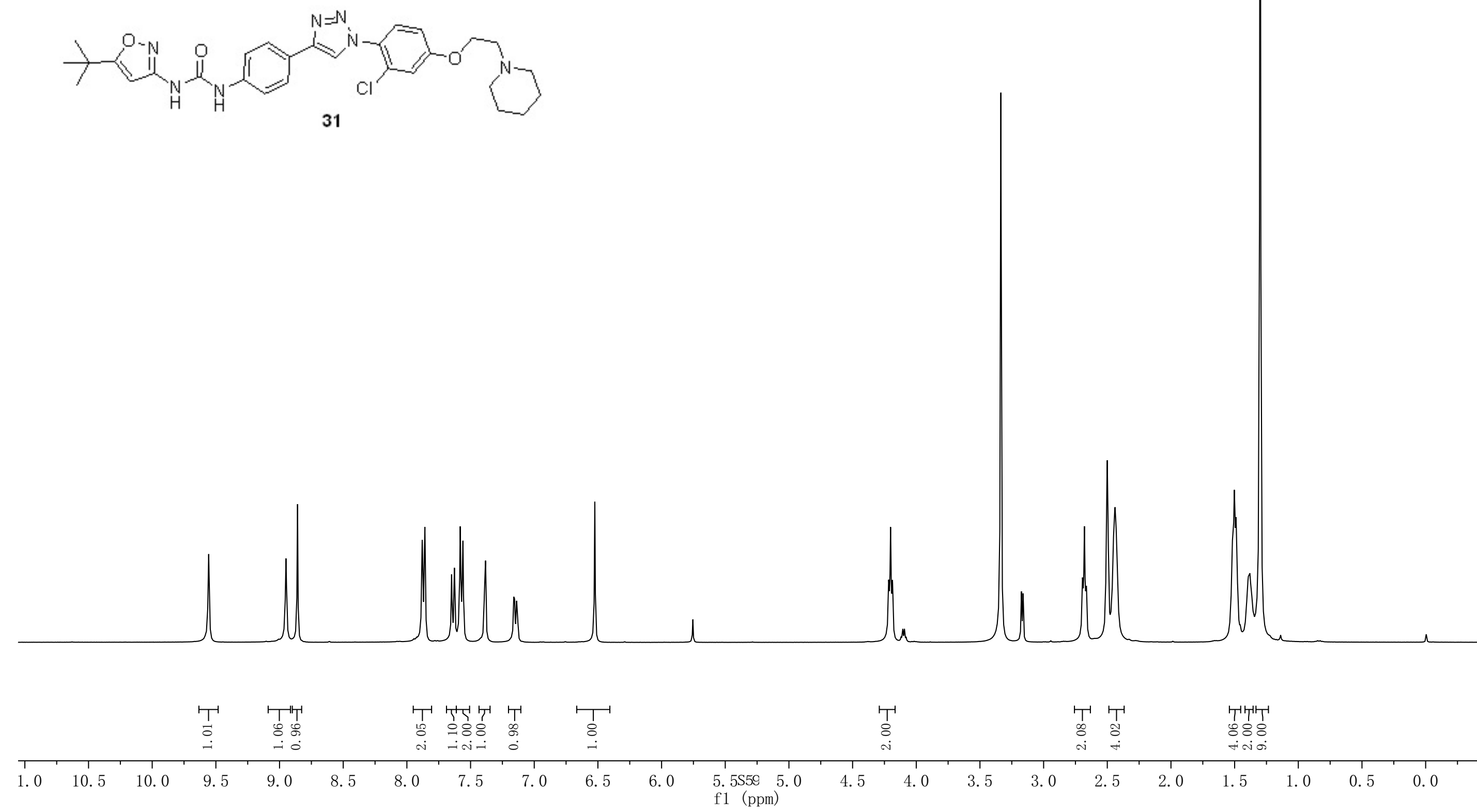


\section{1}

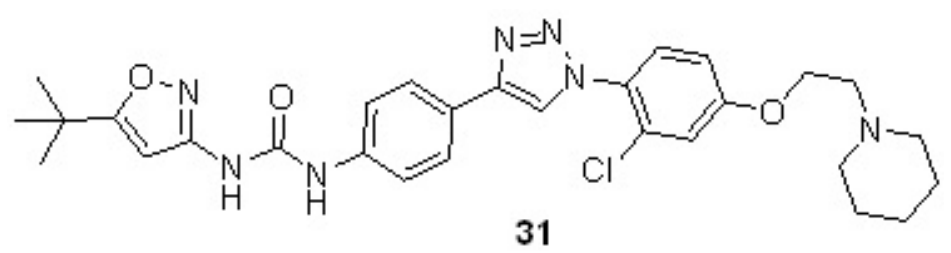

31

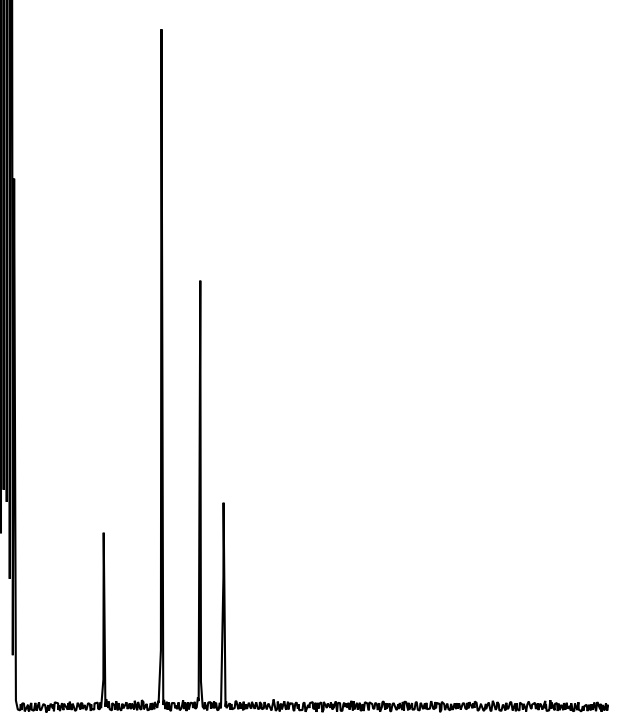



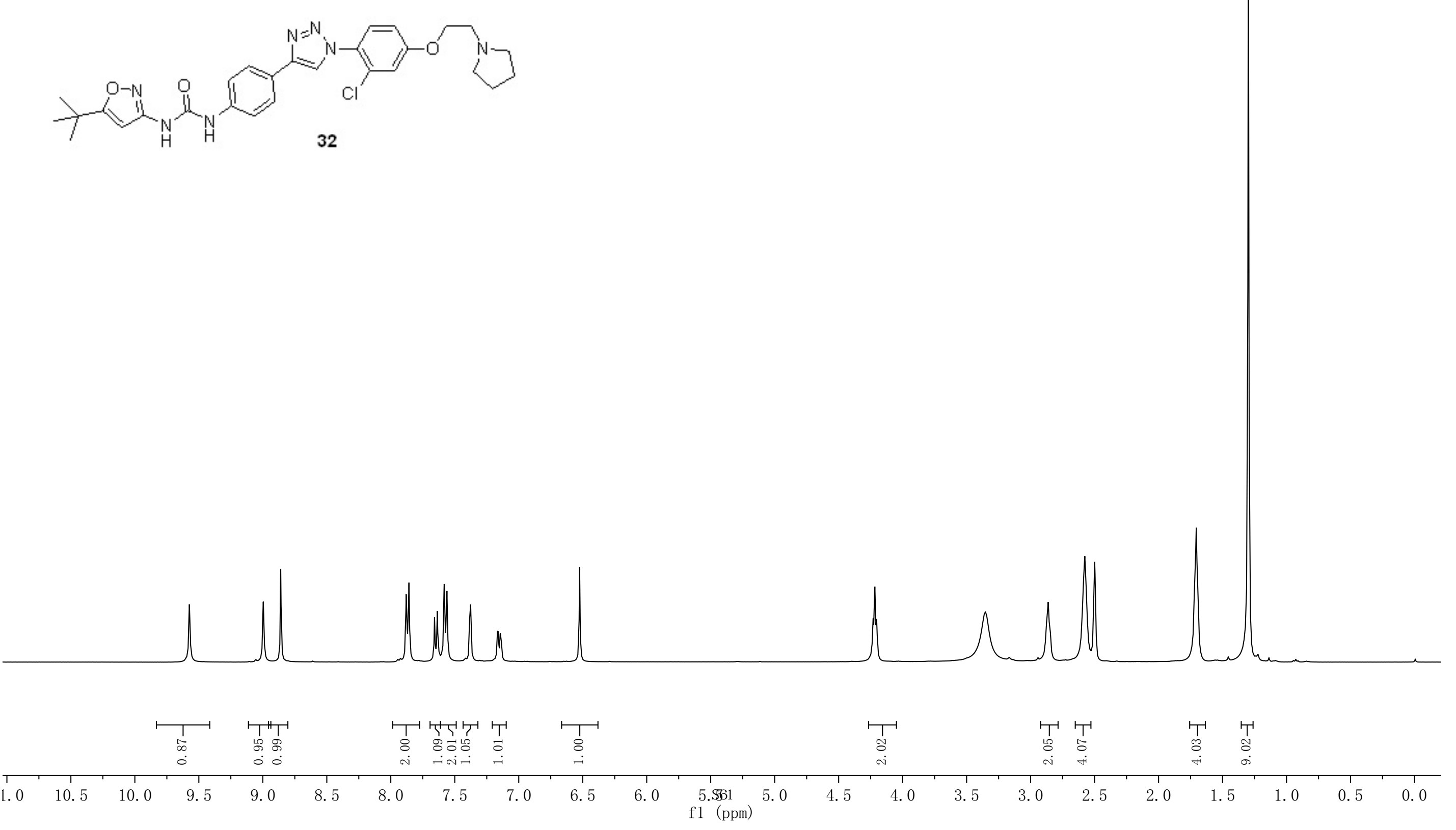


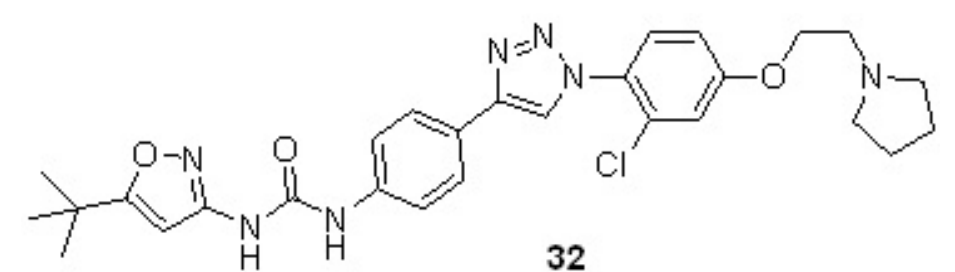

32

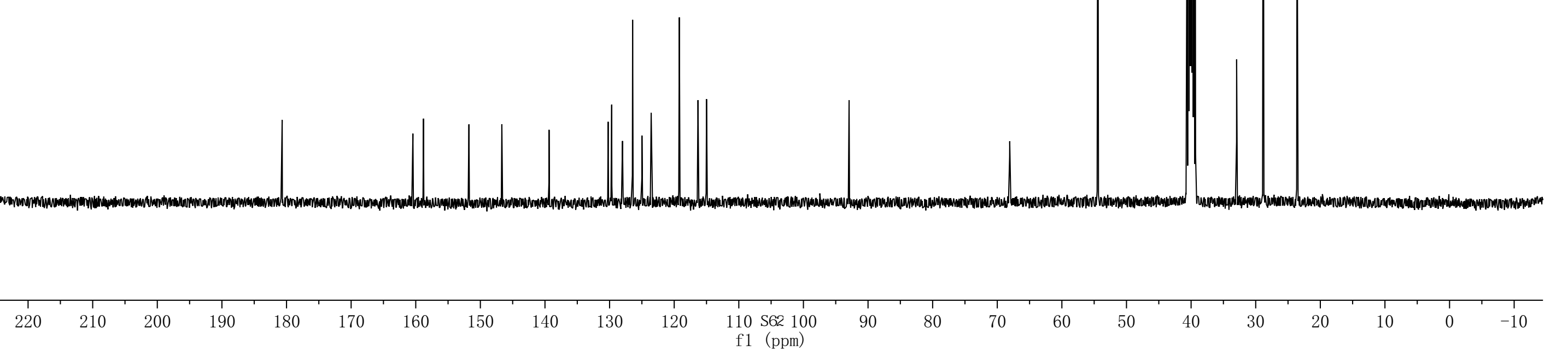

